\title{
Meet the Oligarchs: Business Legitimacy, State Capacity and Taxation
}

\section{Citation}

Di Tella, Rafael, Juan Dubra, and Alejandro Lagomarsino. "Meet the Oligarchs: Business Legitimacy, State Capacity and Taxation." Harvard Business School Working Paper, No. 17-046, December 2016.

\section{Permanent link}

http://nrs.harvard.edu/urn-3:HUL.InstRepos:30861194

\section{Terms of Use}

This article was downloaded from Harvard University's DASH repository, and is made available under the terms and conditions applicable to Open Access Policy Articles, as set forth at http:// nrs.harvard.edu/urn-3:HUL.InstRepos:dash.current.terms-of-use\#OAP

\section{Share Your Story}

The Harvard community has made this article openly available.

Please share how this access benefits you. Submit a story.

Accessibility 


\section{Meet the Oligarchs: Business Legitimacy, State Capacity and Taxation}

Rafael Di Tella Juan Dubra

Alejandro Lagomarsino

Working Paper 17-046 


\title{
Meet the Oligarchs: Business Legitimacy, State Capacity and Taxation
}

\author{
Rafael Di Tella
}

Harvard Business School

Juan Dubra

Universidad de Montevideo

Alejandro Lagomarsino

Harvard University

Working Paper 17-046 


\title{
Meet the Oligarchs: \\ Business Legitimacy, State Capacity and Taxation*
}

\author{
Rafael Di Tella \\ Juan Dubra \\ Alejandro Lagomarsino \\ Harvard Business School, CIfAR \\ Universidad de Montevideo \\ and NBER \\ Harvard University
}

First Draft. December 5, 2016

\begin{abstract}
We analyze the role of people's beliefs about the rich in the determination of public policy in the context of a randomized online survey experiment. A question we study is the desirability of government-private sector meetings, a variable we argue is connected to State capacity. Survey respondents primed with negative views about business leaders want fewer meetings, as well as higher taxes to the top 1\% and more regulation. We also study how these effects change when subjects are (additionally) primed with positive/negative views about government officials. Distrust in the government increases the preferred tax rate on the top 1\% only when business legitimacy is low. A model with multiple equilibria helps interpret these findings. In one of the equilibria, meetings are allowed, business legitimacy is high, and people set a low income tax rate for businesspeople. In the other, meetings are forbidden, business legitimacy is low, and people set high taxes to punish the businesspeople for their corrupt behavior.
\end{abstract}

Keywords: Business Legitimacy, State Capacity, Meetings, Taxes, Top 1\%, Regulation.

*Contact information: Rafael Di Tella (rditella@hbs.edu); Juan Dubra (dubraj@um.edu.uy); Alejandro Lagomarsino (alagomarsino@g.harvard.edu). For comments and suggestions, we are grateful to Jason Jackson, Julio Rotemberg, Paola Giuliano, seminar participants at the Uruguayan Central Bank, Northwestern, and CIfAR meetings at Toronto. 


\section{Introduction}

Businesspeople are sometimes perceived to be unpleasant, self-serving and even corrupt. In the US, where they have sometimes been lionized, the public is increasingly uneasy about the power of business and of the socalled "top 1\%". ${ }^{2}$ In this paper we study two possible consequences of this belief, namely that it causes an increase in the demand for taxing and regulating business and that it leads to a deterioration in State capacity. Our reasoning is that the perception that businesspeople are corrupt makes the public want to reduce the power and privileges of business.

Our main "independent variable" is the public's belief about the honesty-efficiency of the very rich. In particular, we are concerned about the possibility that the public might come to believe that the rich made their money in corrupt ways, i.e., that they see them as "oligarchs" instead of "clever innovators". Indeed, a key feature of US capitalism is that some very rich people made their money in business enterprises that are well regarded by the public. This is less common in poor countries, where businesspeople might have power, but often enjoy less social status. Since beliefs about the poor (whether they are lazy or just unlucky) appear to be correlated with features of economic systems, a natural question concerns the possible consequences of believing the rich are undeserving. ${ }^{3}$ For simplicity, we focus on business people, and the related concept of business legitimacy, but, of course, rich people vary in the extent to which their wealth is derived from business interests.

We are interested in the causal impact of this belief on State capacity. While there are many dimensions of State capacity, we are particularly interested in the information available to policymakers. Accordingly, we propose a new metric: the public's intolerance for close contact between government officials and business. This measure builds on one of the basic tensions of democracy: everyone is expected to have similar influence on government, even if some people (those in business for example) can be expected to have lots of information that is helpful to government when setting policy. A standard way of soliciting, and of conveying, specialized information involves direct contact (e.g., during a meeting) between the businessperson and the public official. But naturally, such close contact arises suspicions of privileged access, undue influence and even bribes, so the public is understandably nervous about the existence of these meetings. ${ }^{4}$ Our main hypothesis is that lack of business legitimacy causes people to demand fewer meetings and this causes low State capacity. This complements

\footnotetext{
2 In 2001, a Gallup poll found that a combined $48 \%$ of US respondents said they were either very or somewhat satisfied with the size and influence of major corporations, and the same percentage were very or somewhat dissatisfied. Since 2003, a majority of Americans have been dissatisfied. Dissatisfaction peaked at 67\% in 2011. See "Majority of Americans Dissatisfied With Corporate Influence”, Gallup Economy, January 20, 2016.

${ }^{3}$ Research on comparative economic systems has emphasized the role of beliefs, at least since de Tocqueville. See, for example, Piketty (1995) and Hall and Soskice (2001). On beliefs about the poor, see Alesina and Glaeser (2004). On beliefs about the rich, see Di Tella and MacCulloch (2009). Work on beliefs about the income-generating process of the rich and poor is naturally connected to work on trust (see Knack \& Keefer 1995 and La Porta, et al. 1997). For a review of work emphasizing two-way causal effects between beliefs and institutions, see Alesina \& Giuliano (2016).

4 The title of a recent article summarizes this well: "Regulators Lean on Financial Firms to Explain Industry to Them, Study Shows". See The Wall Street Journal, September 16, 2016. The report on which it is based (CFA Institute 2016) concludes "We find the idea of constructive interaction between regulators and industry personnel to be compelling as a factor in effective regulation. We also acknowledge that many such interactions create either the appearance of a conflict of interest or actual divergent interests that can compromise regulatory effectiveness and public confidence in the integrity of the system." Their proposals include "Regulators and firms should endeavor to provide more transparency in their interactions for public consumption. Audio or video recordings of interactions should be maintained as part of the public record."
} 
previous work on the causes of State capacity emphasizing the role of historical factors (which we review below).

Documenting how low business legitimacy lowers the demand for private-public sector meetings is important because it suggests a possible explanation for the existence of inefficient regulations in developing countries with weak private sectors. Indeed, some of the regulations present in poor countries are so obviously counterproductive that a reasonable explanation is ignorance on the part of the bureaucrats putting them in place. The standard explanation in Economics is that they are put into place by interest groups (see for example, Tullock 1967, Stigler 1971, Shleifer and Vishny 1994). But why would interest groups (businesses or bureaucrats) with specific knowledge choose forms of regulation that are ostensibly inefficient? ${ }^{5} \mathrm{~A}$ more reasonable answer is that bureaucrats put in place bad regulations because they don't know better and they can't talk to those that know because they would be suspected of taking bribes. ${ }^{6}$

We also document how low business legitimacy causes an increase in the demand for taxing the rich and for regulating business. This complements previous work on the role of information regarding one's own position in the distribution of income in determining people's views about taxation by Kuziemko, et al. (2015). And work that documented a negative correlation between regulation and measures of trust (including perceptions of corruption), in different settings (see, for example Djankov et al. 2002; Di Tella and MacCulloch 2009; Aghion, et al. 2010; Pinotti 2012). These papers are potentially useful because they help explain differences in economic systems. Work on American exceptionalism has emphasized how differences in beliefs can explain differences in taxation and economic organization. Economists, starting with Piketty (1995), have developed models where beliefs about the income-generating process play a central role in the demand for policies (see also Benabou and Ok 2001, Benabou \& Tirole 2013, and Alesina and Angeletos 2005b). Some of these models have emphasized the link to corruption, an important trait if the varieties of capitalism literature is going to be applied to the study of poor countries (Alesina and Angeletos 2005a focus on corruption arising from redistribution; Di Tella and MacCulloch 2009, focus on grand corruption; while Aghion et al. 2010 focus on bureaucratic extortion). Our paper involves a natural extension of this literature as it involves studying beliefs about the rich (which may be involved in grand corruption/capture) and which may be somewhat independent from beliefs about the poor.

We present a model where beliefs about the rich and whether they behave honestly help determine the amount of contact between the private and public sectors, as well as the amount of regulation and taxation that prevail in the economy. We then introduce some data to test these hypotheses. Our key assumption is that the public's perception of the legitimacy of business and the level of trust in government is formed over time through experiences and the accumulation of messages, including those from the media. Our empirical strategy then, is to expose subjects to a brief description of a well-known, old piece of news regarding business leaders (positive or negative). This is expected to provide a direct reminder of this particular piece of news and, more importantly, an indirect stimulus for related memories (conceptual priming). In addition, we prime them with negative/positive views about government officials, and disentangle the effects of business legitimacy and trust in government on policy preferences. Accordingly, our research design exposes a sample of approximately

\footnotetext{
5 That this is the case is clear from the abundant evidence gathered from work on the "tollbooth" variant of capture emphasizing the role of bureaucrats (see Djankov, et al. 2002, De Soto 1989). Coate and Morris (1995) is a classic demonstration that inefficient redistribution may be employed as long as it is "sneaky" (i.e., not apparent to the public). ${ }^{6}$ For example, the owner of a factory might know the times at which delivery of key inputs is both convenient for suppliers, convenient for the factory and does not cause traffic congestion in the neighborhood. This information would be helpful to the public official in charge of regulating the times that trucks are allowed in the urban areas.
} 
9,000 American subjects taking an online survey on Amazon Mechanical Turk (MTurk) with positive/negative information about American businesspeople and public officials. It then gathered their responses about their preferences for private-public sector meetings, taxation, and regulation. Previous work has also used priming in studies of social preferences (Fong and Luttmer 2007; Chen and Li 2009; Shayo and Zussman 2011), public opinion (Gerber, et al. 2010), and ideology (Berdejó and Chen 2012). The latter is particularly relevant as it does so in the field.

We find that, regardless of the government treatment (positive or negative), subjects exposed to positive depictions of businesses more often report a pro-meetings stance relative to those exposed to a negative depiction of businesses. We do not find an effect of business legitimacy on the desire to tax the top 1\% when subjects have been primed with positive views of government officials. But, in contrast, when they are primed with depictions of corrupt government, subjects exposed to low business legitimacy are significantly more likely to report a higher desired tax rate on the top 1\% than those primed to trust businesses. Similarly, lowering trust in government has no effect on preferences for taxing the rich when individuals are primed to trust businesses (this is the same question for which Kuziemko, et al. (2015) found "quantitatively small effects" of inequality). When treated with low business legitimacy, more distrust in the government generates a higher demand for taxes on the top $1 \%$. Using several proxies for regulation, we find significant causal effects connecting low business legitimacy to a desire to increase regulation in the economy, and assess how this connection is different if we focus on trust in government.

The paper proceeds as follows: Section 2 below discusses some of the prior work in this topic. Section 3 presents a simple model where beliefs about the rich are central in determining State capacity. Section 4 describes the empirical strategy and survey implementation. Section 5 presents the main results from the survey. Section 6 discusses additional topics explored in a complementary survey. Section 7 offers some concluding thoughts.

\section{Motivation and Previous Literature (selective)}

There is ample anecdotal evidence suggesting uneasiness on the part of the public regarding meetings between public officials and members of the private sector. Many countries have enacted laws that allow citizens to know what goes on in these meetings. These were particularly visible after the 2008 financial crisis, as the following exchange during the congressional hearings regarding AIG (on January 27, 2010) illustrates:

Representative Mary Kaptur: ...you made about a hundred calls to Federal Chair Ben Bernanke, but then the next highest number of calls in that period, you made 103 to a man name Dan Jester... May I just ask, what firm did he worked for? Timothy Geithner: He worked for, as you know, he worked for Goldman Sachs. ${ }^{7}$

One standard justification for close contact with the private sector involves the exchange of information that helps policymakers. For example, when some of the European Central Bank's top decision makers were criticized for meeting with asset managers and bankers in the days prior to making important decisions, an ECB spokesman explained "it was important for policy makers to understand financial markets, since this is how monetary policy is transmitted into the real economy." 8 Both the US Federal Reserve and the Bank of England,

7 The Federal Bailout of AIG: Hearing before the Committee on Oversight and Government Reform, House of Representatives, one hundred eleventh congress, second session, January 27, 2010, Serial No. 111-107. Available at http://www.gpoaccess.gov/congress/index.html.

${ }^{8}$ From "ECB officials met bankers before key decisions", Financial Times, Tuesday November 3, 2015. 
in contrast, ban members of the rate-setting committee from discussing issues regarding monetary policy with "outside interests" during the week prior to a policy decision. In early 2015, the ECB "launched its own review of the issue, setting out new principles for how its officials should interact with the private sector."'

The study of State legitimacy has a long tradition in political science and sociology. The related concept of business (or commercial) legitimacy, namely the acceptance of the authority and privileges that emerge from the economic system, is a question less often studied, certainly in Economics. ${ }^{10}$ There is, of course, a tradition that goes back to de Tocqueville, and especially to Max Weber, that emphasizes the peculiarities of the American economic system where the preeminence given to business in the US occupies a central role. ${ }^{11}$ Our conjecture is that business legitimacy stems from the efficiency, and also the honesty of a few, visible, business leaders. ${ }^{12}$ It is possible that there are differences over time in the type of businesspeople that are seen to prevail in a country, depending on their salience in the media. For example, during the initial dot-com bubble tech entrepreneurs were ubiquitous in the media, whereas after the 2008 financial meltdown it was more standard for bankers to capture the public imagination. Similarly, one might expect businesspeople in developing countries to be more active in "crony" sectors than those in rich countries. ${ }^{13}$

Previous work has emphasized the importance of State capacity. For example, Wade (1990) focused on the role of government intervention during the East Asian industrialization, in particular on the "synergies between markets and public administration". In a study of the computer industry in Brazil, Korea and India, Evans (1995) argued that the most effective bureaucracies were those that were both autonomous from interest groups and enjoying deep links with the private sector (i.e., "embedded"). In the same tradition, we view private-public sector meetings as a key input into the production of informed bureaucrats. De-legitimized businesspeople, however, may be less useful as a source of information. ${ }^{14}$ Accordingly, we expect the public to be less inclined to use meetings, both because they are not a source of useful information and because they may suspect that, even if they happen to have information, inefficient businesspeople may have more to gain from offering bribes than by surrendering it. Economists have emphasized other dimensions of State capacity. One tradition, for example, is focused on the ability to enforce contracts and collect taxes (e.g., Besley and Persson 2009), while another focuses on physical presence (e.g., Acemoglu, García-Jimeno, and Robinson 2014; for an example where technology increases capacity, see Muralidharan, Niehaus, \& Sukhtankar 2014). Some of the work has emphasized the connection between State capacity and military needs (e.g., Tilly 1992; Besley and Persson 2009;

\footnotetext{
${ }^{9}$ From "ECB officials met bankers before key decisions", Financial Times, Tuesday November 3, 2015.

10 A large literature in sociology studies different forms of legitimacy, as well as strategies for maintaining it (see, for example, Suchman 1995; for an example in the institutional tradition, see Powell \& Di Maggio 1991). See also work in political psychology on "false consciousness" and system justification (for a review, see Jost, Banaji, \& Nosek 2004).

${ }^{11}$ For an illuminating discussion of how the "capitalist ethos" developed, and the role played by Benjamin Franklin as "the prophet of the American Dream", see Reinert (2015). There is limited evidence behind the idea of higher business legitimacy in the US than in Europe (but see Malach-Pines, et al. 2005)

12 Perhaps because people think in terms of metaphors (as argued by Johnson \& Lakoff 1980).

13 Akerlof et al. (1993), La Porta, Lopez-De-Silanes, and Zamarripa (2003), Morck, Wolfenzon, and Yeung (2005) and Khanna \& Yafeh (2007) discuss the role of regulations and of corporate governance in the success of businesses that are inefficient and/or corrupt. Based on these ideas, The Economist magazine published a "crony-capitalism" index using data on billionaire wealth in sectors where there is a lot of interaction with State (see "Comparing crony capitalism around the world", May $\left.5^{\text {th }}, 2016\right)$.

14 The CFA Institute (2016) reports "Despite the potential appearance of conflict of interest, the practitioners and regulators we spoke with are in general agreement that more interaction leads to better regulatory outcomes, perhaps in recognition of the inherent asymmetry of information between financial services firms and their clients and regulators. Many of those we spoke with believe that in the years since the global financial crisis, the tendency has been toward less collaborative relationships between firms and those who regulate them, at least in part because of suspicions that the crisis was evidence of corruption of the public interest."
} 
Gennaioli and Voth 2015) or the size of firms (Kleven, Kreiner, and Saez 2016). There is also work emphasizing the complementarity between State building and good institutions (e.g., Acemoglu 2005; Dinecco 2009).

There is a large literature on political influence through lobbies that act as intermediaries between firms and elected politicians. This line of work emphasizes the role of information, noting that spending on lobbying was 5 times larger than on campaign contributions. This multiple is reported in de Figueiredo and Cameron (2006) and corresponds to the US in the late 1990's. They stress, "Perhaps surprisingly, lobbying, not campaign contributions, absorbs the bulk of 'influence dollars' spent by special interest groups". ${ }^{15}$ They finds evidence consistent with large increases in lobbying expenditures when the legislature is controlled by politicians with opposite views, which they interpret as evidence that, "biased groups must work harder to convince the legislature about policy relevant conditions". Recent work by Bertrand, Bombardini, and Trebbi (2014) reports evidence in support of the view that lobbyists provide firms access to politicians and politicians with access to expert information. We study another layer of this process which consist on what are people's beliefs regarding the lobbying process, and how these beliefs could put a constraint on state capacity.

Finally, our paper contributes to a large literature on trust, (see for example, Knack \& Keefer 1995; La Porta, et al. 1997; Guiso, Sapienza, \& Zingales (2004, 2007); Aghion, et al. 2010; Algan \& Cahuc 2010). ${ }^{16}$ Part of this work has focused on the different dimensions of trust (one example is work connecting trust to expectations of trust by Butler, et al. $(2015,2016))$. Our approach is to separate the role of generalized trust, trust in government officials and trust in business.

\section{A model of the demand for public-private sector meetings and taxation}

In this game there are 3 stages and 4 players (nature, a businessman, the public, and a delegate).

First Stage: In the first stage, the businessman and the public play a simultaneous move game. The businessman can decide to invest in becoming a "High quality" businessman (to study and train, which requires high effort $e_{h}$ ), or a "Low quality" businessperson (exert low effort $e_{l}<e_{h}$ ). Simultaneously "the public" decides whether to permit "many" meetings of his delegate with the businessperson or to limit them, allowing just few of them; it must also set the income tax rate (for businesspeople; not the overall tax rate), which can take two values $\tau_{h}$ or $\tau_{l}<\tau_{h} \cdot{ }^{17}$ The decision of the public about meetings is whether the probability of a meeting will be high or low: some meetings will always take place; the question is whether to allow some "extra" meetings. ${ }^{18}$

After the simultaneous decisions by the public and the businessperson, nature chooses a type $\pi_{h}$ or $\pi_{l}$ for the delegate tied to the quality of her information; in particular $\pi$ will be the precision of the delegate's information.

\footnotetext{
${ }^{15}$ The theoretical literature goes back to work on information transmission by a biased party - "cheap talk"- by Crawford \& Sobel (1982). For models where the biased party must pay, see Grossman and Helpman (2001) and Battaglini \& Bénabou (2003). Blanes I Vidal, Draca, and Fons-Rosen (2012) estimate the value of connections to Senators and de Figueiredo and Silverman (2006) estimate the return to lobbying by universities.

16 The importance of trust is emphasized in Banfield (1958), Putnam (1993) and Fukuyama (1995). Arrow (1972) famously asserted "Virtually every commercial transaction has within itself an element of trust .... [and] much of the economic backwardness in the world can be explained by the lack of mutual confidence".

${ }^{17}$ This simultaneity may reflect a more complex coordination game. In a sequential game, the businessman could get training and "force" the public to allow meetings. We argue this can't happen because, for example, there are many businessmen and a single businessman has no incentive to deviate; a simultaneous game captures this.

${ }^{18}$ This ensures that there will be at least some meetings involving low quality businesspeople. Otherwise any inference about what would happen in a meeting between a low quality businessperson and a delegate would be based on "off equilibrium" beliefs.
} 
The probability of type $\pi_{h}$ is $q$. At the same time, nature chooses whether a meeting will take place: if meetings have been permitted, a meeting happens with probability 1; if the public has decided that they will be few, a meeting happens with probability $f<1$. If a meeting takes place, the businessperson learns the quality of the delegate (it is immaterial whether the public also learns it).

Second Stage: If no meeting takes place, nothing happens in stage 2. If a meeting takes place, the businessman can offer a bribe; the delegate then has to accept or reject it. The bribe consists of a payment of $B$ to the delegate, and she commits to increasing her optimal action (in the last stage) by 1 unit.

Prior to stage 3, nature draws a signal about the state of the world, which is observed by the delegate. The delegate receives a signal $s=\omega+\epsilon$ about the true state of the world $\omega \sim N(0,1)$. The precision of the delegate's signal is larger if no bribe was offered: a delegate of type $j=h, l$ receives information with $\epsilon \sim$ $N\left(0, \frac{1}{\pi_{j}}\right)$ if a bribe was offered, and $\epsilon \sim N\left(0, \frac{1}{z \pi_{j}}\right)$ for $z>1$ if the businessperson and the delegate collaborate. The signal is also known to the businessperson, but not to the public. The justification for this assumption is that the delegate receives information, which the businessman and she can interpret, but that is harder for the public to understand. ${ }^{19}$

The assumption that if the bribe is offered the signal has a lower precision (larger variance) is in line with the idea that if a businessperson meets with a regulator, either exchange of useful information takes place, or negotiations leading to the bribe take place, but not both. The meeting is used for one thing, or the other, but not both. This assumption- which is in line with the findings of Campos and Giovannoni (2007)- will also play an important role in driving the results. To understand why, notice that since more information will make the policy better, the businessman would in general like to collaborate with the delegate, but in that case the incentives of the "High quality" businessman and the "Low quality" one would be the same in terms of offering the bribe or not, and multiplicity would not arise.

Third Stage: In the final stage (either after nature chose no meeting, or after the meeting took place) the delegate chooses a policy action $a \in \mathbb{R}$. As explained above, the exchange for the bribe is simple: the businessman offers an amount of money $B$ to increase the action $a$ by 1 unit (we will specify payoffs later, but for now it suffices to say that the business person likes large $a$; say, a more favorable regulation). Figure 1 shows a timeline of the model.

Payoffs are as follows. Let $k$ be a constant, $x$ a technological parameter, and $\tau$ the tax rate. A businessperson with education $e_{i}$ and $\operatorname{cost} c_{i}$, for $i=h$, $l$, who pays a bribe $b$ (the bribe will be either $B>0$ or 0 ), has utility:

$$
u_{B}=(1-\tau)\left(e_{i}\left(k-(\omega-a)^{2}\right)+x a\right)-b-c_{i}
$$

The businessperson has a policy bias: whereas everybody wants the policy action $a$ to match the state, so as to minimize $(\omega-a)^{2}$, the businessperson likes higher $a$. In particular, in the absence of the $x a$ term, the $a$ desired by the businessperson would be $a=\bar{\omega}$ (for $\bar{\omega}$ the expectation of $\omega$, given any information available).

\footnotetext{
19 The assumption that the businessperson can observe the signal is just for simplicity, to avoid an inference problem: when the delegate chooses (in the next stage) a policy action $a$, the businessman must know what it would have been in the absence of a bribe, so as to "check" that the delegate indeed complied with her end of the deal (of increasing her otherwise optimal action by 1 unit). Alternatively, we can assume that by accepting the bribe the delegate commits to the action required by the businessman (and there would be no inference problem); the results are unchanged in this case.
} 
The education term $e_{i}$ increases "honest income" which is defined as $e_{i}\left(k-(\omega-a)^{2}\right)$ : if the action matched the state, income would be $e_{i} k$, but "bad policy" moves $a$ away from $\omega$. The parameter $x$ indexes the businessperson's preference for a biased policy. In particular, the optimal $a$ for the businessperson would be $a=\bar{\omega}+\frac{x}{2 e_{i}} \cdot{ }^{20}$ We assume that taxes are spent in other areas of the economy; we could add a lump sum transfer to the utility of the businessperson, and all results would go through unchanged. The only relevant part of this assumption is that a higher tax hurts the businessperson; with the lump sum transfer it would be only through the increased distortion. Notice that the bribe is paid from "after tax" money (it is a non-tax deductible expense), and that the education cost is either nonmonetary (it is in "utility" terms, it is a cost of effort), or a monetary cost paid from after tax money.

A relevant feature of the preferences of the businessperson is that there is a complementarity between education and policy: more educated businesspeople like better policy more; put differently, a better policy (smaller $\left.(\omega-a)^{2}\right)$ increases the incentives to acquire education.

The public cares about how "efficient" the businessperson is, and about the existence of bribes. For $I_{B}($.$) an$ indicator function of whether a bribe occurred (a function of all shocks and actions, that takes the value of 1 if a bribe happened), the utility function is:

$$
u_{P}=(1-\tau) e_{i}\left(k-(\omega-a)^{2}\right)-c_{i}+\alpha(\tau-C) I_{B}
$$

Bribes distort the policy action and therefore reduce the "honest income" $e_{i}\left(k-(\omega-a)^{2}\right)$ about which the public cares; in that sense, the public cares indirectly about bribes. But we assume that the public also cares directly about the bribes. One justification is that the public dislikes the existence of "unearned" income, or dishonest income, which arises with bribes (this would be similar to Alesina and Angeletos (2005b), where society dislikes differences in income arising due to luck), and therefore would like to punish those responsible for corruption. ${ }^{21}$ An alternative justification is that the public dislikes bribes because of reciprocal altruism (see Levine 1998 and Rotemberg 2008): the public dislikes income in the hands of those that have behaved unaltruistically towards them and bribes are one indicator of such low degree of altruism. ${ }^{22}$ By reducing the income of those deemed unaltruistic through taxes, the public's utility increases.

The parameters $\alpha$ and $C$ indicate how much the public dislikes bribes relative to "efficiency". The term $C>\tau_{h}$ is a cost which is paid whenever a bribe happens; the term $\alpha \tau$ increases the utility of the public, and increases the marginal utility of taxes when bribes happen. When we take the expected utility of the public, the indicator function becomes the probability that $b=B$ (that there is a bribe), and the last term becomes $\alpha P(b=B)(\tau-$ $C)$, so the public prefers a higher tax rate, the higher the probability of a bribe. Note that it is simple to interpret these preferences as "betrayal aversion" if we introduce a higher $\alpha$ when meetings are allowed: the public

\footnotetext{
${ }^{20}$ In this setting $a$ is interpreted as any variable that businesspeople prefer to be set at a higher level than the rest of the population. It could be that higher $a$ means lower regulation and $\omega$ would be the "optimal amount" of regulation; or in an export oriented economy, $a$ could be the exchange rate.

${ }^{21}$ For a discussion of this mechanism see Di Tella and Dubra (2013) and Alesina and Angeletos (2013).

22 An alternative model where distaste for bribes is driven by reciprocal altruism is available upon request.
} 
dislikes scenarios where they trust businesspeople and allow meetings, only to have bribes exchanged. If that is the case, the public is better off not allowing meetings..$^{23}$

The delegate is paid a fixed proportion $p$ of the honest income $e_{i}\left(k-(\omega-a)^{2}\right)$, where $p$ represents the power of the contract. This may reflect an actual contract where performance is rewarded, or some form of reputation whereby bureaucrats who do well don't earn more immediately but face better career paths in the future. In addition, she may also obtain bribes, so her payoff is:

$$
u_{D}=p e_{i}\left(k-(\omega-a)^{2}\right)+b
$$

We present now the main theorem that states the two equilibria of this model. Additionally, with this theorem in hand we derive three straightforward features of the equilibria depicted that will guide most of the results in section 5. ${ }^{24}$ Proofs of these results can be found in Appendix 1.

Theorem 1. There is an open set of parameters for which there are only two subgame perfect equilibria. In one of them the businessperson is "High quality" (bigh effort, and productive) and the public permits meetings. In the other, the businessperson is "Low quality" and the frequency of meetings is low (all unnecessary meetings are forbidden).

In the good equilibrium, since firms are productive, they reap the benefits of betterpolicy and therefore do not offer bribes. In the bad equilibrium firms offer bribes to the low quality delegate, and not to the bigh quality delegate.

Because of the higher incidence of corruption in the bad equilibrium, the corporate tax (the tax to businesspeople, to the oligarchs) is higher than in the good equilibrium.

Corollary 1.a. Given the quality of the delegate, the public gains more from limiting the amount of meetings when the businessperson's quality is low (relative to when it is high).

Corollary 1.b. Given the quality of the businessperson, the public gains more from limiting the amount of meetings when the delegate's quality is low (relative to when it is high).

Corollary 2. The public gains from setting high taxes only when both the delegate and the businessperson are low quality (otherwise the public gains from low taxes).

\section{Empirical strategy}

\subsection{Survey design}

The model explains how beliefs about the honesty and efficiency of business and government determine certain policy preferences. In particular, it explains how beliefs about what goes on in private-public sector meetings are formed, and how these beliefs affect the public's preferences towards regulating meetings. It also explains the determination of preferences over taxation of business. In the following section we take the model's

\footnotetext{
${ }^{23}$ See Bohnet et al. (2008) for evidence of betrayal aversion in the US and other contexts. This formulation with different $\alpha$ can also be obtained in a psychological games setting (à la Geanakopolos, Pearce, and Stacchetti 1989), in which a punch (the bribe) hurts more when the public expected honest behavior.

${ }^{24}$ These refer to what occurs when we parametrize the model with the open set of parameters for which the two equilibria depicted in theorem 1 hold. Even though we assumed a particular functional form for the public's utility, $(1-\tau) e\left(k-(\omega-a)^{2}\right)-c$ can be interpreted as income (or consumption), and the results in the corollaries are relevant as long as the utility of the public is quasilinear in this argument.
} 
prediction to the data. We study the effects of four treatments: each individual taking the survey is treated twice (good or bad business and good or bad government). Our two business treatments involve "priming" subjects during the administration of a standard survey with a report (and questions) on the efficiency-honesty of businesspeople or, alternatively, with a report (and questions) about business involvement in sophisticated economic crimes. We call these business treatments the High Business and the Low Business treatment. Our two government treatments involve another layer of priming during the administration of the survey, this time with a report (and questions) about honest-efficient government officials or corrupt government officials. ${ }^{25}$ We call these the High Government and the Low Government treatment. To rule out order effects, in some cases we first showed individuals the business treatment and then the government treatment, and in some cases the other way around. ${ }^{26}$ There is also a control group, which consists of individuals that were presented with no treatment at all (i.e., their survey did not include reports and questions about businesspeople or government officials).

Figure 2 shows the flow of the survey. We first conduct some basic questions (age, gender, beliefs about the poor and rich, trust, etc.). Second, we treat our subjects with the first set of reports and questions. Third, we ask them a brief set of questions regarding their policy preference in order to separate the first treatment from the second. Fourth, we show them a second treatment (if the first treatment was a business treatment, the second treatment is a government treatment and vice versa). Fifth, we ask them a different and more comprehensive set of questions regarding their policy preferences over meetings, taxes, and regulation. ${ }^{27}$

The survey design allows us to disentangle the effects of business legitimacy and trust in government on policy preferences; and to measure potentially differential effects (on policy preferences) of business legitimacy in scenarios with low and high trust in government (and analogous for trust in government in scenarios with low and high business legitimacy). ${ }^{28}$ For all the results that we show later, the regression specification is the following:

\section{Policy preference ${ }_{i}=$

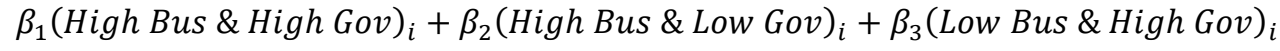 $+\beta_{4}(\text { Low Bus \& Low Gov })_{i}+\gamma X_{i}+\epsilon_{i}$}

(High Bus \& High Gov) ${ }_{i}$ is a dummy variable equal to 1 if individual $i$ was treated with High Business and High Government (0 otherwise), and analogous definitions apply for the other treatments. The omitted group is the control group. We will be mostly interested in the following linear combination of the regression coefficients: ${ }^{29}$

\section{- $\quad \beta_{1}-\beta_{3}$ : effect of business legitimacy conditional on High Government.}

\footnotetext{
${ }^{25}$ We performed two additional treatments (we call them treatments with punishment.). In one of them we prime subjects with government officials that have been caught and punished for corruption, while in the other we prime subjects with businesspeople that have been caught and punished for corruption.

${ }^{26}$ Because there are no significant "order" effects (results available upon request), in this version of the paper we present the treatments "pooled". This means that an individual treated first with High Government and then with Low Business is considered to be in the same category as an individual treated with Low Business first and with High Government later.

${ }^{27}$ A complete questionnaire and all treatments can be found in Appendix 3.

${ }^{28}$ We use the term business legitimacy given the relatively narrow purpose of business (profits) and the importance of honesty/corruption in its determination. Of course, legitimacy is a broad concept that might involve other dimensions (for example, one might expect whites who own businesses in South Africa to have low legitimacy immediately after apartheid, even if they acquired these interests legally, run them efficiently and operate in areas with high social value). We will also refer to this as trust in business. As a reminder of this issue, we use the term trust in government (instead of government legitimacy).

${ }^{29}$ Analogous definitions for the effect of trust in government.
} 
- $\quad \beta_{2}-\beta_{4}$ : effect of business legitimacy conditional on Low Government.

- $\quad \frac{\left(\beta_{1}-\beta_{3}\right)+\left(\beta_{2}-\beta_{4}\right)}{2}$ : effect of business legitimacy.

The reason for focusing on these linear combinations of coefficients instead of just the regressions coefficients per se (which gives the effect of the treatments relative to the control group) is fourfold. First, if we show individuals a negative report about businesspeople in the US (analogous for government), we can't be sure that we are actually priming individuals to distrust businesspeople as this would depend on their prior. If their prior is that businesspeople are even more corrupt than what was stated in the report, then our treatment may actually prime people to trust the businesspeople more. What we can be sure is that those primed with High Business received a more favorable priming on business efficiency-honesty than those primed with Low Business, and so we focus on this comparison. Extreme negative priming could overcome this problem, but this is not feasible as overly biased report may lead individuals to distrust the survey, feel they are being manipulated, etc. Second, if we compare our treatments directly with the control group we need more power to find significant results, than if we compare 'opposite' treatments (i.e. High Business vs Low Business). This is particularly relevant as we are avoiding overly biased reports, or very long reports, with many windows, that could give power but can create an imbalance in the amount of time and effort that respondents in the treatment and control groups devote to the survey. Third, we are interested in looking at effects of business legitimacy conditional on trust in government. For example, as our models predicts (see corollary 2), the effect of business legitimacy on preferences for taxing the rich may be different depending on how much people trust government. To test this hypothesis we need to look at the $1^{\text {st }}$ and $2^{\text {nd }}$ test indicated above. Fourth, those in the control group were exposed to a shorter survey than the other respondents and so the comparison may not be straightforward. An alternative that we considered was to use a 'placebo' treatment (showing a report about something totally unrelated) but this introduced other issues. Our approach, studying linear combinations, avoids these four problems.

\subsection{Survey implementation}

The survey was implemented through Amazon's Mechanical Turk, an internet-based market for tasks. There are some advantages in online experimentation as there is no need to physically connect to subjects and compensate them for their travel (this and other aspects of online labor markets are reviewed in Horton, Rand, and Zeckhauser 2011). They have been used to study several questions in economics, including the effect of peers' wages on job satisfaction (Card, et al. 2012), the effect of inequality on preferences for redistribution (Kuziemko, et al. 2015) or views about social preferences (Weinzierl 2014 and Saez and Stantcheva 2016).

In our case, MTurk was used to attract subjects by offering a small reward (1 dollar) for taking a brief survey (less than 10 minutes, approximately) to "help us learn more about the relationship between politics and government in America". We explained participation was voluntary and that it was anonymous. ${ }^{30}$ We followed many steps to ensure quality responses. Besides restricting the sample in ways that will be explained below, we recruited only individuals with a Human Intelligence Task approval rate equal to or higher than $80 \%$ and we set visibility to "Private" so that only workers that meet this qualification can preview our survey. To check that individuals didn't feel that our survey was overly biased in some way, we coded the comments that respondents made at the end of the survey and found that only a small fraction $(0.35 \%)$ expressed that the survey was

\footnotetext{
${ }^{30}$ We allowed individuals up to 50 minutes to complete the survey and were paid automatically after 8 hours of completing the survey.
} 
biased. ${ }^{31}$ To discourage respondents from skipping some questions, a pop up window appeared whenever an individual intended to go to the next window before answering all the questions in the current window. The pop up indicated the number of questions that were being unanswered and whether the respondent wanted to continue without answering all the questions. We also conducted our survey on a single wave on late November 2015 to ensure that respondents don't answer the survey more than once.

The survey was taken by 9,217 individuals and Table 1 presents a complete list of variable definitions. We collected data on the time spent by subjects on each of the windows that were presented during the survey. We note that several subjects took far less time than the minimum amount of time required to read the questions. To get potentially meaningful answers we restrict the sample in two ways. ${ }^{32}$ First, we consider only individuals that took at least 3 minutes to complete the survey (not considering the time spent in the treatment window). ${ }^{33}$ Second, among these individuals we consider only those who spent at least 3 seconds looking at each of the treatment windows (this last condition doesn't apply to individuals assigned to the control group). The total number of observations after applying these two filters is 7,687. We included two treatments where punishment was made salient (of bad businesspeople or officials), and without these observations our resulting sample includes 5,986 subjects. ${ }^{34}$ The mean number of minutes spent answering the survey is 7.2 minutes. ${ }^{35}$

Table 2 presents summary statistics. The first column focuses on the general sample. Column 2 and 3 show summary statistics splitting our sample in Democrats and Republicans. This split is particularly useful, as we express some of our results in terms of the degree to which the treatments close the gap between Democrats and Republicans. We broadly see that Democrats tend to favor (relative to Republicans) less contact between businesspeople and government officials and more regulation. Focusing on the outcome questions before the second treatment, we see that Democrats have more negative views about meetings taking place between government officials and businesspeople, they want more general regulation on US businesses, and more wages and prices regulation in the economy. Regarding the outcome questions after the second treatment, we see that Democrats have more negative views about competition in the economy, want more government responsibility to ensure that everyone is provided for, are slightly less likely to believe that 'In democracy, the economic system runs badly', prefer a more progressive tax scheme (more taxes to the rich and less to the poor), and are more likely to believe that fraud was one of the central reasons of the 2008 financial crisis.

Column 4-6 aim to gauge the degree to which the sample may be representative of the US population. ${ }^{36}$ The main conclusion is that our sample is fairly representative in terms of demographics (although our sample is slightly younger and more educated) and in terms of policy preferences. In column 4 we compare our sample with that of Kuziemko, et al. (2015) which also conduct their study through Amazon's MTurk. The main conclusion be comparing column 1 and 4 is that the populations are strikingly similar. Kuziemko, et al. (2015) collected their sample between January 2011 and August 2012, and at least with respect to observables, it is

\footnotetext{
31 In a follow up survey that is explained in section 6, we introduced an "attention check" question mid-way through the survey as in Alesina, Stantcheva and Teso (2016). Only $0.82 \%$ of respondents reported some form of inattention at that point.

3221 individuals had corrupted data in the time that they took to complete the survey, so they were not considered in our sample.

33 There is also a very short unrelated experiment that was performed after all this survey was conducted, which we call the candy experiment, which was not considered when restricting the sample. If the reader wants to look at the survey interactively please follow this link: https://hbs.qualtrics.com/SE/?SID=SV_ahE7rZtC1sCrlnT.

34 Results for these treatments are available upon request.

35 Results are robust to other sample definitions and are available upon request.

${ }^{36}$ Note that we are discussing the representativeness of the MTurk sample in the context of the US. Professional companies may be necessary to conduct surveys in other countries such as in Alesina, Stantcheva, and Teso (2016).
} 
quite similar to the sample we collected in November 2015. In column 5 we compare our sample with a wellknown sample of the US population: the World Value Survey. ${ }^{37}$ This survey has been widely used in the politics and economics literature. With respect to similarity in demographics, the two exceptions are age and education (our sample being slightly younger and more educated). In particular, the mean age in our sample is 34.9 while in the WVS is 46.5. The fraction of people with a postgraduate degree is pretty similar in the two samples (13.3\% in our study and $11.5 \%$ in the WVS) but there is a large difference in the fraction of people with no college degree $(39.3 \%$ in our sample and $63.7 \%$ in the WVS). With respect to policy preferences, the two dimensions considered show very similar patterns. ${ }^{38}$ When individuals are asked about competition on a $0-10$ scale (with 0 on absolute agreement with "Competition is good. It stimulates people to work hard and develop new ideas" and 10 on complete agreement with "Competition is harmful. It brings out the worst in people"), the mean response in our survey was 2.6 while in the WVS is 2.7 . When asked whether they agree more with "People should take more responsibility to provide for themselves" or "The government should take more responsibility to ensure that everyone is provided for", we obtain a mean response of 3.9 while in the WVS is 4.2. Finally, in column 6 we show results from the 2015 American Community Service which comprises a wellknown big and representative sample of US population. By comparing it to our sample, we again see that our sample seems comparable, with the exception of age and education.

In Table 3 we look at the distribution of respondents across US states to assess the sample representativeness in this dimension. The distribution closely follows that of the American Consumer Survey 2015. We note, however, that our survey is conducted hiring voluntary participants. Thus, those who choose to participate may be different from those that do not (even if they are identical in terms of observables). Furthermore, as noted above, our sample is slightly biased towards younger and more educated people.

Table 4 presents the data summarized across treatments. It suggests that, at least with respect to observables, the data are balanced across treatments suggesting a successful randomization.

\section{Results}

We present results in terms of meetings, taxes and regulation. Results regarding other questions in the survey are available upon request.

\subsection{Meetings}

We focus on Meetings_Good2. ${ }^{39}$ We regress it on only the treatments (and a constant term) in column 1, include a set of demographic controls in column 2, and political preferences and pre-treatments beliefs in column $3.4^{40}$

\footnotetext{
${ }^{37}$ We considered the $6^{\text {th }}$ wave which corresponds to the years $2010-2014$.

38 The variables Trust and Market_Bad2 were constructed using two identical questions that are asked in the WVS. However, we used a different scale than that of the WVS which prevents the comparison of responses in these two dimensions. The reason why we used a different scale is that in all the questions that an individual had to indicate his relative agreement/disagreement with a statement we used an homogeneous 0-10 scale.

${ }_{39}$ After the first treatment, respondents are asked whether they think that meetings between government officials and businesspeople consist mainly in exchange of bribes or information (Meetings_Good1). After the second treatment, respondents are asked about their preferences for meetings between government officials and businessmen in a slightly different way. They are asked whether they prefer a politician that is more or less pro-meetings (Meetings_Good2). We focus in this latter question, as we will be focusing on post-two-treatments questions throughout the paper (as explained in the survey design section), but the same results can be seen if we focused on Meetings_Good1.

${ }^{40}$ In column 3 we add regressor Obama which is a post-treatments variable about an action that took place in the past. Results in column 3 are robust to dropping this control.
} 
These results can be found in Table 5. Before discussing the coefficients on the treatments, we note some interesting correlations between the outcome variable and the controls. First, general trust (we used the same question that is used in the World Value Survey to define this variable) is positively correlated with a more favorable view of meetings, as one would have expected. Second, both beliefs about the rich and about the poor are correlated with Meetings_Good2 with the expected sign. A more favorable view about the rich (belief that rich people in the US are rich mainly because they made an effort), and a more negative view about the poor (belief that poor people in the US are poor mainly because they did not make an effort), correlate with a more favorable view of meetings. It is interesting to note that beliefs about the rich are correlated with policy preferences even after controlling for beliefs about the poor. Third, being closer to the Democrats has a negative correlation with preferences for meetings.

The effect of business legitimacy and trust in government is positive on the views that individuals have about meetings. To assess this, we look at the linear combination of the coefficients described in section 4.1 $\left(\frac{\left(\beta_{1}-\beta_{3}\right)+\left(\beta_{2}-\beta_{4}\right)}{2}\right.$ for trust in business and $\frac{\left(\beta_{1}-\beta_{2}\right)+\left(\beta_{3}-\beta_{4}\right)}{2}$ for trust in government). We find that the effect of business legitimacy is equal to 0.429 (column 3), which amounts to $82.5 \%$ of the gap between an average Democrat and Republican in our sample. The effect of trust in government is equal to 0.559 (column 3), which amounts to $107.3 \%$ of the gap between an average Democrat and Republican in our sample. The interpretation given in our model to this result is that both trust in business and in government affects state capacity (through the ability to hold meetings).

To check if business legitimacy has a positive effect on preferences for meetings ceteris paribus the level of trust in government (corollary 1a), we perform two hypothesis tests over the estimated coefficients, as described in section 4.1. First, we compare the treatment coefficients for individuals treated with High Business relative to individuals treated with Low Business, when both groups were treated with High Government. The difference in coefficients is positive and statistically significant (0.531 in column 3). It suggests that, conditional on a High Government treatment, individuals have stronger preferences for allowing meetings when treated with High Business than with Low Business. The effect of business legitimacy (conditional on High Government) is equivalent to an increase in support of meetings of $15 \%$ (in terms of the control mean). The second test involves conditioning on Low Government. Qualitatively, similar results obtain.

To check whether the honesty of public officials has a positive effect on preferences for meetings ceteris paribus business legitimacy (corollary 1b), we perform similar tests. First, we compare the treatment coefficients of individuals treated with High Government relative to individuals treated with Low Government, when both groups were treated with High Business. The difference in coefficients is positive and statistically significant (0.661 in column 3) which amounts to saying that conditional on a High Business treatment, individuals have stronger preferences for meetings when treated with High Government than with Low Government. To put these numbers in perspective, the effect of trust in government measured this way (conditional on High Business) amounts to an increase in support of meetings of 18\% (in terms of the control mean). Qualitatively the same results obtain when one conditions on Low Business.

It is possible to provide quantitative comparisons between the effects of business legitimacy on preferences for meetings when treated with High Government/Low Government. There is some suggestive evidence that the effect of business legitimacy on state capacity (through meetings) is stronger when trust in government is high. This 
result is not very robust, although this could be a power issue. ${ }^{41}$ This hypothesis test is given by comparing the effect of business legitimacy conditional on being treated with High Government, relative to the effect of business legitimacy conditional on being treated with Low Government. The differential effect is positive (0.208), so business legitimacy seems to have a greater effect in scenarios where trust in government is high (relative to those where it's low), although this difference is not statistically significant. ${ }^{42}$

\subsection{Taxes}

We also study the effect of business legitimacy on preferences for redistribution. In Table 6, we focus on preferences for taxes on the top $1 \%$, although results for preferences for taxes on household that are in other parts of the income distribution can be found in Appendix 2 (Table A1, A2, and A3), and will be briefly discussed.

We regress the preferred tax rate on the top $1 \%$ on the treatments (and a constant term) in column 1, include a set of demographic controls in column 2, and political preferences and pre-treatments beliefs in column $3 .{ }^{43}$ We first note some interesting correlations. First, beliefs about the rich and about the poor are strongly correlated with preferred taxes: a more favorable view about the rich, and a less favorable view about the poor, correlate with a lower preferred tax rate on the top 1\%. Second, being Democrat, as expected, is positively correlated with a person's preferred tax rate.

Focusing on the treatments, we start by noting that our results replicate other work that found no effect of trust in government on preferences for redistribution. Indeed, Kuziemko, et al. (2015) find that their information treatment lowers trust in government (perhaps because it suggests the government has been ineffective in addressing inequality), and include an auxiliary test designed to isolate trust in government (from other effects). They find that a treatment intended to prime people to distrust the government has no effect on preferences for taxes on the top $1 \% .{ }^{44}$ In Table 6, we find that the effect of trust in government (defined as $\left.\frac{\left(\beta_{1}-\beta_{2}\right)+\left(\beta_{3}-\beta_{4}\right)}{2}\right)$ is not statistically significant.

Our main result with respect to taxes is that lowering business legitimacy when trust in government is low leads to a significant increase in the desired tax on the top $1 \%$. The estimated effect when trust in government is high is insignificant. Similarly, lowering trust in government when business legitimacy is low leads to a higher desired tax rate on the top 1\%, but it has no effect when business legitimacy is high (note that Kuziemko, et al. (2015) sample is drawn from the US, where business legitimacy is expected to be high; thus consistent with this finding). This result is consistent with the model's predictions (see corollary 2), where the mechanism

\footnotetext{
${ }^{41}$ We could also be interested in comparing the differential effects of trust in government on preferences for meetings when treated with High Business/Low Business. The hypothesis test performed to achieve this is actually the same test that the one we perform here. To understand why they are the same, it may be useful to think of the effects as derivatives. In that sense, what we are actually looking at is at the cross-partial derivative of preferences for meetings with respect to trust in business and in government (the order in which you take derivatives doesn't matter and that's why the effect is the same whether we look it first from the private perspective or from the public one). Results indicate that the first derivative with respect to both arguments (trust in business and in government) is positive, so as the cross-partial (although nonsignificant).

${ }^{42}$ Formally, this is what we are testing: High Business|High Government - Low Business|High Government> High Business|Low Government - Low Business|Low Government. The inequality holds when the test is performed in each of the three specifications in columns 1-3, and the p-values are: 0.13 (column 1), 0.14 (column 2), 0.13 (column 3).

43 Results robust to dropping regressor Obama in column 3.

${ }^{44}$ In their main treatment (which combines information on US income inequality and the link between top income tax rates and economic growth) they find an effect on taxes on the top $1 \%$.
} 
emphasized is the public's distaste of bribes. The public wants to punish businesspeople when there are bribes by raising taxes, and bribes in equilibrium happen only when there is a low quality of both the delegate and the businesspeople.

Note that one might have predicted that more trust in government would lead to a demand for higher taxes, as a good government should be able to collect taxes more efficiently or use them better. However, the opposite sign is found, which we interpret as evidence consistent with our model suggesting that demand for taxes on the top $1 \%$ is driven by people's aversion to rich people that are undeserving (and a desire to punish them).

Quantitatively, the effect is reasonable: in column 1 we see that, conditional on Low Government, subjects primed with High Business want a tax on the top 1\% that is approximately 2.7 percentage points lower than those primed with Low Business. The mean of the control group is 34.8 so the effect is non-negligible; it amounts to $31.3 \%$ of the gap between an average Democrat and Republican in our sample. Another way to summarize the results is that, consistent with our model (see corollary 2), subjects only react when primed with both Low Business and Low Government as this is the only treatment with a coefficient statistically different from 0 . Relative to the control group, this combined treatment leads subjects to increase their preferences over taxes on the top $1 \%$ by 1.7 percentage points.

In Appendix 2 we focus on preferences for taxes on other groups in the income distribution. We find similar results on desired taxes on the next top $9 \%$ in Table A1 (which completes the top $10 \%$ of the income distribution). When one looks at preferences for taxes over the next top $40 \%$, and the bottom $50 \%$ (poorest), the treatments have basically no significant effect. We see this as evidence consistent with the model, where taxes are a way of punishing businesspeople, and not of redistributing income. ${ }^{45}$

\subsection{Regulation}

While there is only a small amount of prior work (although rapidly growing) on taxation at the very top and on State capacity (and none on meetings as one of its dimensions), there is a lot of previous work on regulation. Some of this prior work uses data from the World Values Survey (WVS) which can also be used to provide a link to the notion of business legitimacy that we emphasize. Aghion et al. (2010) present a negative correlation between measures of trust and demand for regulation in a cross section of OECD countries and transition economies. We can study this result, using WVS data, within the US (given that this is where we recruit our MTurk sample). In the first column of Table 7 we present the correlation between Trust in Government with four different measures of demand for regulation (three of which studied by Aghion et al. 2010, plus Government Ownership of Business which appears as a useful complement). Consistent with that paper, the first three rows reveal negative coefficients (although the first two are insignificant), while row (4) reveals a positive and significant coefficient. Since data related to trust in business is also available in the WVS, we can explore the patterns in these data. When we repeat the exercise using this dimension of trust we note that all these measures of regulation are strongly negatively correlated with Trust in Business. In the next two columns of Table 7 we include both variables (Trust in Government and Trust in Businesses) in a horserace. Consistent with a large role for opinions about the rich in the demand for regulation, there is a negative correlation between Trust in Business and

\footnotetext{
45 The fact that treatments had no effect on taxes on the next $40 \%$ and bottom $50 \%$ cannot be attributed to a lack of attention in this question. To see why, we can check that the correlation with preferred taxes on the bottom 50\% and Poor didn't make an effort, Rich made an effort, and Obama are highly significant and with the expected sign (see Table A3).
} 
the four measures of demand for regulation, while there appears to be a weaker connection to Trust in Government.

We included three of these questions in our survey to study if at least part of these correlations involves a causal relationship. Table 8 presents the results. We also included a question on whether subjects want to give discretion to policymakers (which is not in the WVS). This is shown in column 4 of Table 8.

The results in Table 8 are consistent with the correlations in Table 7. Column 1 shows that business legitimacy has a negative effect on a subject's beliefs about whether competition is bad, while trust in government has no effect (consistent with row 1 of Table 7). ${ }^{46}$ Second, column 2 shows that business legitimacy causes individuals to say the government should take less responsibility to ensure that everyone is provided for, conditional on the Low Government treatment. Trust in government appears to play no role (consistent with row 2 of Table 7). Third, column 3 shows that both trust in business and in government lead individuals to have more positive views about the economic system in democracies. This is also consistent with the WVS results (row 3 of Table 7). Note that there is a significant effect of trust in government, suggesting that the treatment is sometimes effective. ${ }^{47}$ In the last column, we note that more trust in government causes subjects to want to give more discretion to policymakers. The effect of business legitimacy is negative as expected, although it is not statistically significant.

Note that this exercise provides support for our interpretation of the treatments: the empirical patterns displayed by our reports and questions designed to prime subjects with trust about government (and business), are similar than those displayed by the questions included in the WVS designed to capture trust in government (and business). Finally, we note that our results reinforce the view that trust in business and in government are different concepts as they affect demand for regulation differently (and sometimes in opposite directions).

\section{Complementary survey}

During November 2016 we ran a small complementary survey to measure the "first stage" of our treatments, enhance our understanding of the results found in the taxation questions, and better assess some of the potential advantages/disadvantages of our $2 \times 2$ empirical strategy. We explain each of these objectives in detail in the next subsection as well as the results that we find.

\subsection{First stage and magnitude of results}

The survey title and description of the complementary survey are identical to that of our main survey (with the exception that in the complementary survey we paid $\$ 0.6$ to each participant and indicated that the survey takes 6 minutes approximately, instead of 10). The content and flow of the survey is also identical up to the treatment windows. ${ }^{48}$ We then showed the participants an "attention check" question to enhance the accuracy of the

\footnotetext{
${ }^{46}$ Regarding the magnitude of the effects, we see that the effect of business legitimacy is equal to -0.158 which in terms of the control group mean is $-6 \%$. To put this number in perspective, if we look the ranking of countries in the WVS in this question (where the $1^{\text {st }}$ position corresponds to the country with the highest value of Competition_Bad2), US is in the position 41 (out of 61 countries) in this dimension. If we decrease its value by $6 \%$, we reach the $47^{\text {th }}$ position (Armenia). 47 Note that the question on the economic system in Democracy is asked after the Competition is Harmful and Government should take more responsibility.

48 The survey instrument can be found in Appendix 4. Besides the control group we included the following treatments (always showing the government treatment first): High Business \& High Government, High Business \& Low Government, Low Business \& High Government, Low Business \& Low Government, High Business, and Low Business. To look at the survey interactively: https://hbs.qualtrics.com/SE/?SID=SV_3NPCYdpcbln07Ix.
} 
responses we get in the following (multipart) question. This new outcome question asked individuals their levels of trust in nine organizations: local government, major companies, the police, national government, banks, the press, armed forces, the courts, and their neighbors. With respect to the "attention check", only $0.82 \%$ of the respondents reported inattention during our survey. We used the same question used by Alesina, Stantcheva, and Teso (2016), and these types of questions have been shown by Meade and Craig (2012) to identify careless survey takers, as well as enhance respondent's attention in the questions that follow. The reason why we asked individuals their levels of trust regarding the national government, major companies, and other seven groups/organizations is twofold. First, it is a way of assessing what is the "first stage" of our treatments and corroborate that our treatments actually impact trust in business and in government and not something else. This is particularly relevant given that in these conceptual priming exercises it is hard to pin down treatments that narrowly affect a given dimension, without affecting other dimensions that are not orthogonal to the ultimate outcome variable we are interested in (policy preferences). We had some suggestive evidence that our treatments corresponded to priming individuals to distrust businesses and government (as discussed in section 5.3.) but wanted to assess this in a more straightforward way. ${ }^{49}$ Second, the results we showed before are generally small in magnitude so we wanted to check the magnitude on the impacts of the level of trust are also significant but relatively small.

In figure 3 we show the effect of trust in business (left hand side) and trust in government (right hand side) on the levels of trust on nine groups/organizations. ${ }^{50}$ We corroborate that when we talk about the effect of trust in business we are actually capturing the dimension of trust related to Major Companies, and not something else (it is the only level of trust that is statistically significantly affected at the $5 \%$ level). Also, its impact equals a $7.9 \%$ change in the level of trust in Major Companies, measured in terms of deviations from the control group mean. With respect to the effect of trust in government we see that this is associated with changes in the levels of trust regarding the national government and the courts. To get an idea of the magnitude of these results, it corresponds to a $9.5 \%$ change in the level of trust in the national government and $7.8 \%$ in trust in courts (both measured in terms of deviations from the control group mean).

\subsection{Taxation: actual behavioral changes and understanding the mechanisms}

Up to this point we have dealt with people's opinions but haven't assessed whether our treatments also affect actual behavior. To assess this, and as a way of validating the results we found regarding taxation, we asked individuals to vote for either Citizens for Tax Justice or The American Red Cross. We told them that we would donate $\$ 200$ to the organization with the highest number of votes (which we did). We explained that Citizens for Tax Justice is "an NGO that seeks to require the wealthy to pay their fair share; it is primarily concerned with federal tax policy in the US and its mission is to give ordinary people a greater voice in the development of tax laws" and that The American Red Cross is "an NGO that seeks to provide humanitarian help; it is primarily focused on disaster relief and emergency assistance within the US". Additionally, we included the option of not participating in the voting at all ("I don't want to vote").

\footnotetext{
49 Initially, we didn't include this question in our main survey because individuals may feel alienated if we show them a positive/negative text about business and then ask them what level of trust they have in business. In case this problem could arise, we followed the more conservative approach of not asking questions 'too connected with our treatments' in our main survey.

${ }^{50}$ See section 4.1 for a definition of what we mean by the effect of trust in business and in government. See Table A4 (Appendix 2) for detailed results.
} 
In Table 9 we present the results of a multinomial logit. We are particularly interested in the impact of business legitimacy and trust in government in the log odds ratio of voting for Citizens for Tax Justice relative to voting for The American Red Cross. The results qualitatively replicate what we found in section 5.2. Our main conjecture, which is driven by corollary 2 , is that individuals demand less taxes when trust in government is high only if trust in business is low and vice versa. Regarding the effect of business legitimacy we don't reach conclusive results, as basically both when conditioning on High Government and on Low Government, business legitimacy seems to have no effect. This could be due to lack of power or evidence of attenuation of opinion to action. However, regarding the effect of trust in government, we do see the same pattern than before (and consistent with corollary 2): trust in government has no effect on preferences for taxing the top $1 \%$ when business legitimacy is high, but it has an effect when business legitimacy is low. Also, the effect is in the direction expected: the more an individual trusts the government, the less taxes on the top $1 \%$ he wants.

Besides validating our tax results with an actual behavioral question, we also asked a question to help us understand some of the mechanisms underlying this process. In our model we assume that $\alpha>0$, which means that people prefer high taxes when there is a high probability of bribes occurring. One way we rationalize this is with the idea that the public wants to punish businesspeople when bribes occur. But when there are bribes, wouldn't increasing taxes to the rich benefit corrupt government officials that appropriate this revenue? If this is the case, this would generate a trade-off in people's preferences for taxation: punish corrupt businesspeople while benefiting the delegate (if high taxes) or the other way round (if low taxes). To test whether this trade-off is present in people's mind, we asked them "Imagine that taxes to the top 1\% (richest) of the population increase; what do you think will happen?" We gave them three options: "The money will be used to fund an increase in useful government spending" (selected by $45 \%$ of respondents), "The money will be wasted without clear benefits for the population" (selected by 40\%), and "The money will be appropriated by corrupt government officials" (selected by only $15 \%$ of respondents). ${ }^{51}$ If anything, this is evidence that the mentioned trade-off is not so clearly present in people's mind: either they think that the money is wasted or used for government spending, but not appropriated by government officials. This in turn reinforces our model's setup that posits preferences for higher taxes on the rich when there is a higher probability of corruption.

\subsection{Anchoring}

The third hypothesis we wanted to test is whether priming with a business treatment affects the level of trust in government more or less if an individual has been primed with a government treatment before. If the "anchoring" effect operates in a way such that it "fixes" the level of trust in government, then our 2x2 design has the additional advantage of delivering "cleaner" effects in the sense that the spillovers that the business treatment has on trust in government are mitigated. If on the other hand, this effect operates in the opposite direction, of basically making the people "think about government" whenever they look at something afterwards, our $2 \times 2$ design could raise the concern of delivering confounded effects. We ran the following regression to test this hypothesis:

$$
\begin{aligned}
\text { Trust in } \text { Gov }_{i}= & \beta_{1}(\text { High Bus \& High Gov })_{i}+\beta_{2}(\text { High Bus \&Low Gov })_{i}+\beta_{3}(\text { Low Bus \& High Gov })_{i} \\
& +\beta_{4}(\text { Low Bus \& Low Gov })_{i}+\beta_{5}(\text { High Business })_{i}+\beta_{6}(\text { Low Business })_{i}+\gamma X_{i}+\epsilon_{i}
\end{aligned}
$$

\footnotetext{
51 These are results considering only the control group (sample size is 502). We randomized the order in which these 3 options appeared as a way of ensuring that the aggregate response isn't driven by the order in which the options were presented.
} 
The group that has the dummy (High Business) ${ }_{i}$ activated is the group that was exposed to the High Business treatment just before the "attention check" question (and that wasn't exposed to a government treatment), analogous for (Low Business) ${ }_{i}$. The tests performed are the following: $\left|\beta_{5}-\beta_{6}\right|=\left|\beta_{1}-\beta_{3}\right|$ and $\left|\beta_{5}-\beta_{6}\right|=$ $\left|\beta_{2}-\beta_{4}\right|^{52}$

Results can be found in Table A5 (Appendix 2). We do not reject the null hypothesis in both cases so there is no evidence that a hypothetical "anchoring" effect either helps or hurts the interpretation of our results with the empirical design chosen.

\section{Conclusions}

We study the role of people's beliefs about the rich in the determination of public policy. We focus on three particular policy domains: public-private sector meetings (which we take to be an important determinant of State capacity), demand for taxation on the top $1 \%$, and business regulation. A model explains how these policy preferences may be affected by people's trust in businesses (which we call business legitimacy). We conduct an online survey with a $2 \times 2$ design: subjects are "primed" to trust/distrust businesspeople and to trust/distrust government officials, and we use it to test the model's implications.

There are three main results. First, higher business legitimacy and more trust in government cause subjects to declare more support for politicians who want private meetings between government officials and business people to discuss matters of mutual interest. The interpretation given in our model is that a positive view of business people leads subjects to expect more information (and less bribes) to be exchanged in these meetings, which affects the State's capacity to deliver good policies. There is also suggestive evidence that business legitimacy has a stronger effect on state capacity (through meetings) when there is high trust in government, although this result is not very robust.

Second, business legitimacy and the level of trust in the government interact in the determination of preferences for taxation. Lowering business legitimacy when trust in government is low leads to a significant increase in the desired tax on the top $1 \%$. The estimated effect when trust in government is high is insignificant. Similarly, lowering trust in government when business legitimacy is low leads to a higher desired tax rate on the top $1 \%$. This result is consistent with the model's predictions (see corollary 2), where the mechanism emphasized is the public's distaste of bribes. The public wants to punish businesspeople when there are bribes by raising taxes. And bribes in equilibrium happen only when there is a low quality of both the delegate and the businesspeople. These results are robust to whether we look at the top $10 \%$ instead of just the top $1 \%$. However, the "priming" had no effect on preferences for taxing household in other parts of the income distribution. We see this as supporting our interpretation that people demand taxes to punish businesspeople (or the undeserving rich), and not to redistribute income. In a complementary survey we validated these results with an actual behavioral question: respondents had to vote either for Citizens for Tax Justice (which they were told it is an NGO that "seeks to require the wealthy to pay their fair share"), The American Red Cross, or not vote at all. The organization with the highest number of votes received a donation of $\$ 200$. Results are qualitatively the same than the ones we found with the question regarding the preferred tax rate on the top $1 \%$. When looking at business legitimacy we don't reach conclusive results in this case but we do see the same pattern when focusing on trust in government: distrust in the government makes people more likely to vote for Citizens for Tax Justice

\footnotetext{
52 The alternative hypotheses are: $\left|\beta_{5}-\beta_{6}\right| \neq\left|\beta_{1}-\beta_{3}\right|$ and $\left|\beta_{5}-\beta_{6}\right| \neq\left|\beta_{2}-\beta_{4}\right|$.
} 
(relative to The American Red Cross), and this effect is only present when individuals are primed to distrust businesses.

Third, trust in business and in government are different concepts and affect demand for regulation differently (and sometimes in opposite directions). To assess this we first look at some correlations of demand for regulation and measures of trust with World Value Survey data in the US. We experimentally replicate these correlations with our "priming" exercise. With these causal estimates we conclude that trust in business and government operate differently in people's mind, and find suggestive evidence that while business legitimacy leads to a lower demand for regulation, this is not so clear cut for trust in government. 


\section{Figures and Tables}

\section{Figure 1. Stages of the model}

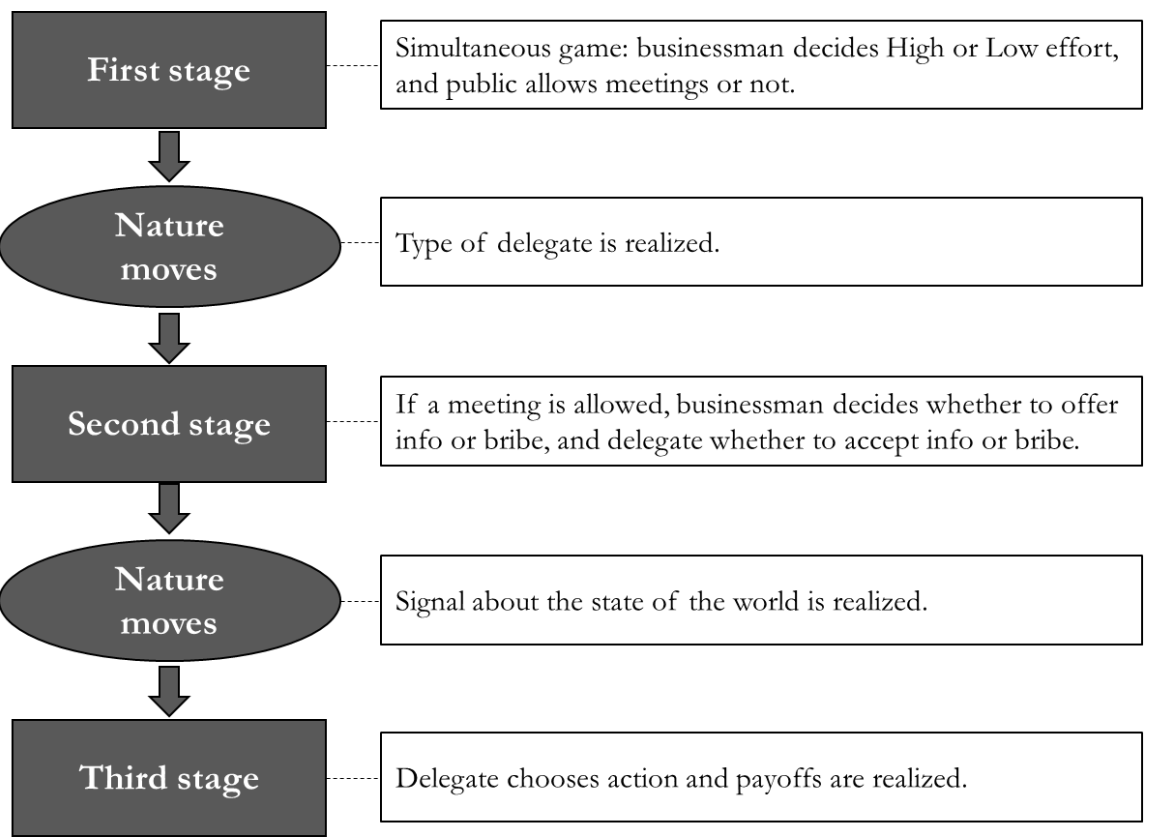

Figure 2. Survey Design

Background information

\section{$\sqrt{7}$}

Treatment 1: High or Low

Business (Government)

Policy preferences: Meetings and

Regulation

Treatment 2: High or Low

Government (Business)

Policy preferences: Meetings, Taxes, and Regulation 
Figure 3. First stage

Effect of Trust in Business Treatments on Trust

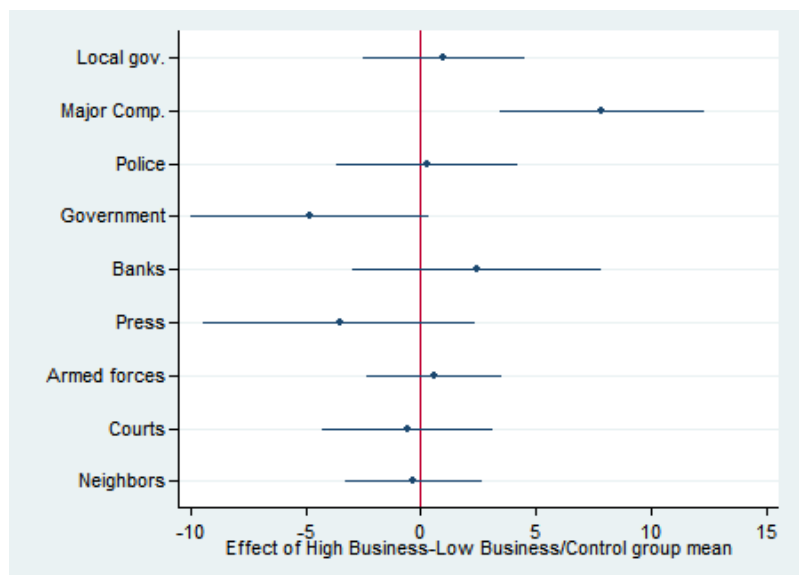

Effect of Trust in Government Treatments on Trust

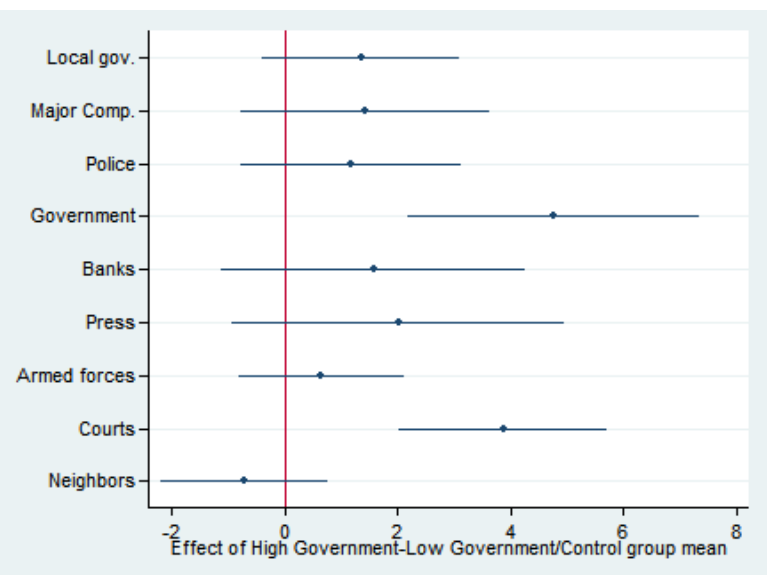

Notes: We ran the regression specification described in section 4 with trust in Local government, Major Companies, The police, The government (in your nation's capital), Banks, The press, The armed forces, The courts, and Your neighbors as dependent variables. In the left panel we present the following linear combination of coefficients: $\frac{\left(\boldsymbol{\beta}_{\mathbf{1}}-\boldsymbol{\beta}_{3}\right)+\left(\boldsymbol{\beta}_{\mathbf{2}}-\boldsymbol{\beta}_{\mathbf{4}}\right)}{\mathbf{2}}$ (as well as their $95 \%$ confidence intervals), and we divide this by the control group mean of the trust variable used as dependent variable. The same applies for the right panel but with $\frac{\left(\boldsymbol{\beta}_{\mathbf{1}}-\boldsymbol{\beta}_{\mathbf{2}}\right)+\left(\boldsymbol{\beta}_{\mathbf{3}}-\boldsymbol{\beta}_{\mathbf{4}}\right)}{\mathbf{2}}$ instead. We considered the sample of people that spent at least 1.5 minutes in the complementary survey (not considering the time spent in the treatment windows) and at least three seconds in every treatment. 


\section{Table 1. Variables definitions}

\begin{tabular}{|c|c|c|}
\hline Variables & $\mathbf{Q}^{\mathbf{a}}$ & Description \\
\hline \multicolumn{3}{|l|}{ Demographics } \\
\hline Male & 1 & $\begin{array}{l}\text { Dummy equal to } 1 \text { if individual is male ( } 0 \text { if female and missing value if neither } \\
\text { male/female). }\end{array}$ \\
\hline Age & 2 & Age in years. \\
\hline White & 3 & Dummy equal to 1 if indicated as one of the races "White". \\
\hline Black & 3 & Dummy equal to 1 if indicated as one of the races "Black". \\
\hline Hispanic & 3 & Dummy equal to 1 if indicated as one of the races "Hispanic or Latino". \\
\hline Asian & 3 & Dummy equal to 1 if indicated as one of the races "Asian". \\
\hline Other_race & 3 & Dummy equal to 1 if indicated as one of the races "Other". \\
\hline Postgraduate degree & 5 & $\begin{array}{l}\text { Dummy equal to } 1 \text { if highest level of education is Master's Degree/Doctoral } \\
\text { Degree/Professional Degree (JD, MD, MBA). }\end{array}$ \\
\hline Only college degree & 5 & $\begin{array}{l}\text { Dummy equal to } 1 \text { if highest level of education is } 2 \text {-Year College Degree/4-Year College } \\
\text { Degree. }\end{array}$ \\
\hline No college degree & 5 & $\begin{array}{l}\text { Dummy equal to } 1 \text { if highest level of education is Eight Grade or less/Some High School/ } \\
\text { "High School degree/GED" or Some College. }\end{array}$ \\
\hline Full-time employee & 6 & Dummy equal to 1 if Full-time employee. \\
\hline Part-time employee & 6 & Dummy equal to 1 if Part-time employee. \\
\hline Self-employed & 6 & Dummy equal to 1 if Self-employed or small business owner. \\
\hline Unemployed & 6 & Dummy equal to 1 if unemployed and looking for work. \\
\hline Student & 6 & Dummy equal to 1 if student. \\
\hline Not_in Labor_Force & 6 & Dummy equal to 1 if not in labor force (for example: retired or full-time parent). \\
\hline \multicolumn{3}{|c|}{ Political preferences and beliefs } \\
\hline Trust & 7 & $\begin{array}{l}\text { Variable taking } 0 \text { if "Need to be very careful" and } 10 \text { if "Most people can be trusted" (scale: } \\
0-10 \text { ), when asked whether most people can be trusted. }\end{array}$ \\
\hline Poor didn't make an effort & 8 & Dummy equal to 1 if respondent believes poor are poor because they made no effort. \\
\hline Rich made an effort & 9 & Dummy equal to 1 if respondent believes rich are rich because they made an effort. \\
\hline Obama & 19 & Dummy equal to 1 if supported Obama or leaned towards Obama. \\
\hline \multicolumn{3}{|c|}{ Outcome variables before second treatment } \\
\hline Meetings_Good1 & 10 & $\begin{array}{l}\text { Variable taking } 0 \text { if "Mainly exchange of bribes for favors" and } 10 \text { if "Mainly exchange of } \\
\text { useful information" (scale: } 0-10 \text { ), when asked regarding what goes on at meetings } \\
\text { between government officials and politicians. }\end{array}$ \\
\hline More_Regulation1 & 11 & $\begin{array}{l}\text { Variable taking } 0 \text { if "Very unlikely" and } 10 \text { if "Very likely", when asked regarding support } \\
\text { for more government regulation on firms (scale: } 0-10 \text { ). }\end{array}$ \\
\hline More_Wages_Regulation1 & 12 & $\begin{array}{l}\text { Variable taking } 0 \text { if "Strongly against" and } 10 \text { if "Strongly in favor", when asked regarding } \\
\text { regulating wages (scale: } 0-10 \text { ). }\end{array}$ \\
\hline More_Prices_Regulation1 & 12 & $\begin{array}{l}\text { Variable taking } 0 \text { if "Strongly against" and } 10 \text { if "Strongly in favor", when asked regarding } \\
\text { regulating prices (scale: } 0-10 \text { ). }\end{array}$ \\
\hline \multicolumn{3}{|c|}{ Outcome variables after second treatments } \\
\hline Meetings_Good2 & 13 & $\begin{array}{l}\text { Variable taking } 0 \text { if individual wants "A politician that is against allowing these meetings" } \\
\text { and } 10 \text { if "A politician that is in favor of allowing these meetings" (scale: } 0-10 \text { ). }\end{array}$ \\
\hline Competiton_Bad2 & 14 & $\begin{array}{l}\text { Variable taking } 0 \text { if respondent believes "Competition is good..." and } 10 \text { if he believes } \\
\text { "Competition is bad..." (scale: } 0-10 \text { ). }\end{array}$ \\
\hline More_Gov_Resp2 & 14 & $\begin{array}{l}\text { Variable taking } 0 \text { if individual believes that "People should take more responsibility..." and } \\
10 \text { if "The government should take more responsibility..." (scale: } 0-10) \text {. }\end{array}$ \\
\hline Market_Bad2 & 15 & $\begin{array}{l}\text { Variable taking } 0 \text { if "Disagree strongly" and } 10 \text { if "Agree strongly", when asked regarding } \\
\text { "In democracy, the economic system runs badly" (scale: } 0-10) \text {. }\end{array}$ \\
\hline Discretion2 & 16 & Dummy equal to 1 if individual wants to give discretion to policymakers. \\
\hline No_Discretion_Reg2 & 16 & $\begin{array}{l}\text { Dummy equal to } 1 \text { if individual doesn't want to give discretion to policymakers and he } \\
\text { wants more regulation overall. }\end{array}$ \\
\hline Tax_1_percent2 & 17 & Preferred tax rate for the top $1 \%$. \\
\hline Tax_next9_percent2 & 17 & $\begin{array}{l}\text { Preferred tax rate for the next top } 9 \% \text { ( } 1 \% \text { of households earn more than them, but } 90 \% \\
\text { earn less). }\end{array}$ \\
\hline Tax_next40_percent2 & 17 & $\begin{array}{l}\text { Preferred tax rate for the next top } 40 \% \text { ( } 10 \% \text { of households earn more than them, but } \\
50 \% \text { earn less). }\end{array}$ \\
\hline Tax_bottom50_percent2 & 17 & Preferred tax rate for the bottom $50 \%$ of the income distribution (poorest). \\
\hline High_Fraud2 & 18 & $\begin{array}{l}\text { Dummy equal to } 1 \text { if individual thinks there was a lot of fraud (during } 2008 \text { financial crisis) } \\
\text { and that it was the main cause of the crisis. }\end{array}$ \\
\hline
\end{tabular}


Table 2. Summary Statistics

\begin{tabular}{|c|c|c|c|c|c|c|}
\hline & $\begin{array}{l}\text { All (our } \\
\text { sample) }\end{array}$ & $\begin{array}{c}\text { Democrats } \\
\text { (our } \\
\text { sample) } \\
\end{array}$ & $\begin{array}{c}\text { Republicans } \\
\text { (our } \\
\text { sample) } \\
\end{array}$ & $\begin{array}{c}\text { Kuziemko, } \\
\text { et al. } \\
(2015) \\
\end{array}$ & $\begin{array}{l}\text { WVS 6 } 6^{\text {th }} \\
\text { Wave }\end{array}$ & ACS 2015 \\
\hline \multicolumn{7}{|l|}{ Demographics } \\
\hline Male & $43.9 \%$ & $43.6 \%$ & $44.8 \%$ & $42.8 \%$ & $48.4 \%$ & $48.6 \%$ \\
\hline Age & 34.9 & 33.8 & 37.4 & 35.4 & 46.5 & 47.1 \\
\hline White & $80.5 \%$ & $74.8 \%$ & $93.1 \%$ & $77.8 \%$ & $69.8 \%$ & $74.8 \%$ \\
\hline Black & $9.2 \%$ & $12.5 \%$ & $1.8 \%$ & $7.6 \%$ & $10.4 \%$ & $12.2 \%$ \\
\hline Hispanic & $6.6 \%$ & $7.6 \%$ & $4.3 \%$ & $4.4 \%$ & $13.4 \%$ & $15.5 \%$ \\
\hline Asian & $6.8 \%$ & $8.7 \%$ & $2.9 \%$ & $7.6 \%$ & - & $6.2 \%$ \\
\hline Other race & $2.6 \%$ & $2.9 \%$ & $2.0 \%$ & $2.6 \%$ & - & $2.8 \%$ \\
\hline Postgraduate degree & $13.3 \%$ & $14.2 \%$ & $11.4 \%$ & $12.6 \%$ & $11.5 \%$ & $10.2 \%$ \\
\hline Only college degree & $47.3 \%$ & $47.5 \%$ & $47.2 \%$ & $40.7 \%$ & $24.8 \%$ & $25.7 \%$ \\
\hline No college degree & $39.3 \%$ & $38.2 \%$ & $41.4 \%$ & $46.7 \%$ & $63.7 \%$ & $64.1 \%$ \\
\hline Full-time employee & $46.6 \%$ & $47.1 \%$ & $45.7 \%$ & $33.2 \%$ & $42.7 \%$ & $43.9 \%$ \\
\hline Part-time employee & $12.8 \%$ & $12.6 \%$ & $13.3 \%$ & $13.3 \%$ & $8.8 \%$ & $16.7 \%$ \\
\hline Self-employed & $12.4 \%$ & $12.1 \%$ & $12.6 \%$ & $10.5 \%$ & $5.1 \%$ & $7.2 \%$ \\
\hline Unemployed & $8.0 \%$ & $8.6 \%$ & $6.7 \%$ & $12.4 \%$ & $9.4 \%$ & $3.9 \%$ \\
\hline Student & $8.7 \%$ & $10.0 \%$ & $5.7 \%$ & $15.8 \%$ & $4.7 \%$ & $3.8 \%$ \\
\hline Not in Labor Force & $11.5 \%$ & $9.5 \%$ & $16.0 \%$ & $14.8 \%$ & $23.8 \%$ & $31.7 \%$ \\
\hline \multicolumn{7}{|c|}{ Political preferences and beliefs } \\
\hline Trust & 4.9 & 5.0 & 4.8 & - & - & - \\
\hline Poor didn't make an effort & $22.8 \%$ & $14.7 \%$ & $40.7 \%$ & - & - & - \\
\hline Rich made an effort & $36.9 \%$ & $27.9 \%$ & $57.2 \%$ & - & - & - \\
\hline Obama & $68.8 \%$ & $100 \%$ & $0 \%$ & $67.5 \%$ & - & - \\
\hline \multicolumn{7}{|c|}{ Outcome variables before second treatment (for control group) } \\
\hline Meetings Good1 & 4.0 & 3.9 & 4.2 & - & - & - \\
\hline More Regulation1 & 5.8 & 6.6 & 4.3 & - & - & - \\
\hline More_Wages_Regulation1 & 5.7 & 6.5 & 4.2 & - & - & - \\
\hline More_Prices_Regulation 1 & 4.7 & 5.2 & 3.7 & - & - & - \\
\hline \multicolumn{7}{|c|}{ Outcome variables after second treatment (for control group) } \\
\hline Meetings Good2 & 3.8 & 3.6 & 4.2 & - & - & - \\
\hline Competiton_Bad2 & 2.6 & 2.9 & 2.1 & - & 2.7 & - \\
\hline More_Gov_Resp2 & 3.9 & 4.7 & 2.2 & - & 4.2 & - \\
\hline Market_Bad2 & 4.1 & 4.0 & 4.2 & - & - & - \\
\hline Discretion2 & $31.8 \%$ & $37.5 \%$ & $19.5 \%$ & - & - & - \\
\hline No_Discretion_Reg2 & $36.4 \%$ & $44.1 \%$ & $21.0 \%$ & & & \\
\hline Tax_1_percent2 & 34.8 & 37.6 & 29.0 & 30.2 & - & - \\
\hline Tax_next9_percent2 & 26.5 & 28.4 & 22.9 & - & - & - \\
\hline Tax_next40_percent2 & 17.8 & 18.2 & 17.1 & - & - & - \\
\hline Tax_bottom50_percent2 & 9.3 & 8.9 & 10.3 & - & - & - \\
\hline High_Fraud2 & $31.9 \%$ & $33.9 \%$ & $27.7 \%$ & - & - & - \\
\hline Observations & 5986 & 4095 & 1858 & 3746 & 2138 & $2,490,616$ \\
\hline
\end{tabular}

Notes. Column 1-3: We considered the sample of people that spent at least three minutes in the main survey (not considering the candy experiment and time spent in the treatment windows) and at least three seconds in every treatment (when applicable). Individuals primed with punishment treatments are not included. Column 4 : We considered the respondents that took any of the omnibus treatment surveys of Kuziemko, et al. (2015); participants could only choose one ethnicity in this study; variable Obama is actually a variable that takes value 1 if individual answered Barack Obama when asked "Who did you support in the presidential election in 2008? If you were not able to vote, just choose the person you wanted to win the election at that time"; for the question on taxes we considered the control group of the omnibus treatment surveys (sample size is 1976). Column 5: data source is the $6^{\text {th }}$ wave of the World Value Survey US sample; individuals whose employment status was "Other" were omitted; variables Competition_Bad2 and More_Gov_Resp2 were constructed with the same questions than used in our study (the only difference is that in the WVS answers range from 1-10 so we rescaled these answers to a $0-10$ scale). Column 6: data source is the American Community Survey 2015; we considered individuals with 18 years old or older. 
Table 3. US States

\begin{tabular}{|c|c|c|}
\hline State & $\begin{array}{c}\text { Our sample } \\
\text { (\% of the total) }\end{array}$ & $\begin{array}{c}\text { ACS } 2015 \\
\text { (\% of the total) }\end{array}$ \\
\hline Alabama & 1.29 & 1.51 \\
\hline Alaska & 0.05 & 0.22 \\
\hline Arizona & 2.46 & 2.10 \\
\hline Arkansas & 0.85 & 0.92 \\
\hline California & 9.92 & 12.12 \\
\hline Colorado & 1.69 & 1.69 \\
\hline Connecticut & 0.97 & 1.14 \\
\hline Delaware & 0.38 & 0.30 \\
\hline District of Columbia & 0.28 & 0.22 \\
\hline Florida & 7.07 & 6.52 \\
\hline Georgia & 3.41 & 3.11 \\
\hline Hawaii & 0.30 & 0.45 \\
\hline Idaho & 0.62 & 0.49 \\
\hline Illinois & 4.35 & 4.00 \\
\hline Indiana & 2.09 & 2.03 \\
\hline Iowa & 0.97 & 0.97 \\
\hline Kansas & 0.92 & 0.88 \\
\hline Kentucky & 1.49 & 1.38 \\
\hline Louisiana & 1.17 & 1.43 \\
\hline Maine & 0.50 & 0.43 \\
\hline Maryland & 1.84 & 1.88 \\
\hline Massachusetts & 2.01 & 2.18 \\
\hline Michigan & 3.46 & 3.11 \\
\hline Minnesota & 1.51 & 1.70 \\
\hline Mississippi & 0.70 & 0.91 \\
\hline Missouri & 2.12 & 1.89 \\
\hline Montana & 0.22 & 0.33 \\
\hline Nebraska & 0.65 & 0.58 \\
\hline Nevada & 0.89 & 0.90 \\
\hline New Hampshire & 0.52 & 0.43 \\
\hline New Jersey & 2.44 & 2.81 \\
\hline New Mexico & 0.67 & 0.64 \\
\hline New York & 5.72 & 6.29 \\
\hline North Carolina & 3.91 & 3.13 \\
\hline North Dakota & 0.13 & 0.24 \\
\hline Ohio & 4.30 & 3.63 \\
\hline Oklahoma & 0.97 & 1.19 \\
\hline Oregon & 2.02 & 1.28 \\
\hline Pennsylvania & 4.73 & 4.08 \\
\hline Puerto Rico & 0.05 & - \\
\hline Rhode Island & 0.25 & 0.34 \\
\hline South Carolina & 1.39 & 1.54 \\
\hline South Dakota & 0.28 & 0.26 \\
\hline Tennessee & 2.07 & 2.06 \\
\hline Texas & 7.02 & 8.18 \\
\hline Utah & 0.82 & 0.84 \\
\hline Vermont & 0.23 & 0.21 \\
\hline Virginia & 2.93 & 2.63 \\
\hline Washington & 2.78 & 2.24 \\
\hline West Virginia & 0.54 & 0.59 \\
\hline Wisconsin & 1.91 & 1.81 \\
\hline Wyoming & 0.13 & 0.18 \\
\hline
\end{tabular}

Notes. Column 2: data source is the American Community Survey 2015; we considered individuals with 18 years old or older. 
Table 4. Randomization

\begin{tabular}{|c|c|c|c|c|c|}
\hline \multirow[b]{2}{*}{ Variables } & \multicolumn{5}{|c|}{ Treatment group } \\
\hline & $\begin{array}{l}\text { Control } \\
\text { Group } \\
\end{array}$ & $\begin{array}{c}\text { High Bus \& } \\
\text { High Gov } \\
\end{array}$ & $\begin{array}{c}\text { High Bus \& } \\
\text { Low Gov } \\
\end{array}$ & $\begin{array}{c}\text { Low Bus \& } \\
\text { High Gov } \\
\end{array}$ & $\begin{array}{c}\text { Low Bus \& } \\
\text { Low Gov }\end{array}$ \\
\hline \multicolumn{6}{|l|}{ Demographics } \\
\hline \multirow[t]{2}{*}{ Male } & $44.4 \%$ & $47.2 \%$ & $43.2 \%$ & $43.6 \%$ & $41.9 \%$ \\
\hline & - & 0.25 & 0.55 & 0.68 & 0.30 \\
\hline \multirow[t]{2}{*}{ Age } & 34.4 & 35.0 & 35.0 & 35.0 & 35.0 \\
\hline & - & 0.24 & 0.23 & 0.23 & 0.26 \\
\hline \multirow[t]{2}{*}{ White } & $80.5 \%$ & $79.5 \%$ & $81.0 \%$ & $80.0 \%$ & $81.5 \%$ \\
\hline & - & 0.61 & 0.75 & 0.80 & 0.59 \\
\hline \multirow[t]{2}{*}{ Black } & $9.0 \%$ & $8.6 \%$ & $10.0 \%$ & $8.6 \%$ & $9.6 \%$ \\
\hline & - & 0.73 & 0.44 & 0.71 & 0.69 \\
\hline \multirow{2}{*}{ Hispanic } & $6.5 \%$ & $7.6 \%$ & $5.7 \%$ & $7.0 \%$ & $6.5 \%$ \\
\hline & - & 0.37 & 0.44 & 0.62 & 0.99 \\
\hline \multirow[t]{2}{*}{ Asian } & $6.8 \%$ & $7.0 \%$ & $6.6 \%$ & $6.9 \%$ & $6.9 \%$ \\
\hline & - & 0.82 & 0.92 & 0.91 & 0.92 \\
\hline \multirow{2}{*}{ Other race } & $2.8 \%$ & $2.8 \%$ & $2.8 \%$ & $2.3 \%$ & $2.8 \%$ \\
\hline & - & 0.96 & 1.00 & 0.44 & 0.93 \\
\hline \multirow[t]{2}{*}{ Postgraduate degree } & $15.4 \%$ & $13.7 \%$ & $12.0 \% * *$ & $13.5 \%$ & $13.4 \%$ \\
\hline & - & 0.32 & 0.02 & 0.19 & 0.24 \\
\hline \multirow{2}{*}{ Only college degree } & $45.8 \%$ & $46.9 \%$ & $49.4 \% *$ & $46.9 \%$ & $45.8 \%$ \\
\hline & - & 0.65 & 0.09 & 0.60 & 0.98 \\
\hline \multirow[t]{2}{*}{ No college degree } & $38.7 \%$ & $39.3 \%$ & $38.6 \%$ & $39.6 \%$ & $40.8 \%$ \\
\hline & - & 0.80 & 0.96 & 0.67 & 0.38 \\
\hline \multirow[t]{2}{*}{ Full-time employee } & $46.9 \%$ & $48.2 \%$ & $47.4 \%$ & $45.5 \%$ & $45.2 \%$ \\
\hline & - & 0.59 & 0.82 & 0.50 & 0.48 \\
\hline \multirow[t]{2}{*}{ Part-time employee } & $11.9 \%$ & $12.3 \%$ & $11.9 \%$ & $14.0 \%$ & $13.5 \%$ \\
\hline & - & 0.81 & 0.98 & 0.15 & 0.33 \\
\hline \multirow[t]{2}{*}{ Self-employed } & $10.6 \%$ & $12.2 \%$ & $12.7 \%$ & $13.2 \% *$ & $12.0 \%$ \\
\hline & - & 0.30 & 0.12 & 0.06 & 0.38 \\
\hline \multirow[t]{2}{*}{ Unemployed } & $9.5 \%$ & $10.4 \%$ & $7.3 \% *$ & $6.4 \% \%^{* * *}$ & $8.9 \%$ \\
\hline & - & 0.53 & 0.06 & 0.01 & 0.65 \\
\hline \multirow[t]{2}{*}{ Student } & $9.4 \%$ & $6.9 \%$ & $9.1 \%$ & $9.0 \%$ & $8.1 \%$ \\
\hline & - & $0.06^{*}$ & 0.82 & 0.74 & 0.33 \\
\hline \multirow[t]{2}{*}{ Not in Labor Force } & $11.6 \%$ & $9.9 \%$ & $11.6 \%$ & $12.0 \%$ & $12.3 \%$ \\
\hline & - & 0.25 & 0.99 & 0.78 & 0.63 \\
\hline \multicolumn{6}{|c|}{ Political preferences and beliefs } \\
\hline \multirow[t]{2}{*}{ Trust } & 4.8 & 5.0 & 4.9 & 4.9 & 4.9 \\
\hline & - & 0.12 & 0.20 & 0.18 & 0.18 \\
\hline \multirow[t]{2}{*}{$\begin{array}{l}\text { Poor didn't make an } \\
\text { effort }\end{array}$} & $22.8 \%$ & $24.5 \%$ & $22.6 \%$ & $22.3 \%$ & $22.2 \%$ \\
\hline & - & 0.40 & 0.91 & 0.80 & 0.76 \\
\hline \multirow[t]{2}{*}{ Rich made an effort } & $38.6 \%$ & $38.1 \%$ & $36.6 \%$ & $36.7 \%$ & $35.0 \%$ \\
\hline & - & 0.85 & 0.34 & 0.34 & 0.13 \\
\hline \multirow[t]{2}{*}{ Obama } & $67.5 \%$ & $70.5 \%$ & $67.3 \%$ & $69.1 \%$ & $70.6 \%$ \\
\hline & - & 0.19 & 0.93 & 0.41 & 0.18 \\
\hline Observations & 829 & 852 & 1730 & 1732 & 843 \\
\hline
\end{tabular}


Table 5. Effect of Trust in Business and Government on Support for Meetings

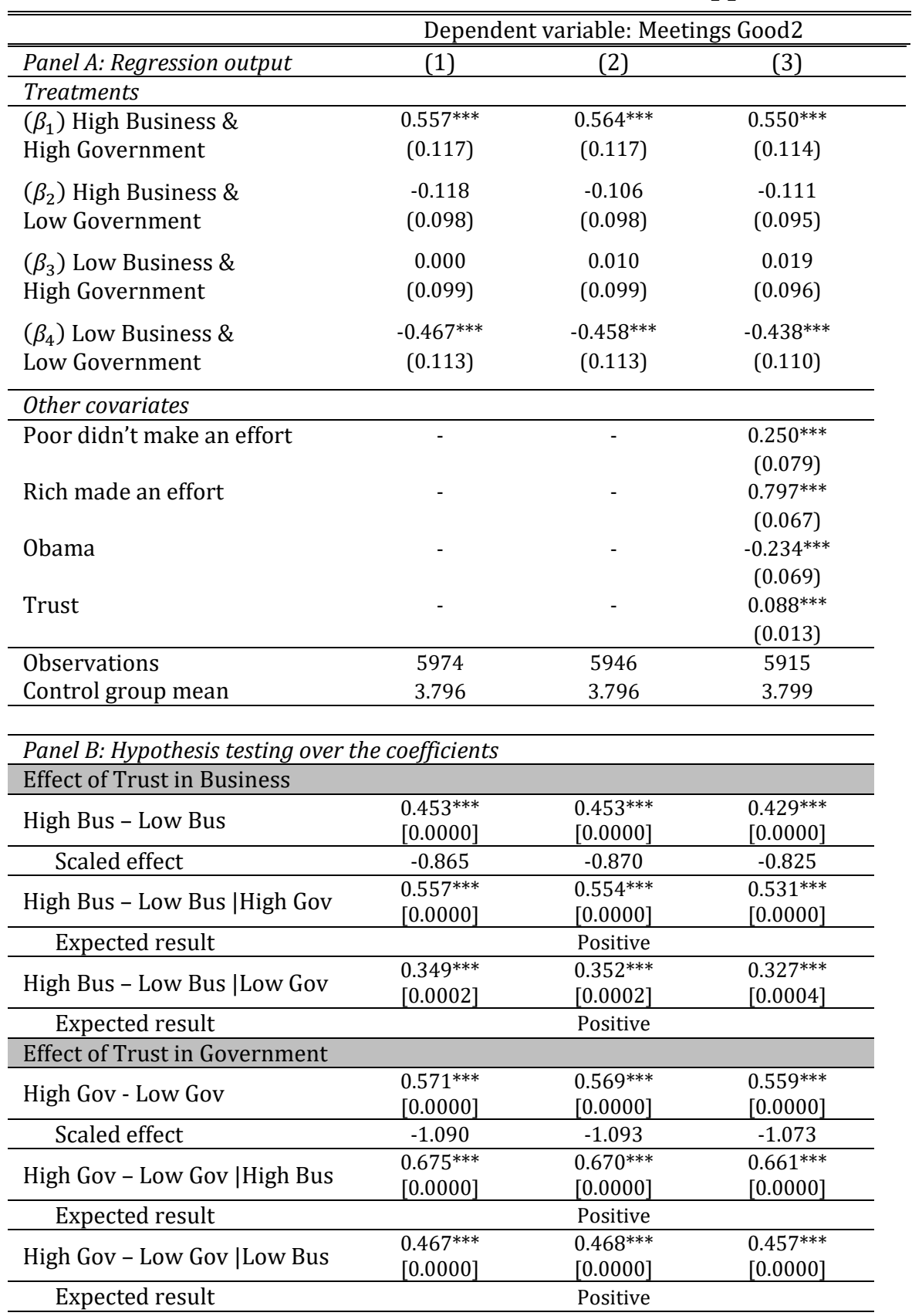

Notes. Robust standard errors in parenthesis. $,^{* *}, * * *$ indicate statistical significance at the $10 \%, 5 \%$ and $1 \%$ levels, respectively. Meetings_Good 2 is a variable taking 0 if individual wants "A politician that is against allowing these meetings" and 10 if "A politician that is in favor of allowing these meetings" (scale: 0 -10). A constant term (not shown) is included in every regression. Regarding the treatments, the control group is the omitted group. Column (1) includes no additional controls. Column (2) includes demographic controls (gender, age, race, education, and type of employment). Column (3) includes same demographic controls, plus political variables and pre-treatment beliefs (include relative support for Obama in previous election, attitudes towards the rich and the poor, and general level of trust). Control group mean reports the mean of the dependent variable for the control group in each specific ation. In Panel B we present linear combinations of certain treatment coefficients and p-values (in brackets) for the test of whether these linear combinations are equal to 0. High Bus - Low Bus $\mid$ High Gov is the difference between the treatment coefficient High Business \& High Government and Low Business \& High Government; High Bus - Low Bus is the weighted average of High Bus - Low Bus |High Gov and High Bus - Low Bus |Low Gov (analogous for other treatment groups). "Scaled effect" is the result of dividing certain effect by the difference between the control group mean of the dependent variable for democrats and republicans. Expected results are defined according to the model's predictions (corollary 1a and 1b). We considered the sample of people that spent at least three minutes in the survey (not considering the candy experiment and time spent in the treatment windows) and at least three seconds in every treatment (when applicable). Respondents assigned to treatments with punishment were not included. 
Table 6. Effect of Trust in Business and Government on Preferences for Taxes on the top 1\%

\begin{tabular}{|c|c|c|c|}
\hline & \multicolumn{3}{|c|}{ Dependent variable: Tax_1_percent2 } \\
\hline Panel A: Regression output & $(1)$ & $(2)$ & (3) \\
\hline \multicolumn{4}{|l|}{ Treatments } \\
\hline$\left(\beta_{1}\right)$ High Business \& & -0.021 & -0.062 & -0.461 \\
\hline High Government & $(1.020)$ & $(1.015)$ & $(0.976)$ \\
\hline$\left(\beta_{2}\right)$ High Business \& & -0.926 & -0.841 & -1.028 \\
\hline Low Government & $(0.864)$ & $(0.857)$ & $(0.820)$ \\
\hline$\left(\beta_{3}\right)$ Low Business \& & -0.228 & -0.051 & -0.456 \\
\hline High Government & $(0.865)$ & $(0.859)$ & $(0.824)$ \\
\hline$\left(\beta_{4}\right)$ Low Business \& & $1.742 *$ & $1.951^{*}$ & 1.352 \\
\hline Low Government & $(1.043)$ & $(1.040)$ & $(0.991)$ \\
\hline \multicolumn{4}{|l|}{ Other covariates } \\
\hline Poor didn't make an effort & - & - & $\begin{array}{c}-3.866^{* * *} \\
(0.632)\end{array}$ \\
\hline Rich made an effort & - & - & $\begin{array}{c}-7.167^{* * *} \\
(0.565)\end{array}$ \\
\hline Obama & - & - & $\begin{array}{c}8.246^{* * *} \\
(0.598)\end{array}$ \\
\hline Trust & - & - & $\begin{array}{c}-0.055 \\
(0.113) \\
\end{array}$ \\
\hline Observations & 5966 & 5938 & 5922 \\
\hline Control group mean & 34.755 & 34.693 & 34.745 \\
\hline \multicolumn{4}{|c|}{ Panel B: Hypothesis testing over the coefficients } \\
\hline \multicolumn{4}{|c|}{ Effect of Trust in Business } \\
\hline High Bus - Low Bus & $\begin{array}{c}-1.228^{*} \\
{[0.0531]}\end{array}$ & $\begin{array}{l}-1.397^{* *} \\
{[0.0275]}\end{array}$ & $\begin{array}{l}-1.188^{* *} \\
{[0.0486]}\end{array}$ \\
\hline High Bus - Low Bus |High Gov & $\begin{array}{c}0.207 \\
{[0.8151]}\end{array}$ & $\begin{array}{c}-0.011 \\
{[0.9897]}\end{array}$ & $\begin{array}{c}-0.005 \\
{[0.9957]}\end{array}$ \\
\hline Expected result & & t significa & \\
\hline High Bus - Low Bus |Low Gov & $\begin{array}{c}-2.668^{* * *} \\
{[0.0034]}\end{array}$ & $\begin{array}{c}-2.792^{* * *} \\
{[0.0022]}\end{array}$ & $\begin{array}{c}-2.380^{* * *} \\
{[0.0056]}\end{array}$ \\
\hline Expected result & & Negative & \\
\hline Scaled effect & -0.313 & -0.316 & -0.269 \\
\hline \multicolumn{4}{|l|}{ Effect of Trust in Government } \\
\hline High Gov - Low Gov & $\begin{array}{c}-0.531 \\
{[0.4031]}\end{array}$ & $\begin{array}{c}-0.613 \\
{[0.3336]}\end{array}$ & $\begin{array}{c}-0.622 \\
{[0.3022]}\end{array}$ \\
\hline High Gov - Low Gov |High Bus & $\begin{array}{c}0.905 \\
{[0.3058]}\end{array}$ & $\begin{array}{c}0.779 \\
{[0.3769]}\end{array}$ & $\begin{array}{c}0.567 \\
{[0.5002]}\end{array}$ \\
\hline Expected result & & ot significa & \\
\hline High Gov - Low Gov |Low Bus & $\begin{array}{l}-1.970^{* *} \\
{[0.0307]}\end{array}$ & $\begin{array}{l}-2.002^{* *} \\
{[0.0283]}\end{array}$ & $\begin{array}{l}-1.808^{* *} \\
{[0.0364]}\end{array}$ \\
\hline Expected result & & Negative & \\
\hline Scaled effect & -0.231 & -0.227 & -0.205 \\
\hline
\end{tabular}

Notes. Robust standard errors in parenthesis. *,**,*** indicate statistical significance at the $10 \%, 5 \%$ and $1 \%$ levels, respectively. Tax_1_percent2 is the preferred tax rate for the top 1\%. A constant term (not shown) is included in every regression. Regarding the treatments, the control group is the omitted group. Column (1) includes no additional controls. Column (2) includes demographic controls (gender, age, race, education, and type of employment). Column (3) includes same demographic controls, plus political variables and pre-treatment beliefs (include relative support for Obama in previous election, attitudes towards the rich and the poor, and general level of trust). Control group mean reports the mean of the dependent variable for the control group in each specification. In Panel B we present linear combinations of certain treatment coefficients and p-values (in brackets) for the test of whether these linear combinations are equal to 0. High Bus - Low Bus High Gov is the difference between the treatment coefficient High Business \& High Government and Low Business \& High Government; High Bus - Low Bus is the weighted average of High Bus - Low Bus |High Gov and High Bus - Low Bus |Low Gov (analogous for other treatment groups). "Scaled effect" is the result of dividing certain effect by the difference between the control group mean of the dependent variable for democrats and republicans. Expected results are defined according to the model's predictions (corollary 2). We considered the sample of people that spent at least three minutes in the survey (not considering the candy experiment and time spent in the treatment windows) and at least three seconds in every treatment (when applicable). Respondents assigned to treatments with punishment were not included. 
Table 7. Trust in Business and in Government and Regulation in WVS

\begin{tabular}{|c|c|c|c|c|}
\hline \multirow[b]{3}{*}{ Dependent variables (rows) } & \multicolumn{4}{|c|}{ Explanatory variables } \\
\hline & \multicolumn{2}{|c|}{ With only one of these regressors } & \multicolumn{2}{|c|}{ With both regressors } \\
\hline & $\begin{array}{c}\text { Trust in } \\
\text { Government }\end{array}$ & $\begin{array}{c}\text { Trust in } \\
\text { Business }\end{array}$ & $\begin{array}{c}\text { Trust in } \\
\text { Government }\end{array}$ & $\begin{array}{c}\text { Trust in } \\
\text { Business }\end{array}$ \\
\hline (1)Competition is harmful & $\begin{array}{c}-0.076 \\
(0.070)\end{array}$ & $\begin{array}{c}-0.562^{* * *} \\
(0.070)\end{array}$ & $\begin{array}{c}0.070 \\
(0.071)\end{array}$ & $\begin{array}{c}-0.582^{* * *} \\
(0.072)\end{array}$ \\
\hline $\mathrm{N}$ & 5655 & 5574 & \multicolumn{2}{|c|}{5532} \\
\hline \multirow{2}{*}{$\begin{array}{l}\text { (2)Government should take } \\
\text { more responsibility }\end{array}$} & -0.052 & $-0.642^{* * *}$ & 0.107 & $-0.669 * * *$ \\
\hline & $(0.087)$ & $(0.087)$ & $(0.089)$ & $(0.090)$ \\
\hline $\mathrm{N}$ & 5668 & 5586 & \multicolumn{2}{|c|}{5544} \\
\hline \multirow{2}{*}{$\begin{array}{l}\text { (3)The economic system runs } \\
\text { badly in democracies }\end{array}$} & $-0.073^{* * *}$ & $-0.043^{* *}$ & $-0.063^{* * *}$ & $-0.033^{*}$ \\
\hline & $(0.020)$ & $(0.019)$ & $(0.021)$ & $(0.019)$ \\
\hline $\mathrm{N}$ & 2332 & 2266 & \multicolumn{2}{|c|}{2249} \\
\hline \multirow{2}{*}{$\begin{array}{l}\text { (4) Government ownership of } \\
\text { business }\end{array}$} & $0.386^{* * *}$ & $-0.315^{* * *}$ & $0.480^{* * *}$ & $-0.435^{* * *}$ \\
\hline & $(0.070)$ & $(0.070)$ & $(0.072)$ & $(0.072)$ \\
\hline $\mathrm{N}$ & 5662 & 5582 & \multicolumn{2}{|c|}{5543} \\
\hline
\end{tabular}

Notes. Robust standard errors in parenthesis; OLS regressions estimates using sampling weights that normalize each wave (marginal effects for a Probit model in the case of variable 3 are presented). Data source is World Value Survey, waves 1995-2014, US sample. *, **, *** indicate statistical significance at the $10 \%, 5 \%$ and $1 \%$ levels, respectively. The dependent variables come from the answers to the following questions: (1) "Competition is good: it stimulates people to work hard and develop new ideas. Or competition is harmful: it brings out the worst in people." The variable takes on values from 1 to 10, a higher score indicating a higher level of distrust of competition. (2) "People should take more responsibility to provide for themselves or the government should take more responsibility." The variable ranges from 1 to 10, with a higher score indicating a stronger support for government intervention. (3) "In democracy, the economic system runs badly. Could you please tell me if you agree strongly, agree, disagree, or disagree strongly?" The variable takes a value equal to 1 if respondent answered strongly agree or agree, and 0 otherwise. (4) "Government or Private ownership of business and industry should be increased". The variable ranges from 1 to 10 with a higher score indicating a stronger support for Government ownership. Main explanatory variables are two dummies: Trust in Business is a dummy equal to 1 if individual expressed having "A great deal" or "Quite a lot" of confidence on "Major Companies" (0 if expressed "Not very much" or "None at all"); definition for Trust in Government is analogous but with respect to "The government (in your nation's capital)". All regressions control for gender, age, education, income level, and wave fixed effects. 
Table 8. Regulation: Competition, Government Responsibility, Market performance, and Discretion

\begin{tabular}{lcccc}
\hline \hline & $\begin{array}{c}\text { Competition } \\
\text { Bad2 }\end{array}$ & $\begin{array}{c}\text { More Gov } \\
\text { Resp2 }\end{array}$ & Market Bad2 & Discretion2 \\
\hline \hline Panel A: Regression output & $(1)$ & $(2)$ & $(3)$ & $(4)$ \\
\hline Treatments & & & & \\
\hline ( $\left.\beta_{1}\right)$ High Business \& & -0.025 & $0.266^{*}$ & $-0.380^{* * *}$ & $0.044^{*}$ \\
High Government & $(0.102)$ & $(0.139)$ & $(0.112)$ & $(0.024)$ \\
$\left(\beta_{2}\right)$ High Business \& & 0.009 & 0.140 & -0.051 & -0.019 \\
Low Government & $(0.087)$ & $(0.119)$ & $(0.097)$ & $(0.020)$ \\
$\left(\beta_{3}\right)$ Low Business \& & 0.125 & $0.238^{* *}$ & $-0.166^{*}$ & $0.063^{* * *}$ \\
High Government & $(0.087)$ & $(0.119)$ & $(0.097)$ & $(0.020)$ \\
$\left(\beta_{4}\right)$ Low Business \& & $0.176^{*}$ & $0.386^{* * *}$ & 0.157 & -0.010 \\
Low Government & $(0.101)$ & $(0.141)$ & $(0.113)$ & $(0.023)$ \\
\hline Observations & 5973 & 5977 & 5966 & 5978 \\
Control group mean & 2.612 & 3.927 & 4.087 & 0.318 \\
\hline
\end{tabular}

\begin{tabular}{|c|c|c|c|c|}
\hline \multicolumn{5}{|c|}{ Panel B: Hypothesis testing over the coefficients } \\
\hline \multicolumn{5}{|l|}{ Effect of Trust in Business } \\
\hline High Bus - Low Bus & $\begin{array}{l}-0.158^{* *} \\
{[0.0126]}\end{array}$ & $\begin{array}{c}-0.109 \\
{[0.2041]}\end{array}$ & $\begin{array}{c}-0.211^{* * *} \\
{[0.0020]}\end{array}$ & $\begin{array}{c}-0.014 \\
{[0.2995]}\end{array}$ \\
\hline Expected result & Negative & Negative & Negative & - \\
\hline Scaled effect & -0.200 & -0.043 & 1.531 & -0.078 \\
\hline High Bus - Low Bus |High Gov & $\begin{array}{c}-0.15^{*} \\
{[0.0966]}\end{array}$ & $\begin{array}{c}0.028 \\
{[0.8179]}\end{array}$ & $\begin{array}{l}-0.214^{* *} \\
{[0.0255]}\end{array}$ & $\begin{array}{c}-0.019 \\
{[0.3180]}\end{array}$ \\
\hline High Bus - Low Bus|Low Gov & $\begin{array}{c}-0.167^{*} \\
{[0.0619]}\end{array}$ & $\begin{array}{l}-0.246^{* *} \\
{[0.0444]}\end{array}$ & $\begin{array}{l}-0.208^{* *} \\
{[0.0317]}\end{array}$ & $\begin{array}{c}-0.009 \\
{[0.6342]}\end{array}$ \\
\hline \multicolumn{5}{|l|}{ Effect of Trust in Government } \\
\hline High Gov - Low Gov & $\begin{array}{c}-0.043 \\
{[0.5009]}\end{array}$ & $\begin{array}{c}-0.011 \\
{[0.8961]}\end{array}$ & $\begin{array}{c}-0.326^{* * *} \\
{[0.0000]}\end{array}$ & $\begin{array}{l}0.068^{* * *} \\
{[0.0000]}\end{array}$ \\
\hline Expected result & Not significant & Not significant & Negative & - \\
\hline Scaled effect & -0.054 & -0.004 & 2.362 & 0.378 \\
\hline High Gov - Low Gov|High Bus & $\begin{array}{c}-0.034 \\
{[0.7055]}\end{array}$ & $\begin{array}{c}0.126 \\
{[0.2984]}\end{array}$ & $\begin{array}{c}-0.329^{* * *} \\
{[0.0006]}\end{array}$ & $\begin{array}{l}0.063^{* * *} \\
{[0.0016]}\end{array}$ \\
\hline High Gov - Low Gov|Low Bus & $\begin{array}{c}-0.051 \\
{[0.5647]}\end{array}$ & $\begin{array}{c}-0.148 \\
{[0.2240]}\end{array}$ & $\begin{array}{c}-0.323^{* * *} \\
{[0.0008]}\end{array}$ & $\begin{array}{l}0.073^{* * *} \\
{[0.0003]}\end{array}$ \\
\hline \multicolumn{5}{|c|}{$\begin{array}{l}\text { Notes. Panel A presents regressions estimates with robust standard errors in parenthesis; OLS estimates except } \\
\text { for column (4) where marginal effects for a Probit model are presented; a constant term (not shown) is included } \\
\text { in every regression. Regarding the treatments, the control group is the omitted group. *, **, *** indicate } \\
\text { statistical significance at the } 10 \%, 5 \% \text { and } 1 \% \text { levels, respectively. Dependent variable definitions are the } \\
\text { following: (1) Variable taking } 0 \text { if "Competition is good..." and } 10 \text { if "Competition is bad..." (scale: } 0-10 \text { ). ( } 2 \text { ) } \\
\text { Variable taking } 0 \text { if individual believes that "People should take more responsibility..." and } 10 \text { if "The } \\
\text { government should take more responsibility..." (scale: } 0-10 \text { ). ( } 3 \text { ) Variable taking } 0 \text { if "Disagree strongly" and } 10 \\
\text { if "Agree strongly", when asked regarding "In democracy, the economic system runs badly" (scale: 0-10). (4) } \\
\text { Dummy equal to } 1 \text { if individual wants to give discretion to policymakers. Control group mean reports the mean } \\
\text { of the dependent variable for the control group in each specification. In Panel B we present linear combinations } \\
\text { of certain treatment coefficients and p-values (in brackets) for the test of whether these linear combinations are } \\
\text { equal to } 0 \text {. High Bus - Low Bus |High Gov is the difference between the treatment coefficient High Business \& } \\
\text { High Government and Low Business \& High Government; High Bus - Low Bus is the weighted average of High } \\
\text { Bus - Low Bus |High Gov and High Bus - Low Bus |Low Gov (analogous for other treatment groups). "Scaled } \\
\text { effect" is the result of dividing certain effect by the difference between the control group mean of the dependent } \\
\text { variable for democrats and republicans. Expected results are defined according to the correlations observed } \\
\text { with WVS data (Table } 7 \text { ). We considered the sample of people that spent at least three minutes in the survey } \\
\text { (not considering the candy experiment and time spent in the treatment windows) and at least three seconds in } \\
\text { every treatment (when applicable). Respondents assigned to treatments with punishment were not included. }\end{array}$} \\
\hline
\end{tabular}


Table 9. Effect of Trust in Business and Government on Voting for Taxes on the top 1\%

\begin{tabular}{|c|c|c|c|}
\hline \multirow[b]{2}{*}{ Panel A: Regression output } & \multicolumn{3}{|c|}{$\begin{array}{c}\text { Dependent variable: } \\
\ln \left(\frac{P(\text { Vote Citizens for Tax Justice })}{P(\text { Vote American Red Cross })}\right)\end{array}$} \\
\hline & $(1)$ & $(2)$ & (3) \\
\hline \multicolumn{4}{|l|}{ Treatments } \\
\hline$\left(\beta_{1}\right)$ High Business \& & 0.041 & 0.063 & 0.119 \\
\hline High Government & $(0.138)$ & $(0.139)$ & $(0.144)$ \\
\hline$\left(\beta_{2}\right)$ High Business \& & 0.134 & 0.125 & 0.184 \\
\hline Low Government & $(0.138)$ & $(0.140)$ & $(0.145)$ \\
\hline$\left(\beta_{3}\right)$ Low Business \& & -0.133 & -0.129 & -0.091 \\
\hline High Government & $(0.141)$ & $(0.142)$ & $(0.149)$ \\
\hline$\left(\beta_{4}\right)$ Low Business $\&$ & 0.139 & 0.147 & 0.179 \\
\hline Low Government & $(0.138)$ & $(0.140)$ & $(0.145)$ \\
\hline \multicolumn{4}{|l|}{ Other covariates } \\
\hline Poor didn't make an effort & - & - & $\begin{array}{c}-0.629^{* * *} \\
(0.137)\end{array}$ \\
\hline Rich made an effort & - & - & $\begin{array}{c}-0.553^{* * *} \\
(0.112)\end{array}$ \\
\hline Clinton & - & - & $\begin{array}{c}0.726^{* * *} \\
(0.108)\end{array}$ \\
\hline Trust & - & - & $\begin{array}{c}-0.022 \\
(0.019) \\
\end{array}$ \\
\hline Observations & 2,462 & 2,450 & 2,444 \\
\hline Control group mean & -0.687 & -0.690 & -0.696 \\
\hline \multirow{2}{*}{\multicolumn{4}{|c|}{$\begin{array}{l}\text { Panel B: Hypothesis testing over the coefficients } \\
\text { Effect of Trust in Business }\end{array}$}} \\
\hline & & & \\
\hline High Bus - Low Bus & $\begin{array}{c}0.084 \\
{[0.3906]}\end{array}$ & $\begin{array}{c}0.085 \\
{[0.3917]}\end{array}$ & $\begin{array}{c}0.108 \\
{[0.2933]}\end{array}$ \\
\hline High Bus - Low Bus |High Gov & $\begin{array}{c}0.174 \\
{[0.2148]}\end{array}$ & $\begin{array}{c}0.192 \\
{[0.1725]}\end{array}$ & $\begin{array}{c}0.210 \\
{[0.1516]}\end{array}$ \\
\hline Expected result & \multicolumn{3}{|c|}{ Not significant } \\
\hline High Bus - Low Bus |Low Gov & $\begin{array}{c}-0.005 \\
{[0.9693]}\end{array}$ & $\begin{array}{c}-0.022 \\
{[0.8718]}\end{array}$ & $\begin{array}{c}0.005 \\
{[0.9694]} \\
\end{array}$ \\
\hline Expected result & & Negative & \\
\hline \multicolumn{4}{|l|}{ Effect of Trust in Government } \\
\hline High Gov - Low Gov & $\begin{array}{c}-0.183^{*} \\
{[0.0629]}\end{array}$ & $\begin{array}{c}-0.169^{*} \\
{[0.0870]}\end{array}$ & $\begin{array}{c}-0.168 \\
{[0.1002]}\end{array}$ \\
\hline High Gov - Low Gov |High Bus & $\begin{array}{c}-0.093 \\
{[0.4977]}\end{array}$ & $\begin{array}{c}-0.062 \\
{[0.6548]}\end{array}$ & $\begin{array}{c}-0.066 \\
{[0.6456]}\end{array}$ \\
\hline Expected result & \multicolumn{3}{|c|}{ Not significant } \\
\hline High Gov - Low Gov |Low Bus & $\begin{array}{l}-0.272^{*} \\
{[0.0528]}\end{array}$ & $\begin{array}{c}-0.276^{*} \\
{[0.0509]}\end{array}$ & $\begin{array}{l}-0.270^{*} \\
{[0.0650]}\end{array}$ \\
\hline Expected result & & Negative & \\
\hline
\end{tabular}

Notes. Robust standard errors in parenthesis (Panel A). Multinomial logit model estimated, where the dependent variable can take three values: Voted for Citizens for Tax Justice, Voted for The American Red Cross, and didn't vote. Regarding the treatments, the control group is the omitted group. Column (1) includes no additional controls. Column (2) includes demographic controls (gender, age, race, education, and type of employment). Column (3) includes same demographic controls, plus political variables and pre-treatment beliefs (includes relative support for Clinton in previous election, attitudes towards the rich and the poor, and general level of trust). Control group mean reports the mean of the dependent variable for the control group in each specification. In Panel B we present linear combinations of certain treatment coefficients and p-values (in brackets) for the test of whether these linear combinations are equal to 0. High Bus - Low Bus |High Gov is the difference between the treatment coefficient High Business \& High Government and Low Business \& High Government; High Bus - Low Bus is the weighted average of High Bus - Low Bus |High Gov and High Bus - Low Bus |Low Gov (analogous for other treatment groups). Expected results are defined according to the model's predictions (corollary 2). ${ }^{* *},{ }^{* * *}$ indicate statistical significance at the $10 \%, 5 \%$ and $1 \%$ levels, respectively. We considered the sample of people that spent at least 1.5 minutes in the complementary survey (not considering the time spent in the treatment windows) and at least three seconds in every treatment (when applicable). 


\section{References}

Acemoglu, D. (2005). Politics and economics in weak and strong states. Journal of Monetary Economics, 52(7), 1199-1226.

Acemoglu, D., García-Jimeno, C., \& Robinson, J. A. (2015). State Capacity and Economic Development: A Network Approach, 105(8), 2364-2409.

Aghion, P., Algan, Y., Cahuc, P., \& Shleifer, A. (2010). Regulation and distrust. The Quarterly Journal of Economics, 125(3), 1015-1049.

Akerlof, G. a, \& Romer, P. M. (1993). Looting: The Economic Underworld of Bankruptcy for Profit. Brookings Papers on Economic Activity, 1993(2), 1-73.

Alesina, A., \& Angeletos, G.-M. (2005a). Corruption, inequality, and fairness. Journal of Monetary Economics, 52(7), $1227-1244$.

Alesina, A., \& Angeletos, G.-M. (2005b). Fairness and Reidstribution. The American Economic Review, 57(3), 415426.

Alesina, A., \& Angeletos, G.-M. (2013). Fairness and redistribution: Reply. American Economic Review, 103(1), 554-561.

Alesina, A., \& Giuliano, P. (2016). Culture and Institutions. Journal of Economic Literature, Forthcoming.

Alesina, A., \& Glaeser, E. (2004). Fighting Poverty in the US and Europe: A World of Difference. Oxford University Press.

Alesina, A., Stantcheva, S., \& Teso, E. (2016). Intergenerational Mobility and Preferences for Redistribution (Mimeo).

Algan, Y., \& Cahuc, P. (2010). Inherited trust and growth. American Economic Review, 100(5), 2060-2092.

Arrow, K. J. (1972). Gifts and Exchanges. Pbilosophy \& Public Affairs, 1(4), 343-362.

Banfield, E. C. (1958). The moral basis of a backward society. (N. Y. F. Press, Ed.).

Battaglini, M., \& Bénabou, R. (2003). Trust, Coordination, and the Industrial Organization of Political Activism. Journal of the European Economic Association, 1(4), 851-889.

Benabou, R., \& Ok, E. A. (2001). Social mobility and the demand for Redistribution: The POUM Hypothesis. The Quarterly Journal of Economics, 116(2), 447-487.

Benabou, \& Tirole, J. (2006). Belief in a Just World and Redistributive Politics. The Quarterly Journal of Economics, 121(2), 699-746.

Berdejó, C., \& Chen, D. L. (2012). Priming Ideology? Electoral Cycles Without Electoral Incentives Among Elite U . S . Judges. Mimeo, (February).

Bertrand, M., Bombardini, M., \& Trebbi, F. (2014). Is It Whom You Know or What You Know? An Empirical Assessment. American Economic Review, 104(12), 3885-3920.

Besley, T., \& Persson, T. (2009). The Origins of State Capacity: Property Rights, Taxation, and Politics. American Economic Review, 99(4), 1218-1244.

Blanes I Vidal, J., Draca, M., \& Fons-Rosen, C. (2012). Revolving door lobbyists. American Economic Review, 102(7), 3731-3748. 
Bohnet, I., Greig, F., Herrmann, B., \& Zeckhauser, R. (2008). Betrayal Aversion: Evidence from Brazil, China, Oman, Switzerland, Turkey, and the United States. The American Economic Review, 98(1), 294-310.

Butler, J., Giuliano, P., \& Guiso, L. (2015). The Right Amount of Trust. Forthcoming Journal of the European Economic Association.

Butler, J., Giuliano, P., \& Guiso, L. (2016). Trust and Cheating. The Economic Journal, 126, 1703-1738.

Campos, N. F., \& Giovannoni, F. (2007). Lobbying, corruption and political influence. Public Choice, 131, 1-21.

Card, D., Mas, A., Moretti, E., \& Saez, E. (2012). Inequility at work: The effect of peer salaries on job satisfaction. American Economic Review, 102(6), 2981-3003.

CFA. (2016). Corrupt or Collaborative? An assessment of Regulatory Capture.

Chen, Y., \& Li, S. (2009). Group identity and social preferences. The American Economic Review, 99(1), 431-457.

Coate, S., \& Morris, S. (1995). On the Form of Transfers to Special Interests. Journal of Political Economy, 103(6), 1131-56.

Crawford, V., \& Sobel, J. (1982). Strategic Information Transmission. Econometrica, 50(6), 1431-1451.

de Figueiredo, J. M., \& Cameron, C. M. (2006). Endogenous Cost Lobbying: Theory and Evidence. Discussion Paper Series, 156.

de Figueiredo, J. M., \& Silverman, B. S. (2006). Academic Earmarks and the Returns to Lobbying. Journal of Law and Economics, 49(2), 597-625.

De Soto, H. (1989). The Other Path: The Invisible Revolution in the Third World (Vol. 53). Harper and Row.

Di Tella, R., \& Dubra, J. (2013). Fairness and redistribution: Comment. The American Economic Review, 103(1), 549-553.

Di Tella, R., \& MacCulloch, R. (2009). Why Doesn't Capitalism Flow to Poor Countries? Brookings Papers on Economic Activity, 285-321.

Dincecco, M. (2009). Fiscal Centralization, Limited Government, and Public Revenues in Europe, 1650-1913. The Journal of Economic History, 69(1), 48-103.

Djankov, S., La Porta, R., Lopez-de-Silanes, F., \& Shleifer, A. (2002). The Regulation of Entry. Quarterly Journal of Economics, 117(1), 1-37.

Evans, P. (1995). Embedded Autonomy: States and Industrial Transformation (Vol. 1). Princeton University Press.

Fong, C. M., \& Luttmer, E. F. P. (2009). What Determines Giving to Hurricane Katrina Victims? Experimental Evidence on Racial Group Loyalty. American Economic Journal: Applied Economics, 1(2), 64-87.

Fukuyama, F. (1995). Trust: the social virtues and the creation of prosperity. New York: Free Press.

Geanakopolos, J. P., Pearce, D., \& Stacchetti, E. (1989). Psychological game and sequential rationality. Games and Economic Behavior, 1, 60-79.

Gennaioli, N., \& Voth, H. J. (2015). State Capacity and Military Conflict. Review of Economic Studies, 82(4), 1409_ 1448.

Gerber, A. S., Huber, G. A., Doherty, D., Dowling, C. M., \& Ha, S. E. (2010). Personality and Political Attitudes: 
Relationships across Issue Domains and Political Contexts. American Political Science Review, 104(1), 111133.

Grossman, G. M., \& Helpman, E. (2001). Special Interest Politics (Vol. 53). MIT Press.

Guiso, L., Sapienza, P., \& Zingales, L. (2004). The role of social capital in financial development. The American Economic Review, 94(3), 526-556.

Guiso, L., Sapienza, P., \& Zingales, L. (2008). Trusting the Stock Market. The Journal of Finance, 63(6), 25572600 .

Hall, P. A., \& Soskice, D. (2001). An Introduction to Varieties of Capitalism. In P. A. Hall \& D. Soskice (Eds.), Varieties of Capitalism. Oxford University Press.

Horton, J. J., Rand, D. G., \& Zeckhauser, R. J. (2011). The online laboratory: Conducting experiments in a real labor market. Experimental Economics, 14(3), 399-425.

Johnson, M., \& Lakoff, G. (1980). Metaphors We Live By. Chicago: University of Chicago Press.

Jost, J. T., Banaji, M. R., \& Nosek, B. A. (2004). A Decade of System Justification Theory: Accumulated Evidence of Conscious and Unconscious Bolstering of the Status Quo. Political Psychology, 25(6), 881-919.

Khanna, T., \& Yafeh, Y. (2007). Business Groups in Emerging Markets: Paragons or Parasites? Journal of Economic Literature, XLV(June), 331-372.

Kleven, H. J., Kreiner, C. T., \& Saez, E. (2016). Why Can Modern Governments Tax So Much? An Agency Model of Firms as Fiscal Intermediaries. Economica, 83(330), 219-246.

Knack, S., \& Keefer, P. (1995). Institutions and Economic Performance: Cross Country Tests Using Alternative Institutional Measures. Economics and Politics, 7(3), 207-227.

Kuziemko, I., Norton, M. I., Saez, E., \& Stantcheva, S. (2015). How elastic are preferences for redistribution? Evidence from randomized survey experiments. American Economic Review, 105(4), 1478-1508.

La Porta, R., Lopez-De-Silane, F., Shleifer, A., \& Vishny, R. W. (1997). Trust in Large Organizations. AER Papers and Proceedings, 87(May), 333-338.

La Porta, R., Lopez-De-Silanes, F., \& Zamarripa, G. (2003). Related Lending. The Quarterly Journal of Economics, (February), 231-268.

Levine, D. K. (1998). Modeling Altruism and Spitefulness in Experiments. Review of Economic Dynamics, 1(3), 593-622.

Malach-Pines, A., Levy, H., Utasi, A., \& Hill, T. L. (2005). Entrepreneurs as cultural heroes: A cross-cultural, interdisciplinary perspective. Journal of Managerial Psychology, 20(6), 541-555.

Meade, A. W., \& Craig, S. B. (2012). Identifying careless responses in survey data. Psychological Methods, 17(3), $437-455$.

Morck, R., Wolfenzon, D., \& Yeung, B. (2005). Corporate Governance, Economic Entrenchment, and Growth. Journal of Economic Literature, 43(September), 655-720.

Muralidharan, K., Niehaus, P., \& Sukhtankar, S. (2014). Building State Capacity: Evidence from Biometric Smartcards in India (NBER Working Paper No. 19999).

Piketty, T. (1995). Social Mobility and Redistributive Politics. The Quarterly Journal of Economics, CX(3), 1-55. 
Pinotti, P. (2012). Trust, Regulation and Market Failures. Review of Economics and Statistics, 94(3), 650-658.

Powell, W., \& Di Maggio, P. (Eds.). (1991). The new institutionalism in organizational analysis. Chicago: University of Chicago Press.

Putnam, R. D. (1993). Making democracy work: Civic traditions in modern Italy. N.J.: Princeton University Press.

Reinert, S. A. (2015). The Way to Wealth around the World: Benjamin Franklin and the Globalization of American Capitalism. The American Historical Review, 120(1), 61-97.

Rotemberg, J. J. (2008). Minimally acceptable altruism and the ultimatum game. Journal of Economic Behavior and Organization, 66(3-4), 457-476.

Saez, E., \& Stantcheva, S. (2016). Generalized Social Marginal Welfare Weights for Optimal Tax Theory. American Economic Review, 106(1), 24-45.

Shayo, M., \& Zussman, A. (2011). Judicial ingroup bias in the shadow of terrorism. Quarterly Journal of Economics, 126(3), 1447-1484.

Shleifer, A., \& Vishny, R. W. (1994). Politicians and Firms. The Quarterly Journal of Economics, 109(4), 995-1025.

Stigler, G. J. (1971). The Theory of Economic Regulation. The Bell Journal of Economics and Management Science, 2(1), 3-21.

Suchman, M. C. (1995). Managing Legitimacy: Strategic and Institutional Approaches. The Academy of Management Review, 20(3), 571-610.

Tilly, C. (1992). Coercion, Capital and European States, A.D. 990 -1992 (Revised Ed). Cambridge.

Tullock, G. (1967). The Welfare Costs of Tariffs, Monopolies, and Theft. Western Economic Journal, 5(3), 224 232.

Wade, R. (1990). Governing the Market: Economic Theory and the Role of Government in East Asian Industrialization (Vol. 53). Princeton University Press.

Weinzierl, M. (2014). The promise of positive optimal taxation: Normative diversity and a role for equal sacrifice. Journal of Public Economics, 118, 128-142. 


\section{Appendix 1: Model}

In the following section we first prove theorem 1 . After this, we prove the corollaries. We start by finding which conditions must hold in order to get the two equilibria mentioned in theorem 1 , and then we check there is a set of parameters that satisfy these conditions.

\section{Third stage}

In the last stage, conditional on her information, the delegate chooses the policy action $a$. There are three cases to consider.

1) No meeting, or meeting and bribe rejected. In this case, the delegate's information is just her signal $s=$ $\omega+\epsilon$, where $\epsilon$ 's precision is $\pi_{j}$, for $j=h, l$. In this case for any fixed $e$, the delegate chooses $a$ to maximize $E\left(p e\left(k-(\omega-a)^{2}\right) \mid s\right)$, which yields (here $n$ stands for no meeting):

$a_{n}=E(\omega \mid s)=\frac{1}{1+\pi_{j}} 0+\frac{\pi_{j}}{1+\pi_{j}} s=\frac{\pi_{j}}{1+\pi_{j}} s$. Then $E\left(\left(\omega-a_{n}\right)^{2} \mid s\right)$ is the conditional variance of $\omega$, which is $\frac{1}{1+\pi_{j}}$ and the expected utility of the delegate is:

$$
u_{D}=E\left(p e\left(k-\left(\omega-a_{n}\right)^{2}\right) \mid s\right)=p e\left(k-E\left(\left(\omega-a_{n}\right)^{2} \mid s\right)\right)=p e\left(k-\frac{1}{1+\pi_{j}}\right)
$$

The utilities of the businessperson (before receiving his information) and the public are:

$$
u_{B}=u_{P}=(1-\tau) e\left(k-\frac{1}{1+\pi_{j}}\right)-c
$$

2) Meeting, no bribe offered (information exchanged). The delegate observes her signal with a higher precision. The delegate chooses $a$ to maximize her utility, which yields (with $m$ standing for meeting)

$a_{m}=E(\omega \mid s)=\frac{z \pi_{j}}{1+z \pi_{j}} s$, and the variance of $\omega$ conditional on $s$ is $\frac{1}{1+z \pi_{j}}$. Then utilities are:

$$
\begin{gathered}
u_{D}=E\left(p e\left(k-\left(\omega-a_{n}\right)^{2}\right) \mid s\right)=p e\left(k-\frac{1}{1+z \pi_{j}}\right) \\
u_{B}=u_{P}=(1-\tau) e_{i}\left(k-\frac{1}{1+z \pi_{j}}\right)-c_{i}
\end{gathered}
$$

3) Meeting, and bribe exchanged. The delegate observes her signal $s$ with precision $\pi_{j}$ and chooses $a_{n}+1$ (her optimal $a$ in case of no meetings, plus the 1 unit contracted upon in the bribe). Since $E\left(\left(\omega-a_{n}-1\right)^{2} \mid s\right)=E\left(\left(\omega-a_{n}\right)^{2}-2\left(\omega-a_{n}\right)+1 \mid s\right)=\frac{1}{1+\pi_{j}}+1$, utilities are then:

$$
u_{D}=p e\left(k-E\left(\left(\omega-a_{n}-1\right)^{2} \mid s\right)\right)+B=p e\left(k-\frac{1}{1+\pi_{j}}-1\right)+B
$$




$$
\begin{gathered}
u_{B}=E\left[(1-\tau)\left(e\left(k-(\omega-a)^{2}\right)+x a\right)-b-c\right]=(1-\tau)\left(e\left(k-\frac{1}{1+\pi_{j}}-1\right)+x\right)-B-c \\
u_{P}=(1-\tau) e\left(k-\frac{1}{1+\pi_{j}}-1\right)-c+\alpha(\tau-C)
\end{gathered}
$$

\section{Second (meeting) stage}

We now analyze the decisions of businesspeople regarding the bribe, and that of the delegate regarding acceptance. We build an equilibrium in which high quality businesspeople do not offer bribes, and low business types offer bribes to low quality delegates. We start in the subgame where the bribe has been offered, and check what parameter conditions are needed for the configuration of behavior we want.

a) All delegate types take the bribe when offered by a low quality businessperson; for $j=h, l$ :

$$
p e_{l}\left(k-\frac{1}{1+\pi_{j}}-1\right)+B>p e_{l}\left(k-\frac{1}{1+\pi_{j}}\right) \Leftrightarrow B>p e_{l}
$$

The condition says that the bribe must be larger than the efficiency loss due to the distortion of 1 unit in the optimal action; in an extreme $(p=0)$, if the delegate does not care about the outcome, she takes the bribe (regardless of $e$ ).

b) All delegate types reject a bribe offered by a high quality businessperson. This is just to avoid a deviation by the high business (obviously, if the delegate is going to reject the bribe, the businessperson is worse off; but if the high businessperson deviates and offers, it must be in the delegate's best interest to reject). In order for that to be the case, we need for $j=h, l$ :

$$
p e_{h}\left(k-\frac{1}{1+\pi_{j}}\right)>p e_{h}\left(k-\frac{1}{1+\pi_{j}}-1\right)+B \Leftrightarrow B<p e_{h}
$$

Thus our parameter requirement \#1 is that:

$$
e_{h}>\frac{B}{p}>e_{l}
$$

c) High business types do not want to offer the bribe to any delegate type. Note that for any businessman, offering a bribe which will be rejected is suboptimal: if the bribe is offered, no information can be exchanged, and therefore he loses the chance of communicating his information, and doesn't get the benefit of the bribe. So as long as part "a" and "b" holds, we need no further condition for "c" to hold.

d) The low quality businessman will not offer the bribe to the high delegate:

$$
\begin{gathered}
(1-\tau) e_{l}\left(k-\frac{1}{1+z \pi_{h}}\right)-c_{l}>(1-\tau)\left(e_{l}\left(k-\frac{1}{1+\pi_{h}}-1\right)+x\right)-B-c_{l} \Leftrightarrow \\
e_{l}\left(1+\frac{1}{1+\pi_{h}}-\frac{1}{1+z \pi_{h}}\right)>x-\frac{B}{1-\tau}
\end{gathered}
$$


e) The low quality businessman will offer the bribe to the low quality delegate:

$$
\begin{gathered}
(1-\tau) e_{l}\left(k-\frac{1}{1+z \pi_{l}}\right)-c_{l}<(1-\tau)\left(e_{l}\left(k-\frac{1}{1+\pi_{l}}-1\right)+x\right)-B-c_{l} \Leftrightarrow \\
e_{l}\left(1+\frac{1}{1+\pi_{l}}-\frac{1}{1+z \pi_{l}}\right)<x-\frac{B}{1-\tau}
\end{gathered}
$$

The combination of (3) and (4) yields parameter requirement \#2:

$$
e_{l}\left(1+\frac{1}{1+\pi_{h}}-\frac{1}{1+z \pi_{h}}\right)>x-\frac{B}{1-\tau}>e_{l}\left(1+\frac{1}{1+\pi_{l}}-\frac{1}{1+z \pi_{l}}\right)
$$

Parameter requirement \#2 is simplified by noting that a necessary condition is $z \pi_{h} \pi_{l}<1$ which ensures that the bracket in the lhs is greater than the rhs; then one needs to fit $x-\frac{B}{1-\tau}$ in between.

\section{First stage}

To simplify notation slightly, let $\frac{1}{1+z \pi_{h}}+(1-q) \frac{1}{1+z \pi_{l}} \equiv \frac{1}{1+z \bar{\pi}}$, and $q \frac{1}{1+\pi_{h}}+(1-q) \frac{1}{1+\pi_{l}} \equiv \frac{1}{1+z \widetilde{\pi}}$. Also, recall that we are showing the existence of an equilibrium in which the tax rate is low in the good equilibrium, and high in the bad equilibrium.

1) Meetings and low taxes (good) equilibrium: If meetings will be allowed, it must be that it is a best response to become educated for the businessman:

$$
\begin{aligned}
& \left(1-\tau_{l}\right) e_{h}\left(k-\frac{1}{1+z \bar{\pi}}\right)-c_{h}> \\
& \quad\left(1-\tau_{l}\right)\left[q e_{l}\left(k-\frac{1}{1+z \pi_{h}}\right)+(1-q)\left(e_{l}\left(k-\frac{1}{1+\pi_{l}}-1\right)+x\right)\right]-(1-q) B-c_{l}
\end{aligned}
$$

Rearranging this becomes parameter requirement \#3:

$$
\begin{gathered}
\left(1-\tau_{l}\right)\left[q\left(e_{h}-e_{l}\right)\left(k-\frac{1}{1+z \pi_{h}}\right)+(1-q) e_{h}\left(k-\frac{1}{1+z \pi_{l}}\right)-(1-q)\left(e_{l}\left(k-\frac{1}{1+\pi_{l}}-1\right)+x\right)\right] \\
> \\
c_{h}-c_{l}-(1-q) B
\end{gathered}
$$

And if the businessman will be educated, it must be optimal for the public to allow meetings and keep taxes low. The public could deviate in three different ways: forbid meetings and keep low taxes, forbid meetings and increase taxes, and allow meetings and increase taxes. ${ }^{53}$ We check the first deviation is not profitable:

$$
\left(1-\tau_{l}\right) e_{h}\left(k-\frac{1}{1+z \bar{\pi}}\right)-c_{h}>
$$

${ }^{53}$ The third deviation is clearly not profitable. This is because in a scenario with "High quality" business, bribes will not take place and the only reason the public would find it profitable to increase taxes is in a scenario with bribes. 


$$
\begin{gathered}
f\left(1-\tau_{l}\right) e_{h}\left(k-\frac{1}{1+z \bar{\pi}}\right)+(1-f)\left(1-\tau_{l}\right) e_{h}\left(k-\frac{1}{1+\tilde{\pi}}\right)-c_{h} \Leftrightarrow \\
k-\frac{1}{1+z \bar{\pi}}>k-\frac{1}{1+\tilde{\pi}}
\end{gathered}
$$

It is straightforward to check that (5) is always satisfied.

Suppose now that the public considers a deviation in which it forbids meetings, and increases taxes. We know that this will not change high business types behavior (higher types make bribes less attractive, but high business types don't bribe), so the condition for the public not to want to deviate this way is:

$$
\begin{aligned}
\left(1-\tau_{l}\right) e_{h}\left(k-\frac{1}{1+z \bar{\pi}}\right)-c_{h}> & \\
& f\left(1-\tau_{h}\right) e_{h}\left(k-\frac{1}{1+z \bar{\pi}}\right)+(1-f)\left(1-\tau_{h}\right) e_{h}\left(k-\frac{1}{1+\tilde{\pi}}\right)-c_{h} \Leftrightarrow \\
& \left(1-\tau_{l}-f\left(1-\tau_{h}\right)\right)\left(k-\frac{1}{1+z \bar{\pi}}\right)>(1-f)\left(1-\tau_{h}\right)\left(k-\frac{1}{1+\tilde{\pi}}\right)
\end{aligned}
$$

This condition is satisfied since (5) holds, and $\left(1-\tau_{l}-f\left(1-\tau_{h}\right)\right)>(1-f)\left(1-\tau_{h}\right) \Leftrightarrow \tau_{h}>\tau_{l}$.

2) No meetings and high taxes (bad) equilibrium: If meetings will not be allowed it must be a best response for the businessperson not to become educated:

$$
\begin{gathered}
f\left[q\left(1-\tau_{h}\right) e_{l}\left(k-\frac{1}{1+z \pi_{h}}\right)+(1-q)\left(\left(1-\tau_{h}\right)\left(e_{l}\left(k-\frac{1}{1+\pi_{l}}-1\right)+x\right)-B\right)\right] \\
+(1-f)\left(1-\tau_{h}\right) e_{l}\left(k-\frac{1}{1+\widetilde{\pi}}\right)-c_{l}> \\
\left(1-\tau_{h}\right) e_{h}\left[f\left(k-\frac{1}{1+z \bar{\pi}}\right)+(1-f)\left(k-\frac{1}{1+\widetilde{\pi}}\right)\right]-c_{h}
\end{gathered}
$$

Which rearranging becomes parameter requirement \#4:

$$
\begin{gathered}
\left(1-\tau_{h}\right)\left[f\left(\begin{array}{c}
q\left(e_{h}-e_{l}\right)\left(k-\frac{1}{1+z \pi_{h}}\right)+(1-q) e_{h}\left(k-\frac{1}{1+z \pi_{l}}\right) \\
-(1-q)\left(e_{l}\left(k-\frac{1}{1+\pi_{l}}-1\right)+x\right) \\
< \\
c_{h}-c_{l}-f(1-q) B
\end{array}\right]+\left(e_{h}-e_{l}\right)(1-f)\left(k-\frac{1}{1+\tilde{\pi}}\right)\right] \\
\hline
\end{gathered}
$$

If businessmen will not be educated, it must be optimal for the public not to allow meetings and set high taxes. The public could deviate in three ways: allow meetings and keep taxes high, allow meetings and decrease taxes, and forbid meetings but decrease taxes. To check that the first deviation is not profitable we can alternatively 
see under what conditions the public would be better off cancelling a meeting (assuming the public keeps the tax rate fixed), which yields parameter requirement \#5: ${ }^{54}$

$$
\begin{gathered}
\left(1-\tau_{h}\right)\left(k-\frac{1}{1+\tilde{\pi}}\right)>\left(1-\tau_{h}\right) e_{l}\left[q\left(k-\frac{1}{1+z \pi_{h}}\right)+(1-q)\left(k-\frac{1}{1+\pi_{l}}-1\right)\right]+\alpha(1-q)\left(\tau_{h}-C\right) \\
\Leftrightarrow \\
\alpha(1-q)\left(C-\tau_{h}\right)>\left(1-\tau_{h}\right) e_{l}\left[q \frac{1}{1+\pi_{h}}-q \frac{1}{1+z \pi_{h}}-(1-q)\right]
\end{gathered}
$$

If the public decides to deviate, and allow meetings, while also decreasing taxes, the condition is that:

$$
\begin{gathered}
f\left(\left(1-\tau_{h}\right) e_{l}\left[q\left(k-\frac{1}{1+z \pi_{h}}\right)+(1-q)\left(k-\frac{1}{1+\pi_{l}}-1\right)\right]+\alpha(1-q)\left(\tau_{h}-C\right)\right)+(1 \\
-f)\left(1-\tau_{h}\right) e_{l}\left(k-\frac{1}{1+\tilde{\pi}}\right) \\
> \\
\left(1-\tau_{l}\right) e_{l}\left[q\left(k-\frac{1}{1+z \pi_{h}}\right)+(1-q)\left(k-\frac{1}{1+\pi_{l}}-1\right)\right]+\alpha(1-q)\left(\tau_{l}-C\right)
\end{gathered}
$$

Rearranging some terms, this yields parameter requirement \#6:

$$
\alpha(1-q)\left[f\left(\tau_{h}-C\right)+C-\tau_{l}\right]>e_{l}\left\{\begin{array}{c}
\left(1-\tau_{l}\right)\left[q\left(k-\frac{1}{1+z \pi_{h}}\right)+(1-q)\left(k-\frac{1}{1+\pi_{l}}-1\right)\right] \\
\left.-\left(1-\tau_{h}\right)\left[\begin{array}{c}
1 \\
{\left[q\left(k-\frac{1}{1+z \pi_{h}}\right)+(1-q)\left(k-\frac{1}{1+\pi_{l}}-1\right)\right]+} \\
(1-f)\left(k-\frac{1}{1+\tilde{\pi}}\right)
\end{array}\right]\right\}
\end{array}\right.
$$

To make sure the public wouldn't prefer to lower taxes, while still forbidding meetings, we need:

\footnotetext{
${ }^{54}$ Of course, a high cost of a bribe will make meetings not desirable. Another way to obtain the result, even when $\alpha=0$, is if $\pi_{h}-q+z \pi_{h}(1-2 q)+(1-q) z \pi_{h}^{2}+1>0$, which ensures that the bracket in the right hand side is negative. Note that one case in which this works is with $q \approx 0$. This is another way of saying that taxes need not play an instrumental role in the development of the equilibrium multiplicity.
} 


$$
\begin{aligned}
f\left(\left(1-\tau_{h}\right) e_{l}[\right. & \left.\left.q\left(k-\frac{1}{1+z \pi_{h}}\right)+(1-q)\left(k-\frac{1}{1+\pi_{l}}-1\right)\right]+\alpha(1-q)\left(\tau_{h}-C\right)\right) \\
& +(1-f)\left(1-\tau_{h}\right) e_{l}\left(k-\frac{1}{1+\tilde{\pi}}\right) \\
& >f\left(\left(1-\tau_{l}\right) e_{l}\left[q\left(k-\frac{1}{1+z \pi_{h}}\right)+(1-q)\left(k-\frac{1}{1+\pi_{l}}-1\right)\right]+\alpha(1-q)\left(\tau_{l}-C\right)\right) \\
& +(1-f)\left(1-\tau_{l}\right) e_{l}\left(k-\frac{1}{1+\tilde{\pi}}\right)
\end{aligned}
$$

Rearranging some terms, this yields parameter requirement \#7:

$$
\alpha>e_{l}\left[\frac{(1-f)}{f(1-q)}\left(k-\frac{1}{1+\widetilde{\pi}}\right)+\frac{q}{1-q}\left(k-\frac{1}{1+z \pi_{h}}\right)+\left(k-\frac{1}{1+\pi_{l}}-1\right)\right]
$$

Note that it will be sufficient to pick an $\alpha$ big enough to satisfy parameter requirements \#5, \#6, and \#7.

\section{Numerical example}

In this section we check that there is an open set of parameters that sustain the two equilibria described in theorem 1, thus proving that result.

We need to find values for the following 17 parameters $\left(e_{h}, e_{l}, c_{h}, c_{l}, p, x, B, z, \pi_{h}, \pi_{l}, \tau_{h}, \tau_{l}, k, \alpha, C, q, f\right)$ such that these conditions hold:

Parameter requirement \#1: $e_{h}>\frac{B}{p}>e_{l}$

Parameter requirement \#2:55

$$
\begin{aligned}
& e_{l}\left(1+\frac{1}{1+\pi_{h}}-\frac{1}{1+z \pi_{h}}\right)>x-\frac{B}{1-\tau_{h}}>e_{l}\left(1+\frac{1}{1+\pi_{l}}-\frac{1}{1+z \pi_{l}}\right) \\
& e_{l}\left(1+\frac{1}{1+\pi_{h}}-\frac{1}{1+z \pi_{h}}\right)>x-\frac{B}{1-\tau_{l}}>e_{l}\left(1+\frac{1}{1+\pi_{l}}-\frac{1}{1+z \pi_{l}}\right)
\end{aligned}
$$

Parameter requirement \#3:

$$
\begin{gathered}
\left(1-\tau_{l}\right)\left[q\left(e_{h}-e_{l}\right)\left(k-\frac{1}{1+z \pi_{h}}\right)+(1-q) e_{h}\left(k-\frac{1}{1+z \pi_{l}}\right)-(1-q)\left(e_{l}\left(k-\frac{1}{1+\pi_{l}}-1\right)+x\right)\right] \\
>c_{h}-c_{l}-(1-q) B
\end{gathered}
$$

Parameter requirement \#4:

55 Alternatively, we could do this with just one tax rate, and then take two marginally different. 


$$
\left(1-\tau_{h}\right)\left[f\left(\begin{array}{c}
q\left(e_{h}-e_{l}\right)\left(k-\frac{1}{1+z \pi_{h}}\right)+(1-q) e_{h}\left(k-\frac{1}{1+z \pi_{l}}\right) \\
-(1-q)\left(e_{l}\left(k-\frac{1}{1+\pi_{l}}-1\right)+x\right) \\
< \\
c_{h}-c_{l}-f(1-q) B
\end{array}\right]+\left(e_{h}-e_{l}\right)(1-f)\left(k-\frac{1}{1+\tilde{\pi}}\right)\right]
$$

Parameter requirement \#5:56

$$
\alpha(1-q)\left(C-\tau_{h}\right)>\left(1-\tau_{h}\right) e_{l}\left[q \frac{1}{1+\pi_{h}}-q \frac{1}{1+z \pi_{h}}-(1-q)\right]
$$

Parameter requirement \#6:

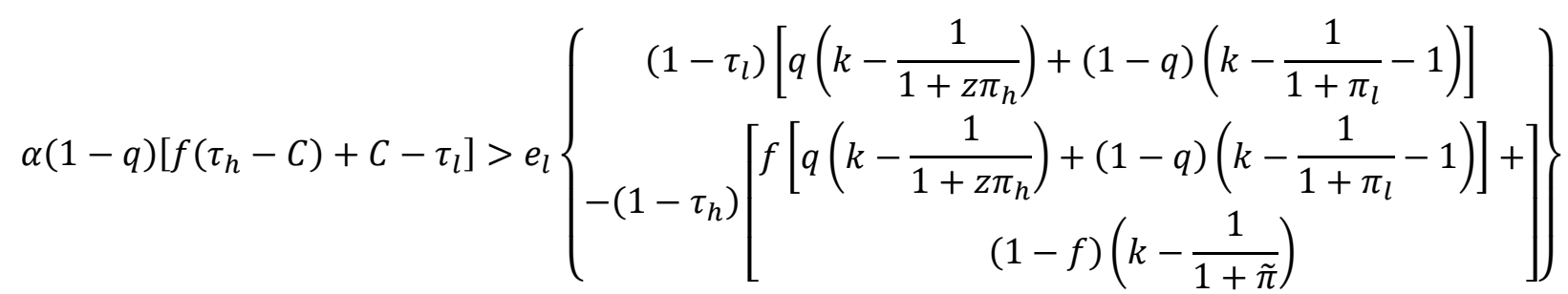

Parameter requirement \#7:

$$
\alpha>e_{l}\left[\frac{(1-f)}{f(1-q)}\left(k-\frac{1}{1+\tilde{\pi}}\right)+\frac{q}{1-q}\left(k-\frac{1}{1+z \pi_{h}}\right)+\left(k-\frac{1}{1+\pi_{l}}-1\right)\right]
$$

The following values for $\left(e_{h}, e_{l}, c_{h}, c_{l}, p, x, B, z, \pi_{h}, \pi_{l}, \tau_{h}, \tau_{l}, k, \alpha, C, q, f\right)$ satisfy all these restrictions: ${ }^{57}$ $\left(16,1, \frac{23}{2}, 0, \frac{2}{3}, \frac{451}{120}, 2,3, \frac{1}{2}, \frac{1}{3}, \frac{1}{5}, \frac{1}{5}-\frac{1}{1000}, \frac{3}{2}, 1000, \frac{1}{2}, \frac{1}{1000}, \frac{1}{1000}\right)$.

56 This holds trivially if we set $q=0$, as the rhs is less than 0 .

57 They also satisfy all the other restrictions given in the setup of the model: $\pi_{h}>\pi_{l}>0,1>\tau_{h}>\tau_{l}>0, C>\tau_{h}$, $p, x, B, k>0, e_{h}>e_{l}>0, q, f \in(0,1), z>1, c_{h}>c_{l} \geq 0$. 


\section{Proof of corollary 1.a. and 1.b.:}

Public's expected utility for each combo of delegate type and business quality is the following, depending on whether the Public accepts or forbids meetings:

Delegate type: $\pi_{h}$

Delegate type: $\pi_{l}$

"High quality"
Businessman and
meetings allowed
"Low quality"
Businessman and
meetings allowed
"High quality"
Businessman and
meetings forbidden
"Low quality"
Businessman and
meetings forbidden

\begin{tabular}{|c|c|}
\hline $\begin{array}{c}(1-\tau) e_{h}\left(k-\frac{1}{1+z \pi_{h}}\right)-c_{\mathrm{h}} \\
(1-\tau) e_{h}\left(k-\frac{1}{1+z \pi_{l}}\right)-c_{\mathrm{h}}\end{array}$ & $\begin{array}{c}(1-\tau) e_{l}\left(k-\frac{1}{1+\pi_{l}}-1\right)-c_{l} \\
+\alpha(\tau-C)\end{array}$ \\
\hline$(1-\tau) e_{l}\left(k-\frac{1}{1+z \pi_{h}}\right)-c_{l}$ & $\begin{array}{c}(1-\tau) e_{h}\left((1-f)\left(k-\frac{1}{1+\pi_{l}}\right)+f\left(k-\frac{1}{1+z \pi_{l}}\right)\right)-c_{h} \\
(1-\tau) e_{h}\left((1-f)\left(k-\frac{1}{1+\pi_{h}}\right)+f\left(k-\frac{1}{1+z \pi_{h}}\right)\right)-c_{h}\end{array}$ \\
\hline$(1-\tau) e_{l}\left((1-f)\left(k-\frac{1}{1+\pi_{h}}\right)+f\left(k-\frac{1}{1+z \pi_{h}}\right)\right)-c_{l}$ & $\begin{array}{c}(1-\tau) e_{l}\left((1-f)\left(k-\frac{1}{1+\pi_{l}}\right)+f\left(k-\frac{1}{1+\pi_{l}}-1\right)\right. \\
+f \alpha(\tau-C)-c_{l}\end{array}$ \\
\hline
\end{tabular}

Notes: Low quality businesspeople offer bribes only to delegates of type $\pi_{l}$ (and delegates accept bribes).

To prove corollary 1.a. we need to show that: $(4,1)-(2,1)>(3,1)-(1,1)$ and that $(4,2)-(2,2)>(3,2)-(1,2)$, where $(\mathrm{x}, \mathrm{y})$ denotes a position in the matrix above.

The first of these conditions hold if and only if:

$$
\begin{gathered}
(1-f)\left((1-\tau) e_{l}\left(\frac{1}{1+z \pi_{h}}-\frac{1}{1+\pi_{h}}\right)\right)>(1-f)\left((1-\tau) e_{h}\left(\frac{1}{1+z \pi_{h}}-\frac{1}{1+\pi_{h}}\right)\right) \Leftrightarrow \\
e_{l}\left(\frac{1}{1+z \pi_{h}}-\frac{1}{1+\pi_{h}}\right)>e_{h}\left(\frac{1}{1+z \pi_{h}}-\frac{1}{1+\pi_{h}}\right) \underset{z>1}{e_{h}}>e_{l}
\end{gathered}
$$

The second condition holds if and only if:

$$
\begin{gathered}
(1-f)\left((1-\tau) e_{l}-\alpha(\tau-C)\right)>-(1-f)\left((1-\tau) e_{h}\left(\frac{1}{1+\pi_{l}}-\frac{1}{1+z \pi_{l}}\right)\right) \Leftrightarrow \\
e_{l}>e_{h}\left(\frac{1}{1+z \pi_{l}}-\frac{1}{1+\pi_{l}}\right)+\frac{\alpha(\tau-C)}{(1-\tau)} \\
\frac{\alpha(\tau-C)}{(1-\tau)}<0 \text { and } z>1 \text { so } e_{h}\left(\frac{1}{1+z \pi_{l}}-\frac{1}{1+\pi_{l}}\right)<0 \underset{e_{l}>0}{\Longrightarrow} \text { Inequality holds. }
\end{gathered}
$$

To prove corollary 1.b. we need to show that: $(3,2)-(1,2)>(3,1)-(1,1)$ and that $(4,2)-(2,2)>(4,1)-(2,1)$.

The first of these conditions hold if and only if:

$$
-(1-f)\left((1-\tau) e_{h}\left(\frac{1}{1+\pi_{l}}-\frac{1}{1+z \pi_{l}}\right)\right)>(1-f)\left((1-\tau) e_{h}\left(\frac{1}{1+z \pi_{h}}-\frac{1}{1+\pi_{h}}\right)\right) \Leftrightarrow
$$


$\left(\frac{1}{1+z \pi_{l}}-\frac{1}{1+\pi_{l}}\right)>\left(\frac{1}{1+z \pi_{h}}-\frac{1}{1+\pi_{h}}\right)$

And LHS is -0.25 , while RHS is $-8 / 3$.

The second condition holds if and only if:

$(1-f)\left((1-\tau) e_{l}-\alpha(\tau-C)\right)>(1-f)\left((1-\tau) e_{l}\left(\frac{1}{1+z \pi_{h}}-\frac{1}{1+\pi_{h}}\right)\right) \Leftrightarrow$

$1>\left(\frac{1}{1+z \pi_{h}}-\frac{1}{1+\pi_{h}}\right)+\frac{\alpha(\tau-C)}{(1-\tau) e_{l}}$

$\frac{\alpha(\tau-C)}{(1-\tau) e_{l}}<0$ and $z>1$ so $\left(\frac{1}{1+z \pi_{l}}-\frac{1}{1+\pi_{l}}\right)<0 \Rightarrow$ Inequality holds.

\section{Proof of corollary 2:}

Businesspeople and delegate's optimal strategies are identical whether the level of taxes is high or low. The public only gains (ex post) from setting high taxes when there is an event of corruption and this happens only when both the delegate and the businessman are of Low quality. 


\section{Appendix 2: Other results}

Table A1. Effect of Trust in Business and Government on Preferences for Taxes on the next top 9\%

\begin{tabular}{|c|c|c|c|}
\hline & \multicolumn{3}{|c|}{ Dependent variable: Tax_next9_percent2 } \\
\hline Panel A: Regression output & $(1)$ & $(2)$ & (3) \\
\hline \multicolumn{4}{|l|}{ Treatments } \\
\hline$\left(\beta_{1}\right)$ High Business \& & 0.106 & 0.022 & -0.249 \\
\hline High Government & $(0.795)$ & $(0.790)$ & $(0.765)$ \\
\hline$\left(\beta_{2}\right)$ High Business \& & -0.671 & -0.539 & -0.669 \\
\hline Low Government & $(0.683)$ & $(0.677)$ & $(0.653)$ \\
\hline$\left(\beta_{3}\right)$ Low Business \& & -0.024 & 0.104 & -0.154 \\
\hline High Government & $(0.686)$ & $(0.679)$ & $(0.656)$ \\
\hline$\left(\beta_{4}\right)$ Low Business \& & $1.632^{*}$ & $1.792^{* *}$ & $1.386^{*}$ \\
\hline Low Government & $(0.840)$ & $(0.835)$ & $(0.806)$ \\
\hline \multicolumn{4}{|l|}{ Other covariates } \\
\hline \multirow[t]{2}{*}{ Poor didn't make an effort } & - & - & $-3.031^{* * *}$ \\
\hline & & & $(0.495)$ \\
\hline \multirow[t]{2}{*}{ Rich made an effort } & - & - & $-4.810^{* * *}$ \\
\hline & & & $(0.445)$ \\
\hline \multirow{2}{*}{ Obama } & - & - & $5.264 * * *$ \\
\hline & & & $(0.479)$ \\
\hline \multirow[t]{2}{*}{ Trust } & - & - & 0.035 \\
\hline & & & $(0.091)$ \\
\hline Observations & 5967 & 5939 & 5923 \\
\hline $\mathrm{R}^{2}$ & 0.002 & 0.012 & 0.083 \\
\hline Control group mean & 26.548 & 26.499 & 26.532 \\
\hline \multicolumn{4}{|c|}{ Panel B: Hypothesis testing over the coefficients } \\
\hline \multicolumn{4}{|l|}{ Effect of Trust in Business } \\
\hline High Bus - Low Bus |High Gov & $\begin{array}{c}0.130 \\
{[0.8487]}\end{array}$ & $\begin{array}{c}-0.082 \\
{[0.9038]}\end{array}$ & $\begin{array}{c}-0.095 \\
{[0.8852]}\end{array}$ \\
\hline Expected result & \multicolumn{3}{|c|}{ Negative or not significant } \\
\hline \multirow{2}{*}{ High Bus - Low Bus |Low Gov } & $-2.303^{* * *}$ & $-2.331^{* * *}$ & $-2.055^{* * *}$ \\
\hline & {$[0.0017]$} & {$[0.0015]$} & {$[0.0035]$} \\
\hline Expected result & \multicolumn{3}{|c|}{ Negative } \\
\hline \multicolumn{4}{|l|}{ Effect of Trust in Government } \\
\hline High Gov - Low Gov |High Bus & $\begin{array}{c}0.777 \\
{[0.2534]}\end{array}$ & $\begin{array}{c}0.561 \\
{[0.4079]}\end{array}$ & $\begin{array}{c}0.420 \\
{[0.5223]}\end{array}$ \\
\hline Expected result & \multicolumn{3}{|c|}{ Negative or not significant } \\
\hline High Gov - Low Gov |Low Bus & $-1.656^{* *}$ & $-1.688^{* *}$ & $-1.540^{* *}$ \\
\hline Expected result & & $\frac{[0.0216]}{\text { Negative }}$ & 10.02 \\
\hline
\end{tabular}

Notes. Robust standard errors in parenthesis. ${ }^{*}, * *, * *$ indicate statistical significance at the $10 \%, 5 \%$ and $1 \%$ levels, respectively. Tax_next9_percent2 is the preferred tax rate for the next top $9 \%$ ( $1 \%$ of households earn more than them, but $90 \%$ earn less). A constant term (not shown) is included in every regression. Regarding the treatments, the control group is the omitted group. Column (1) includes no additional controls. Column (2) includes demographic controls (gender, age, race, education, and type of employment). Column (3) includes same demographic controls, plus political variables and pre-treatment beliefs (include relative support for Obama in previous election, attitudes towards the rich and the poor, and general level of trust). Control group mean reports the mean of the dependent variable for the control group in each specification. In Panel B we present linear combinations of certain treatment coefficients and p-values (in brackets) for the test of whether these linear combinations are equal to 0. High Bus - Low Bus |High Gov is the difference between the treatment coefficient High Business \& High Government and Low Business \& High Government; High Bus - Low Bus is the weighted average of High Bus - Low Bus |High Gov and High Bus - Low Bus |Low Gov (analogous for other treatment groups). Expected results are defined according to the model's predictions (corollary 2). We considered the sample of people that spent at least three minutes in the survey (not considering the candy experiment and time spent in the treatment windows) and at least three seconds in every treatment (when applicable). Respondents assigned to treatments with punishment were not included. 
Table A2. Effect of Trust in Business and Government on Preferences for Taxes on the next top 40\%

\begin{tabular}{|c|c|c|c|}
\hline & \multicolumn{3}{|c|}{ "Dependent variable: Tax_next40_percent2 } \\
\hline Panel A: Regression output & $(1)$ & $(2)$ & $(3)$ \\
\hline \multicolumn{4}{|l|}{ Treatments } \\
\hline$\left(\beta_{1}\right)$ High Business \& & 0.191 & 0.092 & -0.012 \\
\hline High Government & $(0.609)$ & $(0.605)$ & $(0.603)$ \\
\hline$\left(\beta_{2}\right)$ High Business \& & -0.352 & -0.279 & -0.352 \\
\hline Low Government & $(0.520)$ & $(0.518)$ & $(0.516)$ \\
\hline$\left(\beta_{3}\right)$ Low Business \& & -0.015 & 0.057 & -0.059 \\
\hline High Government & $(0.521)$ & $(0.518)$ & $(0.516)$ \\
\hline$\left(\beta_{4}\right)$ Low Business \& & 0.541 & 0.636 & 0.467 \\
\hline Low Government & $(0.617)$ & $(0.614)$ & $(0.613)$ \\
\hline \multicolumn{4}{|l|}{ Other covariates } \\
\hline Poor didn't make an effort & - & - & $\begin{array}{c}-1.102^{* * *} \\
(0.406)\end{array}$ \\
\hline Rich made an effort & - & - & $\begin{array}{c}-1.390^{* * *} \\
(0.355)\end{array}$ \\
\hline Obama & - & - & $\begin{array}{c}2.215^{* * *} \\
(0.381)\end{array}$ \\
\hline Trust & - & - & $\begin{array}{c}0.072 \\
(0.074) \\
\end{array}$ \\
\hline Observations & 5965 & 5937 & 5921 \\
\hline $\mathrm{R}^{2}$ & 0.001 & 0.012 & 0.029 \\
\hline Control group mean & 17.778 & 17.751 & 17.780 \\
\hline \multirow{2}{*}{\multicolumn{4}{|c|}{$\begin{array}{l}\text { Panel B: Hypothesis testing over the coefficients } \\
\text { Effect of Trust in Business }\end{array}$}} \\
\hline & & & \\
\hline High Bus - Low Bus |High Gov & $\begin{array}{c}0.206 \\
{[0.6907]}\end{array}$ & $\begin{array}{c}0.035 \\
{[0.9467]}\end{array}$ & $\begin{array}{c}0.047 \\
{[0.9273]}\end{array}$ \\
\hline Expected result & & - & \\
\hline High Bus - Low Bus |Low Gov & $\begin{array}{c}-0.893^{*} \\
{[0.0904]}\end{array}$ & $\begin{array}{c}-0.915^{*} \\
{[0.0821]}\end{array}$ & $\begin{array}{c}-0.819 \\
{[0.1163]}\end{array}$ \\
\hline Expected result & & - & \\
\hline \multicolumn{4}{|l|}{ Effect of Trust in Government } \\
\hline High Gov - Low Gov |High Bus & $\begin{array}{c}0.543 \\
{[0.2945]}\end{array}$ & $\begin{array}{c}0.371 \\
{[0.4714]}\end{array}$ & $\begin{array}{c}0.340 \\
{[0.5063]}\end{array}$ \\
\hline Expected result & & - & \\
\hline High Gov - Low Gov |Low Bus & $\begin{array}{c}-0.556 \\
{[0.2919]}\end{array}$ & $\begin{array}{c}-0.579 \\
{[0.2711]}\end{array}$ & $\begin{array}{c}-0.526 \\
{[0.3143]}\end{array}$ \\
\hline Expected result & & - & \\
\hline
\end{tabular}

Notes. Robust standard errors in parenthesis. ${ }^{*}, * *, * *$ indicate statistical significance at the $10 \%, 5 \%$ and $1 \%$ levels, respectively. Tax_next $40 \_$percent 2 is the preferred tax rate for the next top $40 \%$ ( $10 \%$ of households earn more than them, but $50 \%$ earn less). A constant term (not shown) is included in every regression. Regarding the treatments, the control group is the omitted group. Column (1) includes no additional controls. Column (2) includes demographic controls (gender, age, race, education, and type of employment). Column (3) includes same demographic controls, plus political variables and pre-treatment beliefs (include relative support for Obama in previous election, attitudes towards the rich and the poor, and general level of trust). Control group mean reports the mean of the dependent variable for the control group in each specification. In Panel B we present linear combinations of certain treatment coeffici ents and p-values (in brackets) for the test of whether these linear combinations are equal to 0. High Bus - Low Bus |High Gov is the difference between the treatment coefficient High Business \& High Government and Low Business \& High Government; High Bus - Low Bus is the weighted average of High Bus - Low Bus |High Gov and High Bus - Low Bus |Low Gov (analogous for other treatment groups). We considered the sample of people that spent at least three minutes in the survey (not considering the candy experiment and time spent in the treatment windows) and at least three seconds in every treatment (when applicable). Respondents assigned to treatments with punishment were not included. 
Table A3. Effect of Trust in Business and Government on Preferences for Taxes on the bottom $50 \%$

\begin{tabular}{|c|c|c|c|}
\hline & \multicolumn{3}{|c|}{ Dependent variable: Tax_bottom50_percent2 } \\
\hline Panel A: Regression output & $(1)$ & $(2)$ & (3) \\
\hline \multicolumn{4}{|l|}{ Treatments } \\
\hline$\left(\beta_{1}\right)$ High Business \& & 0.201 & 0.097 & 0.096 \\
\hline High Government & $(0.535)$ & $(0.531)$ & $(0.528)$ \\
\hline$\left(\beta_{2}\right)$ High Business \& & -0.637 & -0.572 & -0.593 \\
\hline Low Government & $(0.441)$ & $(0.439)$ & $(0.440)$ \\
\hline$\left(\beta_{3}\right)$ Low Business \& & -0.101 & -0.065 & -0.064 \\
\hline High Government & $(0.442)$ & $(0.441)$ & $(0.441)$ \\
\hline$\left(\beta_{4}\right)$ Low Business \& & -0.250 & -0.194 & -0.170 \\
\hline Low Government & $(0.492)$ & $(0.492)$ & $(0.492)$ \\
\hline \multicolumn{4}{|l|}{ Other covariates } \\
\hline \multirow[t]{2}{*}{ Poor didn't make an effort } & - & - & $0.924^{* * *}$ \\
\hline & & & $(0.357)$ \\
\hline \multirow[t]{2}{*}{ Rich made an effort } & - & - & $0.725^{* *}$ \\
\hline & & & $(0.304)$ \\
\hline \multirow[t]{2}{*}{ Obama } & - & - & $-1.223^{* * *}$ \\
\hline & & & $(0.323)$ \\
\hline \multirow[t]{2}{*}{ Trust } & - & - & $0.154^{* *}$ \\
\hline & & & $(0.063)$ \\
\hline Observations & 5954 & 5926 & 5910 \\
\hline $\mathrm{R}^{2}$ & 0.001 & 0.014 & 0.023 \\
\hline Control group mean & 9.312 & 9.332 & 9.351 \\
\hline \multicolumn{4}{|c|}{ Panel B: Hypothesis testing over the coefficients } \\
\hline \multicolumn{4}{|l|}{ Effect of Trust in Business } \\
\hline High Bus - Low Bus |High Gov & $\begin{array}{c}0.302 \\
{[0.4994]}\end{array}$ & $\begin{array}{c}0.162 \\
{[0.7143]}\end{array}$ & $\begin{array}{c}0.160 \\
{[0.7176]}\end{array}$ \\
\hline Expected result & & - & \\
\hline High Bus - Low Bus |Low Gov & $\begin{array}{c}-0.387 \\
{[0.3258]}\end{array}$ & $\begin{array}{c}-0.378 \\
{[0.3369]}\end{array}$ & $\begin{array}{c}-0.423 \\
{[0.2809]}\end{array}$ \\
\hline \multirow{2}{*}{\multicolumn{4}{|c|}{$\begin{array}{c}\text { Expected result } \\
\text { Effect of Trust in Government }\end{array}$}} \\
\hline & & & \\
\hline High Gov - Low Gov |High Bus & $\begin{array}{c}0.838^{*} \\
{[0.0603]}\end{array}$ & $\begin{array}{c}0.669 \\
{[0.1295]}\end{array}$ & $\begin{array}{c}0.689 \\
{[0.1172]}\end{array}$ \\
\hline Expected result & & - & \\
\hline High Gov - Low Gov |Low Bus & $\begin{array}{c}0.149 \\
{[0.7059]}\end{array}$ & $\begin{array}{c}0.129 \\
{[0.7445]}\end{array}$ & $\begin{array}{c}0.106 \\
{[0.7857]}\end{array}$ \\
\hline Expected result & & - & \\
\hline
\end{tabular}

Notes. Robust standard errors in parenthesis. *,**,*** indicate statistical significance at the $10 \%, 5 \%$ and $1 \%$ levels, respectively. Tax_bottom50_percent 2 is the preferred tax rate for the bottom $50 \%$ in the income distribution (poorest). A constant term (not shown) is included in every regression. Regarding the treatments, the control group is the omitted group. Column (1) includes no additional controls. Column (2) includes demographic controls (gender, age, race, education, and type of employment). Column (3) includes same demographic controls, plus political variables and pre-treatment beliefs (include relative support for Obama in previous election, attitudes towards the rich and the poor, and general level of trust). Control group mean reports the mean of the dependent variable for the control group in each specification. In Panel B we present linear combinations of certain treatment coefficients and p-values (in brackets) for the test of whether these linear combinations are equal to 0. High Bus - Low Bus |High Gov is the difference between the treatment coefficient High Business \& High Government and Low Business \& High Government; High Bus - Low Bus is the weighted average of High Bus - Low Bus |High Gov and High Bus - Low Bus |Low Gov (analogous for other treatment groups). We considered the sample of people that spent at least three minutes in the survey (not considering the candy experiment and time spent in the treatment windows) and at least three seconds in every treatment (when applicable). Respondents assigned to treatments with punishment were not included. 
Table A4. First stage

\begin{tabular}{|c|c|c|c|c|c|c|c|c|c|}
\hline & $\begin{array}{c}\text { Local } \\
\text { gov. }\end{array}$ & $\begin{array}{l}\text { Major } \\
\text { Comp. }\end{array}$ & Police & Government & Banks & Press & $\begin{array}{c}\text { Armed } \\
\text { forces }\end{array}$ & Courts & Neighbors \\
\hline Panel A: Regression output & (1) & (2) & (3) & (4) & (5) & (6) & (7) & (8) & (9) \\
\hline \multicolumn{10}{|l|}{ Treatments } \\
\hline$\left(\beta_{1}\right)$ High Business \& & 0.00695 & 0.0869 & -0.0619 & -0.0054 & 0.116 & $-0.349^{*}$ & 0.0440 & 0.113 & 0.0127 \\
\hline High Government & $(0.134)$ & $(0.144)$ & $(0.168)$ & $(0.158)$ & $(0.159)$ & $(0.163)$ & $(0.146)$ & $(0.143)$ & $(0.134)$ \\
\hline$\left(\beta_{2}\right)$ High Business \& & -0.0883 & 0.0122 & -0.0938 & $-0.423^{* *}$ & 0.123 & $-0.420 *$ & -0.0344 & -0.185 & 0.110 \\
\hline Low Government & $(0.133)$ & $(0.145)$ & $(0.164)$ & $(0.159)$ & $(0.160)$ & $(0.166)$ & $(0.150)$ & $(0.148)$ & $(0.138)$ \\
\hline$\left(\beta_{3}\right)$ Low Business \& & 0.00458 & -0.216 & 0.0299 & 0.194 & 0.153 & -0.123 & 0.0150 & 0.279 & 0.0385 \\
\hline High Government & $(0.138)$ & $(0.145)$ & $(0.164)$ & $(0.160)$ & $(0.162)$ & $(0.164)$ & $(0.146)$ & $(0.147)$ & $(0.137)$ \\
\hline$\left(\beta_{4}\right)$ Low Business \& & -0.197 & $-0.399 * *$ & -0.221 & -0.209 & -0.118 & $-0.369 *$ & -0.0897 & -0.290 & 0.125 \\
\hline Low Government & (0.139) & $(0.144)$ & $(0.170)$ & $(0.162)$ & $(0.163)$ & $(0.164)$ & $(0.152)$ & $(0.150)$ & $(0.138)$ \\
\hline Observations & 2462 & 2462 & 2462 & 2462 & 2462 & 2462 & 2462 & 2462 & 2462 \\
\hline Control group mean & 5.482 & 4.526 & 5.972 & 4.297 & 4.169 & 3.948 & 7.020 & 5.592 & 6.382 \\
\hline
\end{tabular}

\begin{tabular}{|c|c|c|c|c|c|c|c|c|c|}
\hline \multicolumn{10}{|c|}{ Panel B: Hypothesis testing over the coefficients } \\
\hline \multicolumn{10}{|l|}{ Effect of Trust in Business } \\
\hline \multirow{2}{*}{ High Bus - Low Bus } & 0.055 & $0.357^{* * *}$ & 0.017 & $-0.207^{*}$ & 0.102 & -0.139 & 0.042 & -0.031 & -0.02 \\
\hline & {$[0.574]$} & {$[0.000]$} & {$[0.884]$} & {$[0.070]$} & {$[0.373]$} & [0.246] & [0.690] & {$[0.771]$} & [0.836] \\
\hline \multirow{2}{*}{ High Bus - Low Bus |High Gov } & 0.002 & $0.303^{* *}$ & -0.092 & -0.199 & -0.037 & -0.227 & 0.029 & -0.166 & -0.026 \\
\hline & [0.986] & {$[0.036]$} & {$[0.584]$} & [0.212] & [0.818] & [0.177] & [0.841] & {$[0.254]$} & [0.848] \\
\hline \multirow{2}{*}{ High Bus - Low Bus |Low Gov } & 0.108 & $0.411^{* * *}$ & 0.127 & -0.214 & 0.241 & -0.051 & 0.055 & 0.104 & -0.014 \\
\hline & {$[0.437]$} & {$[0.004]$} & {$[0.456]$} & {$[0.187]$} & {$[0.141]$} & [0.765] & {$[0.720]$} & {$[0.497]$} & [0.918] \\
\hline \multicolumn{10}{|l|}{ Effect of Trust in Government } \\
\hline \multirow{2}{*}{ High Gov - Low Gov } & 0.148 & 0.129 & 0.141 & $0.410^{* * *}$ & 0.132 & 0.159 & 0.092 & $0.434 * * *$ & -0.092 \\
\hline & [0.133] & {$[0.207]$} & {$[0.237]$} & {$[0.000]$} & {$[0.251]$} & [0.185] & [0.387] & {$[0.000]$} & [0.342] \\
\hline \multirow{2}{*}{ High Gov - Low Gov |High Bus } & 0.095 & 0.075 & 0.032 & $0.417^{* * *}$ & -0.007 & 0.071 & 0.078 & $0.298^{* *}$ & -0.098 \\
\hline & [0.479] & {$[0.604]$} & {$[0.850]$} & {$[0.008]$} & {$[0.963]$} & {$[0.676]$} & [0.597] & {$[0.041]$} & {$[0.470]$} \\
\hline \multirow{2}{*}{ High Gov - Low Gov|Low Bus } & 0.201 & 0.183 & 0.251 & $0.402^{* *}$ & 0.271 & 0.246 & 0.105 & $0.569^{* * *}$ & -0.086 \\
\hline & [0.163] & [0.207] & {$[0.140]$} & [0.014] & [0.102] & [0.145] & [0.487] & {$[0.000]$} & [0.533] \\
\hline
\end{tabular}

Notes. Robust standard errors in parenthesis (Panel A); the dependent variables are the level of trust that the respondent has on each group/organization (scale: 0-10). In Panel B we present the linear combination of certain treatment coefficients and p-values (in brackets) for the test of whether these linear combinations are equal to 0. High Bus - Low Bus |High Gov is the difference between the treatment coefficient High Business \& High Government and Low Business \& High Government; High Bus - Low Bus is the weighted average of High Bus - Low Bus |High Gov and High Bus - Low Bus |Low Gov (analogous for other treatment groups). ${ }^{*}, * *, * *$ indicate statistical significance at the $10 \%, 5 \%$ and $1 \%$ levels, respectively. We considered the sample of people that spent at least 1.5 minutes in the complementary survey (not considering the time spent in the treatment windows) and at least three seconds in every treatment. 
Table A5. Anchoring

\begin{tabular}{|c|c|c|c|}
\hline & $\begin{array}{c}\text { Trust in } \\
\text { Government }\end{array}$ & $\begin{array}{c}\text { Trusts in } \\
\text { Government }\end{array}$ & $\begin{array}{c}\text { Trust in } \\
\text { Government }\end{array}$ \\
\hline Pane A: Regression output & (1) & (2) & (3) \\
\hline \multicolumn{4}{|l|}{ Treatments } \\
\hline$\left(\boldsymbol{\beta}_{\mathbf{1}}\right)$ High Business \& & -0.005 & 0.019 & 0.081 \\
\hline High Government & $(0.158)$ & $(0.154)$ & $(0.148)$ \\
\hline$\left(\boldsymbol{\beta}_{2}\right)$ High Business \& & $-0.423^{* * *}$ & $-0.446^{* * *}$ & $-0.370^{* *}$ \\
\hline Low Government & $(0.159)$ & $(0.155)$ & $(0.151)$ \\
\hline$\left(\boldsymbol{\beta}_{\mathbf{3}}\right)$ Low Business \& & 0.194 & 0.188 & 0.188 \\
\hline High Government & $(0.160)$ & $(0.157)$ & $(0.152)$ \\
\hline$\left(\boldsymbol{\beta}_{4}\right)$ Low Business \& & -0.209 & -0.162 & -0.106 \\
\hline Low Government & $(0.162)$ & $(0.159)$ & $(0.152)$ \\
\hline$\left(\boldsymbol{\beta}_{\mathbf{5}}\right)$ High Business & $-0.301^{*}$ & $-0.310^{*}$ & $-0.315^{* *}$ \\
\hline & $(0.164)$ & $(0.160)$ & $(0.153)$ \\
\hline$\left(\boldsymbol{\beta}_{\mathbf{6}}\right)$ Low Business & $\begin{array}{c}-0.453^{* * *} \\
(0.162)\end{array}$ & $\begin{array}{c}-0.445^{* * *} \\
(0.158)\end{array}$ & $\begin{array}{c}-0.385^{* *} \\
(0.150)\end{array}$ \\
\hline \multicolumn{4}{|l|}{ Other covariates } \\
\hline Poor didn't make an effort & - & - & $\begin{array}{c}0.170 \\
(0.109)\end{array}$ \\
\hline Rich made an effort & - & - & $\begin{array}{c}0.468^{* * *} \\
(0.096)\end{array}$ \\
\hline Clinton & - & - & $\begin{array}{l}0.217^{* *} \\
(0.092)\end{array}$ \\
\hline Trust & - & - & $\begin{array}{c}0.286^{* * *} \\
(0.018)\end{array}$ \\
\hline Observations & 3438 & 3422 & 3416 \\
\hline Control group mean & 4.297 & 4.298 & 4.301 \\
\hline $\begin{array}{l}\mathrm{p} \text {-value for test: } \\
\left|\beta_{5}-\beta_{6}\right|=\left|\beta_{1}-\beta_{3}\right|\end{array}$ & 0.8404 & 0.8835 & 0.8619 \\
\hline $\begin{array}{l}\mathrm{p} \text {-value for test: } \\
\left|\beta_{5}-\beta_{6}\right|=\left|\beta_{2}-\beta_{4}\right|\end{array}$ & 0.7926 & 0.5144 & 0.3710 \\
\hline \multicolumn{4}{|c|}{$\begin{array}{l}\text { Note: The dependent variable is the level of trust that the respondent has on "The government } \\
\text { (in your nation's capital)"; scale: } 0-10 \text {. Robust standard errors in parenthesis. ", }{ }^{* *},{ }^{* * *} \text { indicate } \\
\text { statistical significance at the } 10 \%, 5 \% \text { and } 1 \% \text { levels, respectively. We considered the sample of } \\
\text { people that spent at least } 1.5 \text { minutes in the complementary survey (not considering the time } \\
\text { spent in the treatment windows) and at least three seconds in every treatment. The two } \\
\text { alternative hypothesis in the tests we perform are: }\left|\boldsymbol{\beta}_{5}-\boldsymbol{\beta}_{6}\right| \neq\left|\boldsymbol{\beta}_{1}-\boldsymbol{\beta}_{3}\right| \text { and }\left|\boldsymbol{\beta}_{5}-\boldsymbol{\beta}_{6}\right| \neq \\
\left|\boldsymbol{\beta}_{\mathbf{2}}-\boldsymbol{\beta}_{4}\right| \text {. }\end{array}$} \\
\hline
\end{tabular}




\section{Appendix 3: Main survey questionnaire}

You are being asked to take part in a survey being done by a group of researchers from Harvard University that will help us learn more about the relationship between politics and government in America.

The survey will take you about 10 minutes. Please select the link below to complete the survey. At the end of the survey, you will receive a code to paste into the box below to receive credit for taking our survey.

If you have any questions, please contact us at rditella@hbs.edu. The survey is anonymous, and no one will be able to link your answers back to you. Please do not include your name or other information that could be used to identify you.

Survey link:

Code:

1. Gender
a. Male
b. Female
c. I'd prefer to supply my own response:

2. Age

3. Race (select all that apply)
a. White
b. Black
c. Hispanic or Latino
d. Asian
e. Other

4. In which state do you currently reside? 
O Alabama (1)

O Alaska (2)

O Arizona (3)

O Arkansas (4)

O California (5)

Colorado (6)

O Connecticut (7)

O Delaware (8)

District of Columbia (9)

O Florida (10)

O Georgia (11)

O Hawaii (12)

Idaho (13)

Illinois (14)

Indiana (15)

O Iowa (16)

O Kansas (17)

O Kentucky (18)

O Louisiana (19)

O Maine (20)

O Maryland (21)

O Massachusetts (22)

Michigan (23)

O Minnesota (24)

O Mississippi (25)

O Missouri (26)

O Montana (27)

O Nebraska (28)

O Nevada (29)

O New Hampshire (30)

O New Jersey (31)

O New Mexico (32)

O New York (33)

O North Carolina (34)

O North Dakota (35)

O Ohio (36)

O Oklahoma (37)

O Oregon (38)

O Pennsylvania (39)

O Puerto Rico (40)

Rhode Island (41)

O South Carolina (42)

O South Dakota (43)

O Tennessee (44) 
$\begin{array}{ll}\text { O } & \text { Texas (45) } \\ \text { O } & \text { Utah (46) } \\ \text { O } & \text { Vermont (47) } \\ \text { O } & \text { Virginia (48) } \\ \text { O } & \text { Washington (49) } \\ \text { O } & \text { West Virginia (50) } \\ \text { O } & \text { Wisconsin (51) } \\ \text { O } & \text { Wyoming (52) } \\ \text { O } & \text { I do not reside in the United States (53) }\end{array}$

5. Which category best describes your highest level of education?
a. Eighth Grade or less
b. Some High School
c. High School degree/ GED
d. Some College
e. 2-year College Degree
f. 4-year College Degree
g. Master's Degree
h. Doctoral Degree
i. Professional Degree (JD, MD, MBA)

6. What is your current employment status?
a. Full-time employee
b. Part-time employee
c. Self-employed or small business owner
d. Unemployed and looking for work
e. Student
f. Not in labor force (for example: retired, or full-time parent)

7. Generally speaking, would you say that most people can be trusted or that you need to be very careful in dealing with people?
a. Need to be very careful (0)
b. Most people can be trusted (10)

8. Please think about poor people in the US:

Do you think they are poor mainly because (choose the most important reason)
a. they did not make an effort
b. they lacked opportunities
c. they were unlucky

9. Please think about rich people in the US: 
Do you think they are rich mainly because (choose the most important reason)
a. they made an effort
b. they were born into rich families
c. they stole money
d. they had good luck

American business people are amongst the most successful in the world. Some of the most famous include Bill Gates (founder and CEO of Microsoft) and Steve Jobs, (founder of Apple, NeXT and Pixar), who have revolutionized the technology industry. In several other areas, such as biotechnology, entertainment, medical devices, and high-end machinery, US business people have also been at the forefront of innovation.

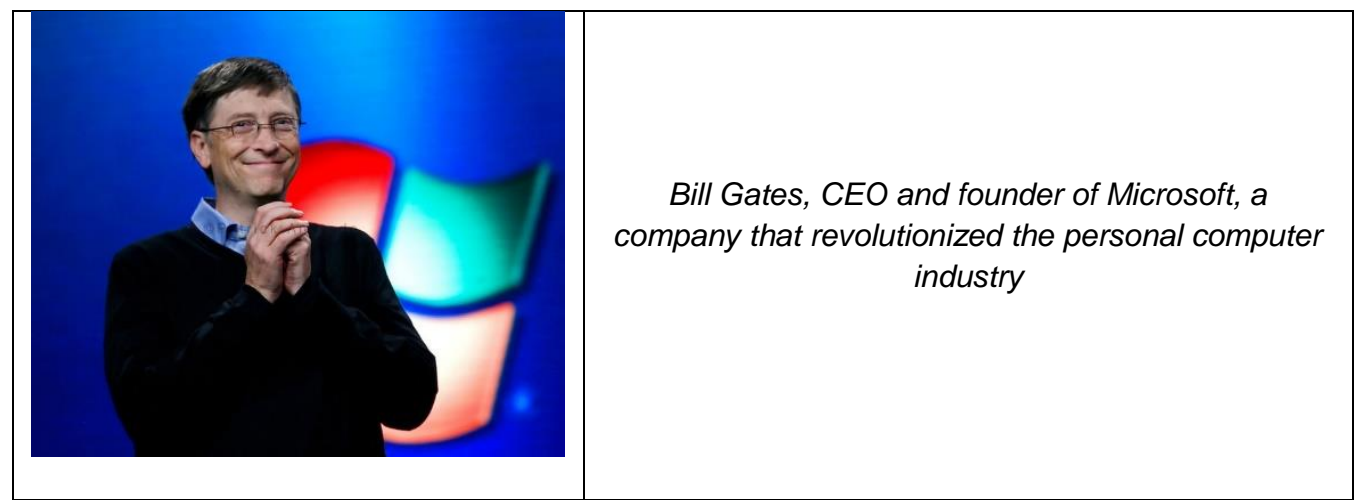

Why do you think American business people have been so successful?

a. It is due to the system: business people in the US are encouraged to work hard and can gain money and prestige by creating truly good products.

b. It is a combination of the system interacting with exceptional individuals, amplified by the availability of capital that allows the successful to expand their business.

c. It is due to the individuals: there are remarkable business people in the US, who are exceptionally creative and naturally hard working.

10. Government officials regularly have private meetings with business people to discuss matters of mutual interest.

Some argue that such meetings are helpful because they allow the exchange of useful information between government and business and the design of more efficient regulation for complex areas.

Critics, on the other hand, argue that these meetings are harmful because they create the opportunity for undue influence, lobbying and the exchange of bribes.

In your view, what goes on at these meetings?

a. Mainly exchange of bribes for favors (0)

b. Mainly exchange of useful information (10) 
11. There are some recent proposals to increase government regulations on firms in the US. How likely is it that you would support these type of proposals?
a. Very unlikely (0)
b. Somewhat unlikely (3-4)
c. Somewhat likely (6-7)
d. Very likely (10)

12. Here are some things the government might do for the economy.

Please show which actions you are in favor of and which you are against. ( $0=$ Strongly against, 2$3=$ Against, $5=$ Neither in favor nor against, $7-8=\operatorname{In}$ favor, $10=$ Strongly in favor)
a. Control of wages by law
b. Control of prices by law

American policymakers and institutions of government are some of the most successful in the world. There are several famous cases of government officials who are dedicated and honest (one example is Robert McCarthy who helped improve the administration of two large federal programs). The US government is consistently ranked as one of the most honest and efficient in the world (for example, according to indices constructed by the World Bank, the US is one of the top countries in terms of Regulatory Quality and Control of Corruption).

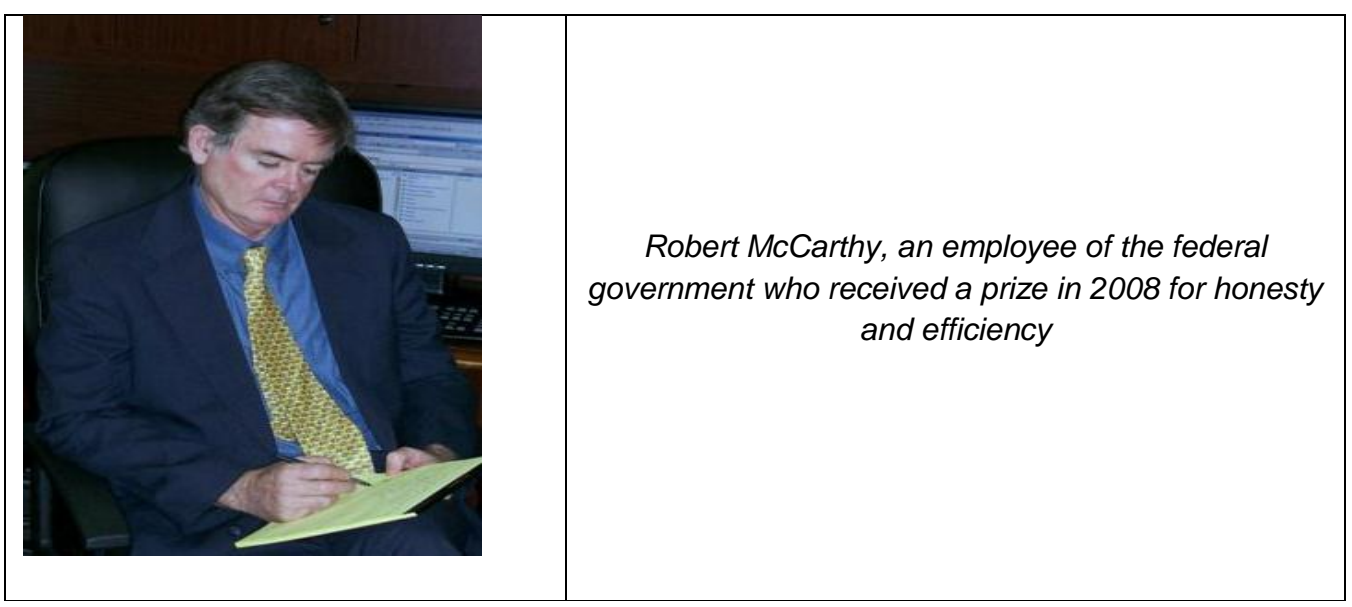

Why do you think the US government is so much more efficient and honest than the governments in other countries?

a. It is a question of incentives: officials in the US can have a long and well-rewarded career in government by being honest and efficient. The temptations are not worth their while.

b. It is due to the existence of independent checks: the American judiciary system has a long tradition of protecting the rule of law and combating corruption. 
13. Going back to the topic of meetings (between government officials and business people), in the political arena we can find a wide range of views.

Some politicians argue strongly in favor of these meetings while others argue strongly against them.

Which type of politician are you more likely to support?

a. A politician that is against allowing these meetings (0)

b. A politician that is in favor of allowing these meetings (10)

14. Now I'd like you to tell me your views on two issues. How would you place your views on this scale? 0 means you agree completely with the statement on the left; 10 means you agree completely with the statement on the right; and if your views fall somewhere in between, you can choose any number in between

a. Competition is good. It stimulates people to work hard and develop new ideas (0)

b. Competition is harmful. It brings out the worst in people (10)

c. People should take more responsibility to provide for themselves (0)

d. The government should take more responsibility to ensure that everyone is provided for (10)

15. I'm going to read off one thing that people sometimes say about a democratic political system. Could you please tell me if you agree strongly, agree, disagree or disagree strongly?

a. In democracy, the economic system runs badly ( $0=$ Disagree strongly, 3-4=Disagree, 6-7=Agree, $10=$ Agree strongly)

16. Some people think it is better to give discretion to policymakers to decide how much regulation to impose on the different sectors of the economy (e.g., how much regulation to impose on banks, on energy companies, etc).

What do you think?

a. Yes, I think it is a good idea to leave them discretion to decide on the proper amount of regulation for each sector

b. No, I don't want them to have discretion; I prefer the economy to have less regulation overall

c. No, I don't want them to have discretion, I prefer the economy to have more regulation overall

17. Now we would like to ask you about the income tax rates* that you think different people should pay. The income tax rate is the percentage of your income that you pay in federal income tax. For example, if you earn $\$ 30,000$ and you pay $\$ 3,000$ in income taxes, your income tax rate is $10 \%$. Please use the sliders below to tell us how much you think each of the following groups should pay as a percentage of their total income.

a. The top 1\% (richest)

b. The next $9 \%$ (1\% of households earn more than them, but $90 \%$ earn less) 
c. The next $40 \%$ (10\% earn more than them, but $50 \%$ earn less)

d. The bottom $50 \%$ (poorest)

*We consider only the Federal income tax, which is a tax on household income. If you receive a regular paycheck, this tax is automatically taken out of your pay. When you file a federal tax return each year, you calculate the exact amount you owe, and you get a tax refund from the federal government if you paid more than you owe. To keep things simple, we do not include other taxes such as social security taxes, state income taxes or sales taxes.

18. What was the role of fraud during the 2008 financial crisis in the US?

Most analysts agree that there was a bubble as a result of excessive risk-taking in financial markets. But those analysts differ in the extent to which they believe fraudulent practices were involved. Which comes closest to your opinion?
a. There was some fraud but this did not cause the crisis.
b. There was a lot of fraud, but there was so much risk-taking that the crisis would have happened anyway.
c. There was a lot of fraud and it was a central cause of the crisis.

19. In the last election, where did you stand politically?
a. Supported Obama
b. Center (but leaning Obama)
c. Center (but leaning Romney)
d. Supported Romney

20. All that's left is the Candy Choice Experiment (takes less than 20 seconds). 


\section{Treatment Low Business}

American business people have been involved in some major scandals over the years. Some of the most famous include Bernie Madoff (a Wall Street financier who was able to swindle investors for nearly 20 years) and Ken Lay (the former CEO of failed energy giant Enron who lobbied to obtain regulatory exemptions and government contracts). In several other areas, such as construction and medical supplies, there is also evidence of significant wrongdoing.

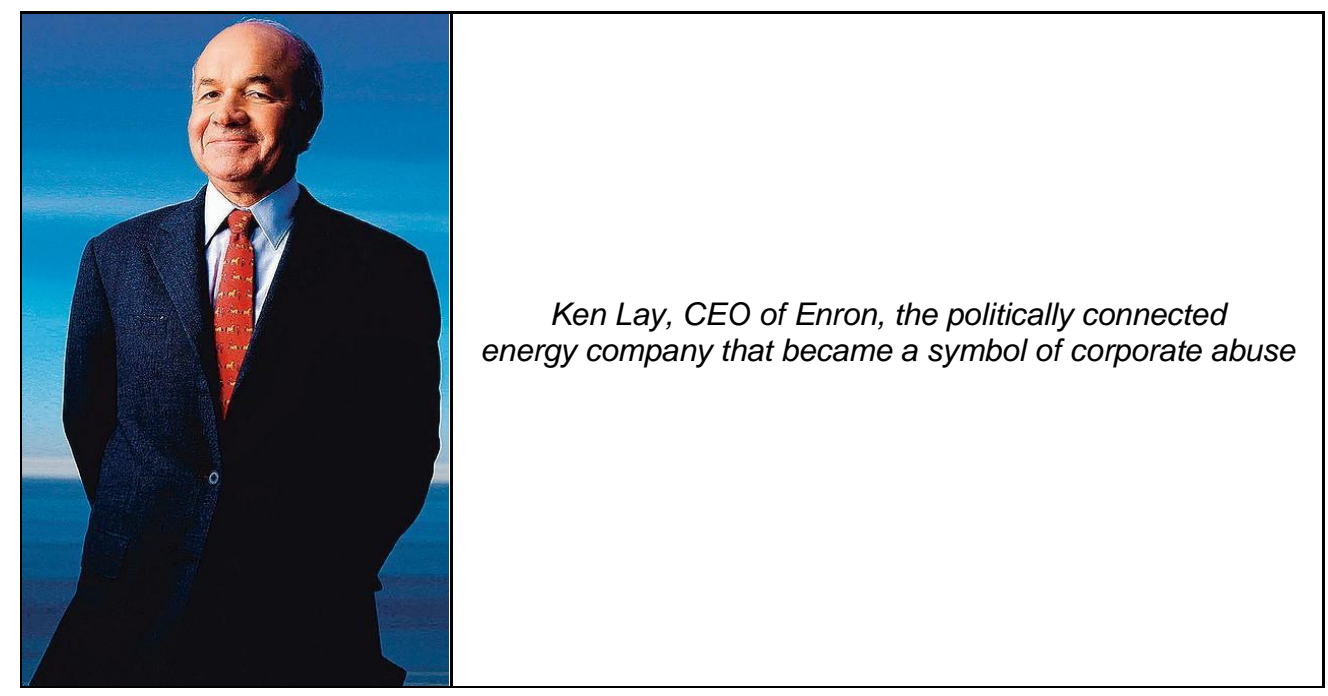

Why do you think there has been so much wrongdoing in American business?

a) It is due to the system: business people in the US are encouraged to focus on profits and can gain lots of money by getting favors from regulators and politicians.

b) It is a combination of the system interacting with greedy individuals, amplified by the availability of capital that allows the dishonest to hide their actions.

c) It is due to the individuals: there are business people in the US that are remarkably greedy and dishonest. 


\section{Treatment Low Business with Punishment}

American business people have been involved in some major scandals over the years. Some of the most famous include Bernie Madoff (a Wall Street financier who was able to swindle investors for nearly 20 years) and Ken Lay (the former CEO of failed energy giant Enron who lobbied to obtain regulatory exemptions and government contracts). In several other areas, such as construction and medical supplies, there is also evidence of significant wrongdoing.

Several of these business people were punished. For example, in 2006 Ken Lay was indicted and found guilty of 10 counts of fraud, each carrying a maximum of 5 to 10 years in prison. This is true of many other cases (the FBI web page has a long list of business people that have been convicted and sent to prison). While some wrongdoers certainly avoid punishment, few other countries are aggressive as the US.

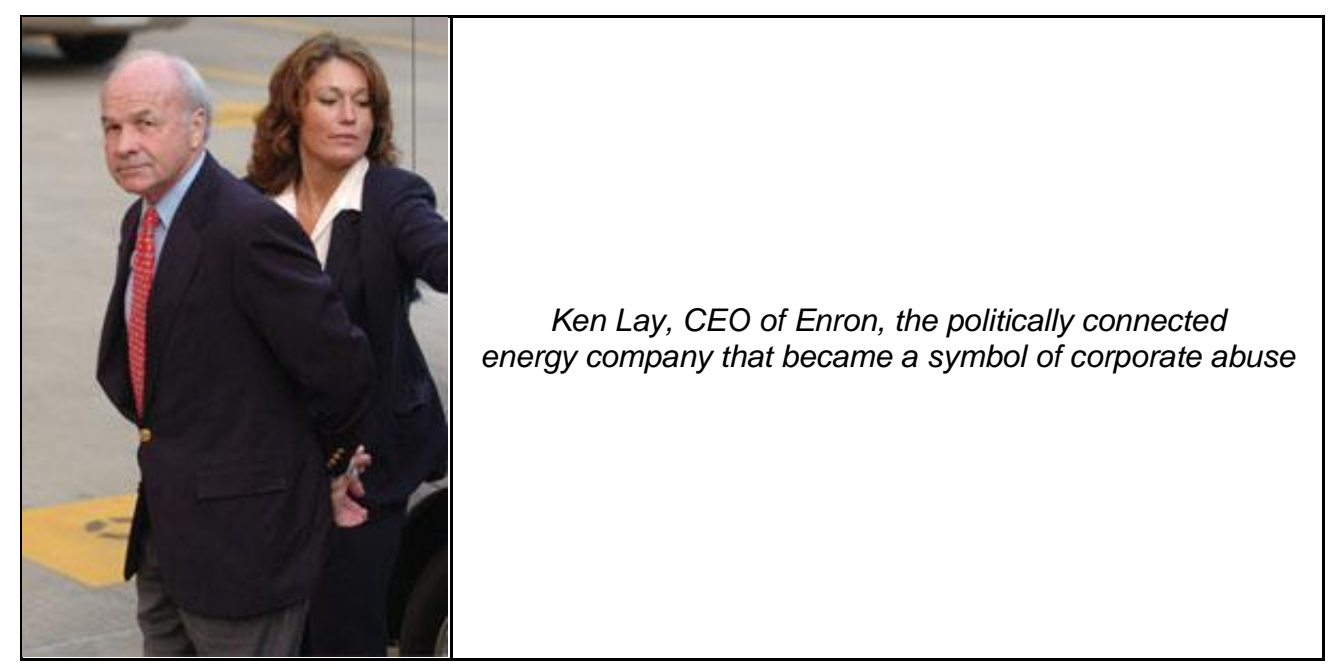

Why do you think the US is so effective in prosecuting corruption in businesses?

a) It is due to the existence of independent checks: the American judiciary system has a long tradition of protecting the rule of law and combating corruption.

b) It is a question of internal checks: business people have incentives to report wrongdoing without fear of reprisals, so eventually bad things come to light. 


\section{Treatment Low Government}

American policymakers and institutions of government have been involved in some major scandals over the years. There are several famous cases of government officials involved in major corruption scandals (one example is Sal DiMasi, who had a long career in government in spite of extorting bribe payments from several businesses, including one business owned by IBM). There are several other examples of significant wrongdoing in government.

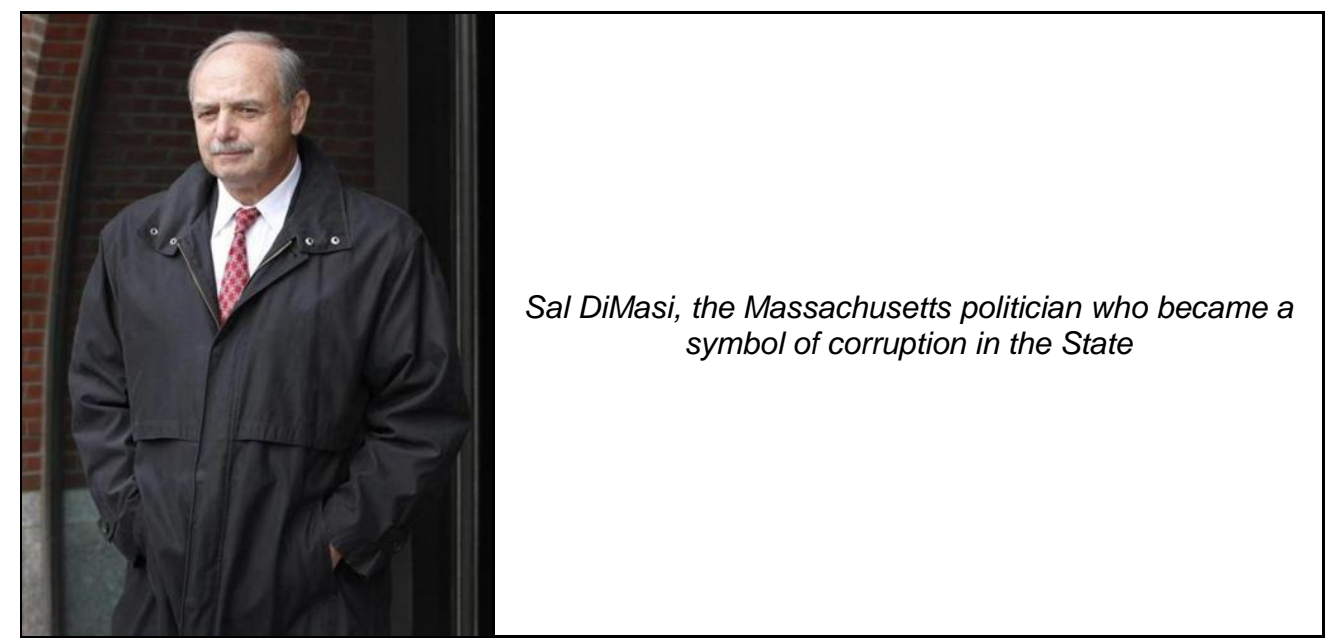

Why do you think so much wrongdoing takes place in American government?

a) It is a question of incentives: government officials in the US can gain large amounts of money extracting payments from firms that want to comply with all existing regulations. The temptations are just too profitable.

b) It is due to the lack of effective checks: the legal system has so many loopholes that corrupt officials can defend themselves in very effective ways. 


\section{Treatment Low Government with Punishment}

American policymakers and institutions of government have been involved in some major scandals over the years. There are several famous cases of government officials involved in major corruption scandals (one example is Sal DiMasi, who had a long career in government in spite of extorting bribe payments from several businesses, including one business owned by IBM). There are several other examples of significant wrongdoing in government.

Eventually, an FBI investigation focused on DiMasi. On October 2009, DiMasi was indicted and found guilty on 9 counts of fraud and conspiracy, and sentenced to 8 years in prison. This is true of many other cases (the FBI web page has a long list of government officials that have been convicted and sent to prison). While some wrongdoers certainly avoid punishment, few other countries are aggressive as the US.



Why do you think the US is so effective in prosecuting corruption in government?

a) It is due to the existence of independent checks: the American judiciary system has a long tradition of protecting the rule of law and combating corruption.

b) It is a question of internal checks: government officials have incentives to report wrongdoing without fear of reprisals, so eventually bad things come to light. 


\section{Appendix 4: Complementary survey questionnaire}

You are being asked to take part in a survey being done by a group of researchers from Harvard University that will help us learn more about the relationship between politics and government in America.

The survey will take you about 6 minutes. Please select the link below to complete the survey. At the end of the survey, you will receive a code to paste into the box below to receive credit for taking our survey.

If you have any questions, please contact us at rditella@hbs.edu. The survey is anonymous, and no one will be able to link your answers back to you. Please do not include your name or other information that could be used to identify you.

Survey link:

Code:

1. Gender
a. Male
b. Female
c. I'd prefer to supply my own response:

2. Age

3. Race (select all that apply)
a. White
b. Black
c. Hispanic or Latino
d. Asian
e. Other

4. In which state do you currently reside? (show options from main survey)

5. Which category best describes your highest level of education?
a. Eighth Grade or less
b. Some High School
c. High School degree/ GED
d. Some College
e. 2-year College Degree
f. 4-year College Degree
g. Master's Degree
h. Doctoral Degree
i. Professional Degree (JD, MD, MBA)

6. What is your current employment status?
a. Full-time employee
b. Part-time employee 
c. Self-employed or small business owner

d. Unemployed and looking for work

e. Student

f. Not in labor force (for example: retired, or full-time parent)

7. Generally speaking, would you say that most people can be trusted or that you need to be very careful in dealing with people?
a. Need to be very careful (0)
b. Most people can be trusted (10)

8. Please think about poor people in the US:

Do you think they are poor mainly because (choose the most important reason)
d. they did not make an effort
e. they lacked opportunities
f. they were unlucky

9. Please think about rich people in the US:

Do you think they are rich mainly because (choose the most important reason)
e. they made an effort
f. they were born into rich families
g. they stole money
h. they had good luck

American business people are amongst the most successful in the world. Some of the most famous include Bill Gates (founder and CEO of Microsoft) and Steve Jobs, (founder of Apple, NeXT and Pixar), who have revolutionized the technology industry. In several other areas, such as biotechnology, entertainment, medical devices, and high-end machinery, US business people have also been at the forefront of innovation.

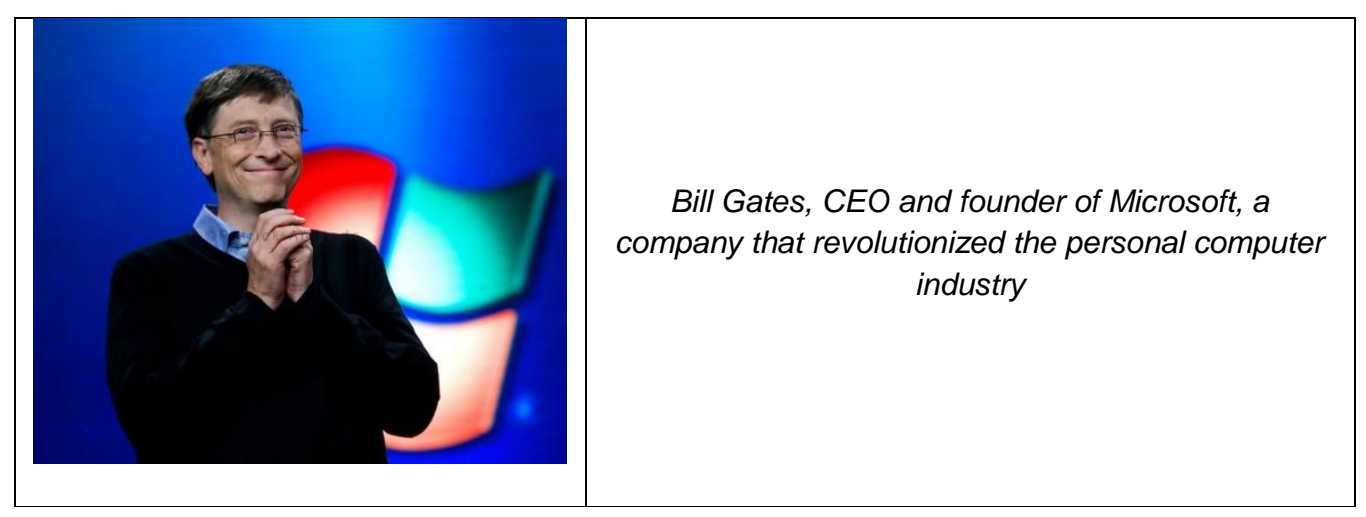

Why do you think American business people have been so successful? 
a. It is due to the system: business people in the US are encouraged to work hard and can gain money and prestige by creating truly good products.

b. It is a combination of the system interacting with exceptional individuals, amplified by the availability of capital that allows the successful to expand their business.

c. It is due to the individuals: there are remarkable business people in the US, who are exceptionally creative and naturally hard working.

10. Government officials regularly have private meetings with business people to discuss matters of mutual interest.

Some argue that such meetings are helpful because they allow the exchange of useful information between government and business and the design of more efficient regulation for complex areas.

Critics, on the other hand, argue that these meetings are harmful because they create the opportunity for undue influence, lobbying and the exchange of bribes.

In your view, what goes on at these meetings?

c. Mainly exchange of bribes for favors (0)

d. Mainly exchange of useful information (10)

11. There are some recent proposals to increase government regulations on firms in the US. How likely is it that you would support these type of proposals?
a. Very unlikely $(0)$
b. Somewhat unlikely (3-4)
c. Somewhat likely (6-7)
d. Very likely (10)

12. Here are some things the government might do for the economy.

Please show which actions you are in favor of and which you are against. ( $0=$ Strongly against, 2$3=$ Against, $5=$ Neither in favor nor against, $7-8=$ In favor, $10=$ Strongly in favor)
a. Control of wages by law
b. Control of prices by law

American policymakers and institutions of government are some of the most successful in the world. There are several famous cases of government officials who are dedicated and honest (one example is Robert McCarthy who helped improve the administration of two large federal programs). The US government is consistently ranked as one of the most honest and efficient in the world (for example, according to indices constructed by the World Bank, the US is one of the top countries in terms of Regulatory Quality and Control of Corruption). 


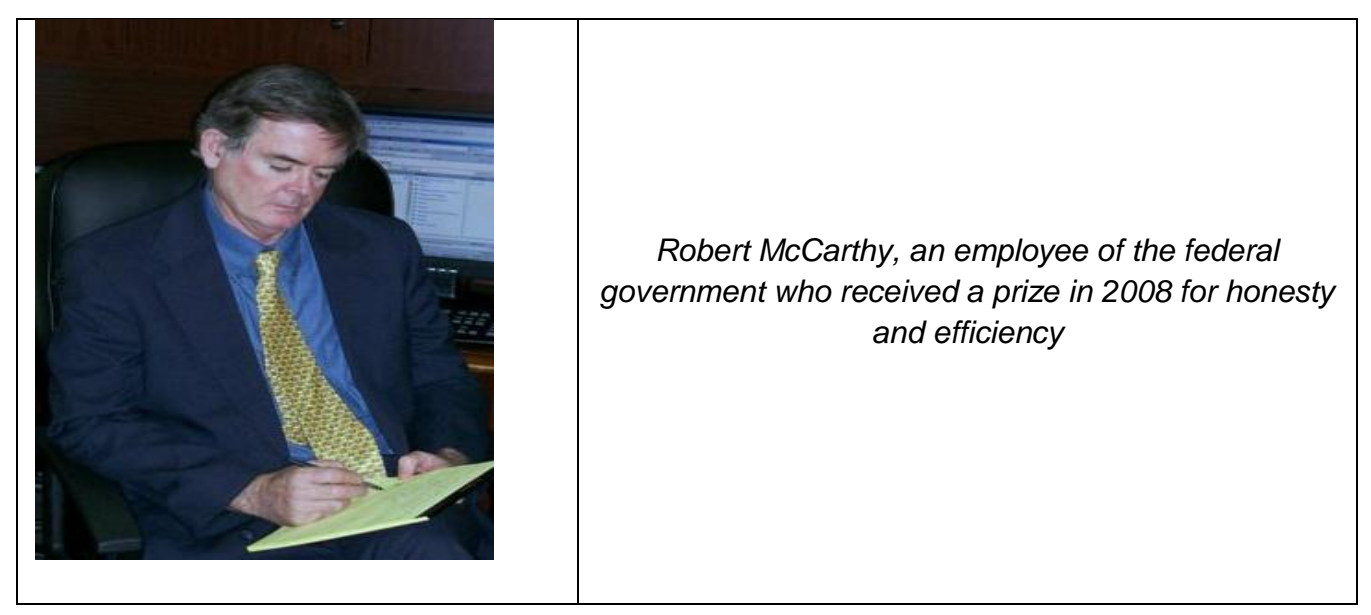

Why do you think the US government is so much more efficient and honest than the governments in other countries?

a. It is a question of incentives: officials in the US can have a long and well-rewarded career in government by being honest and efficient. The temptations are not worth their while.

b. It is due to the existence of independent checks: the American judiciary system has a long tradition of protecting the rule of law and combating corruption.

13. Before proceeding to the next set of questions, we want to ask for your feedback about the responses you provided so far. It is vital to our study that we only include responses from people who devoted their full attention to this study. This will not affect in any way the payment you will receive for taking this survey. In your honest opinion, should we use your responses, or should we discard your responses since you did not devote your full attention to the questions so far?

Yes, I have devoted full attention to the questions so far and I think you should use my responses for your study.

No, I have not devoted full attention to the questions so far and I think you should not use my responses for your study.

14. I am going to name nine organizations/groups. For each one, could you tell me how much confidence you have in them: $(0=$ none at all, $3-4=$ not very much confidence, $6-7=$ quite a lot of confidence, $10=$ a great deal of confidence)

- Local government

- Major Companies

- The police

- The government (in your nation's capital)

- Banks

- The press

- The armed forces

- The courts

- Your neighbors 
15. At the end of this survey we are going to donate $\$ 200$ to charity and we would like you to vote for the organization that should receive the money. The organization with the highest number of votes among the respondents of this survey will receive $\$ 200$. There is only a small number of people taking the survey so please take your time to decide. You will be informed of the results within a week.

a) I vote for Citizens for Tax Justice (an NGO that seeks to require the wealthy to pay their fair share; it is primarily concerned with federal tax policy in the US and its mission is to give ordinary people a greater voice in the development of tax laws).

b) I vote for The American Red Cross (an NGO that seeks to provide humanitarian help; it is primarily focused on disaster relief and emergency assistance within the US).

c) I don't want to vote.

16. Imagine that taxes to the top $1 \%$ (richest) of the population increase; what do you think will happen?
a. The money will be appropriated by corrupt government officials.
b. The money will be wasted without clear benefits for the population.
c. The money will be used to fund an increase in useful government spending.

17. In the last election, where did you stand politically?
a. Supported Clinton
b. Center (but leaning Clinton)
c. Center (but leaning Trump)
d. Supported Trump

18. In previous presidential elections, where did you typically stand?

a) Voted republican

b) Leaned republican

c) Switched depending on the election

d) Leaned democrat

e) Voted democrat

f) Don't know 